OPEN ACCESS

Edited by: Imola Wilhelm,

Biological Research Centre, Hungary

Reviewed by:

Wolfgang Bäumer,

Freie Universität Berlin, Germany

Laurent Misery,

Université de Bretagne Occidentale,

France

*Correspondence:

Balázs István Tóth

toth.istvan@med.unideb.hu

Specialty section:

This article was submitted to Inflammation Pharmacology,

a section of the journal

Frontiers in Pharmacology

Received: 22 July 2021 Accepted: 07 February 2022

Published: 07 March 2022

Citation:

Szöllősi AG, Oláh A, Lisztes E, Griger Z and Tóth BI (2022) Pruritus: A Sensory

Symptom Generated in Cutaneous

Immuno-Neuronal Crosstalk.

Front. Pharmacol. 13:745658.

doi: 10.3389/fphar.2022.745658

\section{Pruritus: A Sensory Symptom Generated in Cutaneous Immuno-Neuronal Crosstalk}

\author{
Attila Gábor Szöllősi ${ }^{1}$, Attila Oláh ${ }^{2}$, Erika Lisztes ${ }^{2}$, Zoltán Griger $^{3}$ and Balázs István Tóth $^{2 *}$ \\ ${ }^{1}$ Department of Immunology, Faculty of Medicine, University of Debrecen, Debrecen, Hungary, ${ }^{2}$ Department of Physiology, \\ Faculty of Medicine, University of Debrecen, Debrecen, Hungary, ${ }^{3}$ Division of Clinical Immunology, Department of Internal \\ Medicine, Faculty of Medicine, University of Debrecen, Debrecen, Hungary
}

Pruritus or itch generated in the skin is one of the most widespread symptoms associated with various dermatological and systemic (immunological) conditions. Although many details about the molecular mechanisms of the development of both acute and chronic itch were uncovered in the last 2 decades, our understanding is still incomplete and the clinical management of pruritic conditions is one of the biggest challenges in daily dermatological practice. Recent research revealed molecular interactions between pruriceptive sensory neurons and surrounding cutaneous cell types including keratinocytes, as well as resident and transient cells of innate and adaptive immunity. Especially in inflammatory conditions, these cutaneous cells can produce various mediators, which can contribute to the excitation of pruriceptive sensory fibers resulting in itch sensation. There also exists significant communication in the opposite direction: sensory neurons can release mediators that maintain an inflamed, pruritic tissue-environment. In this review, we summarize the current knowledge about the sensory transduction of pruritus detailing the local intercellular interactions that generate itch. We especially emphasize the role of various pruritic mediators in the bidirectional crosstalk between cutaneous non-neuronal cells and sensory fibers. We also list various dermatoses and immunological conditions associated with itch, and discuss the potential immune-neuronal interactions promoting the development of pruritus in the particular diseases. These data may unveil putative new targets for antipruritic pharmacological interventions.

Keywords: itch, molecular transduction of pruritus, sensory neurons, inflammation, skin, cytokines, dermatoses

\section{THE CUTANEOUS ITCH}

\section{General Introduction}

Itch is a common somatosensory modality well-known from the everyday life. It was defined as an "unpleasant sensation that elicits the desire or reflex to scratch" by Samuel Hafenreffer in the 17th century (Ikoma et al., 2006, p. 535), which is a pragmatic and valid definition even today. Our knowledge has been hugely expanded since Hafenreffer's definition and, especially in the last 2 decades, we reached a deeper insight into the molecular and cellular details of how itch is generated, yet our understanding is far from complete. Although itch in general is not a life-threatening situation, the clinical management of itching conditions is still one of the biggest challenges of daily dermatological practice. Treatment of chronic itch (lasting longer than 6 weeks) remains an unmet medical challenge in many instances, affecting millions of people worldwide. According to 
epidemiological results the prevalence of chronic itch in the general population is between $8-28 \%$ (Weisshaar and Dalgard, 2009; Leader et al., 2015). Based on these data, it is not surprising that the socioeconomic burden of chronic pruritus is comparable to that of chronic pain. Development of effective treatments is mainly impaired by our lack of understanding of the signaling pathways underlying pruriception, especially in chronic itch, where itch develops and is maintained (at least partly) independently of external stimuli.

Itch can be classified into four categories based on both the different mechanisms by which it may be generated, and by taking into account their clinical appearence (Paus et al., 2006; Bíró et al., 2007; Ständer et al., 2007; Tóth et al., 2015; Dong and Dong, 2018). Pruriceptive itch is peripherally induced itch generated in the skin. In this case, itch is evoked by locally released pruritogens exciting the pruriceptive nerve endings in the skin. The release of these chemical mediators can be triggered acutely by external irritants (e.g. insect bite, poisonous plants or skin sensitizers) or may be related to various, typically inflammatory skin conditions which can affect an extended area of the skin, and is likely to be chronic. Neurogenic itch is also evoked by the (peripheral) excitation of itch sensitive neurons, but in this case the triggering pruritic mediators stem from a "central source" and their production is related to systemic diseases, such as kidney failure, hepatic conditions or immunological diseases. In contrast, neuropathic itch is due to a damage of the itch processing neural network at any level. It can be associated with peripheral neuropathies (e.g. postherpetic neuropathy), nerve compression or irritation (e.g. in notalgia paresthetica) or certain brain lesions and tumors. Finally, psychogenic itch is related to psychiatric disorders or psychological conditions like phobias, obsessive-compulsive disorder or psychotic diseases. In this review, we focus on the role of peripheral interactions in the generation of pruritus, therefore, mainly discussing cases of pruriceptive and some neurogenic pruritus as these are evoked by the excitation of pruriceptive cutaneous nerve endings.

\section{Sensing Pruritus}

\section{Pruriceptive Fibers of the Skin}

The sensory transduction of pruritus, i.e. how propagating action potentials are generated by pruritic stimuli, is realized by exciting a subpopulation of cutaneous bare nerve endings which also express molecular markers typical of nociceptors. Therefore, pruriceptive fibers are generally considered a subpopulation of nociceptors, the selective activation of which results in itch sensation. This is in contrast to a general activation of nociceptors that results in nociception and evokes pain. This is postulated as the selectivity theory of itch, a nowadays generally accepted description of the relation between pruriception and nociception (LaMotte et al., 2014). This is also supported by the findings that depletion of nociceptors by overdosing transient receptor potential 1 (TRPV1) agonists (Cavanaugh et al., 2009; Imamachi et al., 2009) or genetic ablation of TRPV1-lineage nociceptive neurons of the dorsal root ganglia (DRGs) resulted in a dramatic reduction of both nociception and pruriception (Mishra et al., 2011; Mishra and Hoon, 2013). However, intense efforts were taken to identify molecular markers of a "labelled line" for pruriception. Among primary sensory neurons of the DRGs, a few molecular markers were identified which are believed to be (more or less) specifically expressed by pruriceptive sensory neurons. For example, specific neurotransmitters can be released from the central terminal of the pruriceptive sensory neurons which may differentiate these neurons from the nociceptor population. The fact that the ablation of gastrin releasing peptide receptor expressing (GRPR+) neurons-or only the GRPR molecules from the spinal cord-strongly inhibited pruritogen evoked scratching behavior without affecting acute nociception suggested that gastrin releasing peptide (GRP) may be a neurotransmitter released selectively from itch sensitive sensory neurons of DRGs. GRP was indeed detected in peripheral sensory neurons (Sun and Chen, 2007; Barry et al., 2016, 2020) and its expression was found to be elevated in chronic itch conditions in mice (Zhao et al., 2013) and primates (Nattkemper et al., 2013). The optogenic activation of GRP expressing cutaneous sensory fibers resulted in itch behavior, and chemically induced itch was attenuated by conditional deletion of GRP from DRG neurons (Barry et al., 2020). However, other studies resulted in controversial findings as they could not (or hardly) detect GRP in peripheral sensory neurons, rather localized it in the spinal cord, expressed by higher order neurons in the itch pathway (Fleming et al., 2012; Mishra and Hoon, 2013; Sun et al., 2017). Other studies argue for the role of natriuretic polypeptide $b$ (NPPB) as a peripheral itch specific neurotransmitter. It was shown to be expressed in a subpopulation of DRG neurons and its genetic deletion, as well as ablating its receptor, dramatically decreased scratching behavior induced by various pruritogens (Mishra and Hoon, 2013). Moreover, members of Mas1-related G protein-coupled receptors (MRGPRs) were also identified as markers of itch specific neurons (Liu et al., 2009; Liu and Dong, 2015). In mouse, MRGPRs are coded by an extended gene cluster and divided into several subfamilies. However, in human, there are only four members of the family identified, marked as MRGPRX1-4, which do not form orthologous pairs with rodent counterparts (Dong et al., 2001; Lembo et al., 2002). Some MRGPRs, expressed exclusively in skin innervating fibers, are not only markers of pruriceptive neurons, but also serve as receptors for pruritic ligands. Especially the role of MRGPRA3, MRGPRC11 and MRGPRD, as well as the human MRGPRX1 were described to be involved in various forms of non-histaminergic itch. Interestingly, MRGPRA3 and MRGPRD display non-overlapping expression in pruriceptive neurons and are activated by different pruritic ligands, suggesting the existence of different labeled lines even within the non-histaminergic itch sensing neuron population (Liu et al., 2009, Liu et al., 2012 Q.; Han et al., 2013; Liu and Dong, 2015).

Recently, large scale transcriptome profiling studies also characterized and classified somatosensory neurons in an unbiased manner and identified different neuronal subpopulations potentially responsible for pruriception based on their specific expression patterns. Following single cell RNA-Seq, Usoskin et al. (2015) identified 11 clusters of somatosensory neurons by principal component analysis. 
Among them, itch associated markers (Mrgprs, Nppb, histamine receptors (Hrs) serotonin receptors (Htrs) endothelin receptor A (Ednra), etc.) were highly and selectively enriched in the NP1-3 clusters which represents a fraction of the unmyelinated, small size neurons expressing the classical markers of non-peptidergic sensory neurons. Interestingly, within these clusters, marked inhomogeneity was found in the expression of particular pruritic markers, e. g. Nppb and IL-31 receptor (Il31ra) were highly expressed in the NP3 cluster, or Mrgpra3 and Mrgprd displayed highest expression in different clusters, in line with previous data from "biased" studies. Clustering somatosensory neurons using a similar approach, Chiu et al. (2014) also identified a specific subset of DRG neurons highly expressing $N p p b$ and Il31ra genes within the Trpv1 $1^{+} N a v 1.8 / 1.9^{+}$nociceptor population. Interestingly, these cells were mainly negative for isolectin B4 (IB4), a classical marker of non-peptidergic nociceptors (Priestley, 2009). Most recently, a similar single neuron RNAseq transcriptome profiling identified that the neuronal clusters described in mice are highly conserved in non-human primates (Kupari et al., 2021). The NP1-3 classes were also identified in rhesus macaque expressing, among others, MRGPRX1-4 in NP1-NP2 clusters and HR1 in NP3. However, there are some remarkable interspecies differences in the expression of individual genes within some clusters. For example, although somatostatine (SST), Janus kinase 1 (JAK1), IL31RA, Oncostatin $\mathrm{M}$ receptor $\beta$ (OSMR $\beta)$, and Sphingosine-1phosphate receptor 1 (S1PR1) were highly expressed in the NP3 cluster in both mice and macaque, $N p p b$, serotonin receptor $1 \mathrm{~F}$ $(H T R 1 F)$, and neurotensin (NTS) were specifically expressed only in mice whereas the expression of some other genes were mainly restricted to primates (Kupari et al., 2021). In a current study, Nguyen et al. (2021) classified human DRG neurons based on single nucleus RNA sequencing and supported their analysis with multiplex in situ hybridization. They grouped the sensory neurons into 15 classes (H1-H15) that mainly matched the previously described mouse clusters, but they also identified some human-specific classes which does not have a clear mouse counterpart. From the point of view of itch, H10 and H11 classes seem to be the most relevant. The expression pattern of these classes resembled to the mouse NP1-3 classes, likely representing non-peptidergic pruriceptive neurons. Neurons in the H11 class highly expressed OSMR $\beta, J A K 1$ and SST especially similarly to NP3 mouse neurons, whereas MRGPRX1 was found mainly in $\mathrm{H} 10$ as its counterpart genes are characteristic for NP2 mouse cells. However, both human classes also expressed markers characteristic for NP1 group in mice, and in general, the in situ hybridization indicated that $\mathrm{H} 10$ and $\mathrm{H} 11$ are relatively heterogeneous classes of sensory neurons. Interestingly, some $\mathrm{H} 10$ neurons co-expressed the low-threshold mechanosensitive ion channel PIEZO2 with pruriceptive markers that was not found in mice. Thus, it is tempting to consider these cells as the mediators of the human mechanically evoked itch (Nguyen et al., 2021). It is important to mention that these data revealed remarkable differences in the expression of growth factor receptors between the corresponding neuron classes of mice and human, suggesting that the development and differentiation of the analogue somatosensory neurons might be controlled by different mechanisms in rodent and human (Nguyen et al., 2021).

Phenomenologically, pruriceptive fibers can be characterized by their (electro)physiological properties in humans (Schmelz, 2015). The unmyelinated $C$ fibers innervating the skin contains mechanosensitive polymodal nociceptors responding to mechanical, chemical and thermal stimuli, and less numerous mechano-insensitive nociceptive fibers, as well (Schmidt et al., 1995, 1997, 2002). In this latter, mechano-insensitive group, a subset of neurons are identified by their marked responses to the prototypic itch mediator histamine, suggesting that they form an "itch-sensitive" population within the primary afferents. These histamine-sensitive sensory neurons were characterized by low conduction velocity, high transcutaneous electrical threshold, large receptive field and poor two point discrimination threshold for histamine-induced itch (Wahlgren and Ekblom, 1996; Schmelz et al., 1997, 2000, 2003; Schmidt et al., 2002; Schmelz and Schmidt, 2010). A distinct group of histamine insensitive pruriceptive afferents was also proposed by the experiments demonstrating that low intensity-high frequency focal electrical stimulation evoked itch sensation without causing erythema, which erythema is a characteristic consequence of the axon reflex activated by exciting the histamine sensitive fibers (Ikoma et al., 2005; Steinhoff et al., 2006). In contrast to histamine, the pruritic spicules of the cowhage (Mucuna pruriens) pod activated a subgroup of mechanosensitive nociceptive afferents and not the mechanoinsensitive ones (Namer et al., 2008). Moreover, the involvement of nociceptive, myelinated A-fibers was also demonstrated in the itch sensation evoked by cowhage (Ringkamp et al., 2011).

These human data are in good accordance to the above mentioned rodent results describing distinct sub-groups of pruriceptive fibers within the nociceptor population. Indeed, results of rodent behavior experiments on pruriception can be successfully translated to human itch sensation, especially with the use of advanced experimental paradigms which are able to discriminate between nociception and pruriception in mice, like the cheek test or calf injection model. In the cheek model, compounds are injected into the cheek of the animals which results in wiping with the forelimb or scratching with the hind limb in case of algogens and pruritogens, respectively. Similarly, calf injection resulting in pain and itch will induce selectively licking and biting responses, respectively (Shimada and LaMotte, 2008; LaMotte et al., 2011, 2014). These techniques were found to be very useful to discriminate between pruriception and nociception and identifying the selective molecular events in the sensory transduction on pruritus.

\section{Mechanisms of the Sensory Transduction in Pruritus}

The activation of the above detailed pruriceptive primary sensory neurons is responsible for the sensory transduction of itch, which is the first step of pruriception, (i.e. the neural processing of the information which finally will result in itch sensation). The pruritic sensory transduction is typically initiated by chemical mediators acting on their receptors expressed by the cutaneous sensory terminals. During the molecular events of the sensory transduction of itch, pruritic mediators typically bind to a 
metabotropic receptor which initiates the activation of intracellular signaling pathways resulting in the opening of some ion channels responsible for the generator potential which finally evokes the discharge of the neuron (Tóth et al., 2015, 2020; Dong and Dong, 2018).

The ion channels involved in the initial depolarization are considered as molecular integrators and amplifiers of pruriception. The best studied of these ion channels mostly belong to the transient receptor potential (TRP) family of ion channels and show significant overlap with those involved in nociception. The pruriceptive role of the thermosensitive nociceptors TRPV1 and transient receptor potential ankyrin 1 (TRPA1) is the most characterized on sensory neurons (Wilson and Bautista, 2014, 201; Schmelz, 2015; Tóth et al., 2015, 2020). The role of TRPV1 was described primarily in the transduction of histamine induced pruritus, but it is involved in some forms of non-histaminergic pruritus as well (Imamachi et al., 2009; Dong and Dong, 2018). In contrast, TRPA1 is a general integrator in the transduction of itch induced by various non-histaminergic mediators (Wilson et al., 2011; Wilson et al., 2013; Lieu et al., 2014; Wilson and Bautista, 2014). Although histaminergic and non-histaminergic forms of pruritus signal via different pathways and may be transmitted by selective labeled lines, the partially overlapping expression of TRPV1 and TRPA1 is more widespread in sensory afferents and is not restricted to pruriceptors. Beyond their role in pruriception, they are thermosensitive and can mediate different forms of nociception as well: e.g. TRPV1 is a central molecule of inflammatory warm hyperalgesia and TRPA1 plays a role in cold and mechanical hyperalgesia (Tominaga et al., 1998; Caterina et al., 2000; da Costa et al., 2010; Julius, 2013; Vriens et al., 2014). However, in certain cases, TRPA1 and TRPV1 can play a synergistic role in the same process. They were recently shown as key transducers of heat-pain together with transient receptor potential melastatin 3 (TRPM3), another thermosensitive nociceptor TRP channel significantly coexpressed with TRPV1 and TRPA1. Interestingly, despite their co-expression and functional overlap in thermal nociception (Vandewauw et al., 2018; Held and Tóth, 2021), TRPM3 is not involved in transduction of pruritus evoked by either histamine or serotonin (5-HT) and endothelin-1 (ET-1) (Kelemen et al., 2021). These data suggests, that individual TRP channels, even if coexpressed by some sensory neurons, can play selective roles in certain forms of pruriception or nociception. Even different sensations evoked by the same substance can be mediated by different TRP channels: Sphingosine 1-phosphate $(\mathrm{S} 1 \mathrm{P})$ activates S1P receptor 3 (S1PR3) which induces both itch and pain. However, itch transduction is due to activation of TRPA1 via $\mathrm{G}_{\beta \gamma}$ signaling pathway but pain transduction realized by TRPV1 activation via PLC mediated signal transduction (Hill et al., 2018).

Beyond TRPV1 and TRPA1, other ion channels can integrate the effect of pruritogens. Recently, TRPV4 was described to mediate (at least some forms of) 5-HT evoked itch and cellular responses of DRG neurons (Akiyama et al., 2016). Beyond TRP channels, the $\mathrm{Ca}^{2+}$-activated chloride channel anoctamine 1 (ANO1/TMEM16A) (Yang et al., 2008) was proposed to mediate the activation of $\mathrm{C}$ fibers by chloroquine, a strongly pruritic antimalarial drug activating MrgprA3 (Ru et al., 2017). Similar to TRP channels, ANO1 is a thermosensitive nociceptor, as well: it can be activated by noxious warm temperature and mediates nociceptive responses in thermal pain models. Although ANO1 is a chloride channel, its activation can result in depolarization and consequent discharge of DRG neurons due to their relatively higher intracellular $\mathrm{Cl}^{-}$concentration in physiological circumstances and it can contribute to the neural depolarization induced by ET-1 and histamine (Cho et al., 2012). Interestingly ANO1 can also amplify the neural activity elicited by depolarizing nociceptive $\mathrm{Ca}^{2+}$-permeable cationic channels. In nociceptors, $\mathrm{Ca}^{2+}$ influx via TRPV1 was demonstrated to activate ANO1, strongly exacerbating TRPV1 induced depolarization and nociception (Takayama et al., 2015, 2019). Similarly, TRPV4 can be also coupled to ANO1 as reported in secretory cells (Takayama et al., 2014; Derouiche et al., 2018).

\section{Receptors for Pruritogens in Sensory Fibers}

The activation of the above listed neuronal ion channels can be initiated by several receptors of the cutaneous pruriceptive nerve endings which are sensitive for the peripherally released pruritic mediators (Table 1). The most well-known, "traditional" pruritogenic mediator histamine binds to its $G$ protein coupled histamine receptors $(\mathrm{H} 1 \mathrm{R}, \mathrm{H} 3 \mathrm{R}$, and $\mathrm{H} 4 \mathrm{R})$ that are linked to pruritus and expressed on the cutaneous sensory fibers (Panula et al., 2015) (Rossbach et al., 2011). Of these, activation of $\mathrm{H} 1 \mathrm{R}$ and $\mathrm{H} 4 \mathrm{R}$ excites pruriceptors resulting in itch. H1R signalizes via $G_{q / 11}$ proteins (Panula et al., 2015), and is shown to activate phospholipase C $\beta 3$ (PLC $\beta 3$ ) and consequently TRPV1 (Han et al., 2006). Pharmacological data also support the involvement of phospholipase A2 and lipoxygenases in the H1Rinduced activation of TRPV1 (Kim et al., 2004). H4R can also activate TRPV1 via a PLC-mediated pathway (Jian et al., 2016). Moreover, the role of protein kinase $\mathrm{C} \delta(\mathrm{PKC} \delta)$ was also described in the activation of pruriceptors by histamine but not by non-histaminergic pruritogens (Valtcheva et al., 2015). In contrast, the activation of H3R, which is known as an inhibitory histamine receptor transmitting negative feedback on histamine release (Panula et al., 2015), seems to inhibit histamine-induced pruritic responses as its inverse agonists can evoke both activation of pruriceptive neurons and itch (Rossbach et al., 2011).

5 -HT is also a potent pruritogen in both humans and rodents (Weisshaar et al., 1997; Akiyama et al., 2010; Dong and Dong, 2018), which can activate several 5-HT receptors expressed by sensory nerve endings. Among them, pharmacological activators of $5-\mathrm{HT}_{2 \mathrm{~A}}$ and $5-\mathrm{HT}_{7}$ were shown to sensitize TRPV1 responses via PKC- and PKA-dependent pathways (Ohta et al., 2006). In contrast, the genetic ablation of the ionotropic 5-HT3A did not affect 5-HT evoked behavioral responses, while the lack of PLC $\beta 3$ diminished it. This further supports the role of the metabotropic 5 -HT receptors and related signaling pathways in pruriception. However, genetic deletion of TRPV1 did not influence the 5-HTinduced responses which were mainly abolished in the absence of TRPV1 expressing sensory neurons arguing for the role of an 
TABLE 1 | Cutaneous pruritic mediators stimulating sensory nerve endings

\begin{tabular}{|c|c|c|}
\hline Pruritic mediator & Potential sources & $\begin{array}{l}\text { Potential targets on sensory fibers: Receptors, } \\
\text { signal transduction, cellular responses }\end{array}$ \\
\hline Histamine & Mast cells, basophils & $\begin{array}{l}\mathrm{H} 1 \mathrm{R} \rightarrow \mathrm{G}_{\mathrm{q}} \rightarrow \mathrm{PLC} 33 / \mathrm{PLA} 2 \rightarrow \mathrm{TRPV} 1 \\
\mathrm{H} 4 \mathrm{R} \rightarrow \mathrm{PLC} \rightarrow \mathrm{TRPV} 1 \\
\text { Further potential elements of transduction: PKC } \delta \text {, lipoxygenase }\end{array}$ \\
\hline Serotonin & Mast cells, keratinocytes & $\begin{array}{l}5 \text {-HTR7 } \rightarrow \text { TRPA1 } \\
\text { TRPV4 }\end{array}$ \\
\hline Endothelin 1 & Keratinocytes & $\begin{array}{l}\mathrm{ET}_{\mathrm{A}} \rightarrow \mathrm{PLC} \beta 3 \rightarrow \text { TRPA1 } \\
\text { Role of ERK1/2? }\end{array}$ \\
\hline $\begin{array}{l}\text { Proteases } \rightarrow \text { BAM8-22, } \\
\text { SLIGRL/SLIGKV }\end{array}$ & Mast cells, keratinocytes & $\begin{array}{l}\text { (mouse) MRGPRC11 } \rightarrow \mathrm{G}_{\alpha q} \rightarrow \text { TRPA1 } \\
\text { (human) MRGPRX1/MRGPRX2 }\end{array}$ \\
\hline TSLP & Keratinocytes & IL7R $\alpha-T S L P R ~ \rightarrow$ TRPA1 \\
\hline IL-31 & Mast cells & IL-31RA-OSMR $\beta \rightarrow$ ERK1/2 $\rightarrow$ TRPA1/TRPV1 \\
\hline IL-33 & Keratinocytes & IL-1RAcP-ST2 $\rightarrow$ TRPA1/TRPV1 \\
\hline $\mathrm{IL}-13$ & $\mathrm{~T}_{\mathrm{h}} 2$ type immune response & $\mathrm{IL}-13 \mathrm{R} a 1 \rightarrow \mathrm{JAK} 1 \rightarrow$ ?sensitization/activation? \\
\hline $\mathrm{IL}-4$ & $\mathrm{~T}_{\mathrm{h}} 2$ type immune response & IL-4Ra $\rightarrow$ JAK1 $\rightarrow$ ?sensitization/activation? \\
\hline CXCL10 & Neutrophils, Keratinocytes & $\mathrm{CXCR3} \rightarrow \mathrm{Ca}^{2+}$-regulated $\mathrm{Cl}^{-}$channels \\
\hline LTC4 & Various leukocytes, especially in $T_{h} 2$ type immune response & CysLT $2 R \rightarrow$ TRPA1/TRPV1 \\
\hline S1P & $\begin{array}{l}\text { Erythrocytes, Endothelial cells, Mast cells, Dendritic cells; } \\
\text { increased in inflammation }\end{array}$ & $\begin{array}{l}\mathrm{S} 1 \mathrm{PR} 3 \rightarrow \mathrm{G}_{\beta \gamma} \rightarrow \text { TRPA1 } \rightarrow \text { itch (High concentration of S1P: S1PR3 } \rightarrow \\
\mathrm{PLC} \rightarrow \mathrm{TRPV} 1 \rightarrow \text { pain) }\end{array}$ \\
\hline Periostin & Keratinocytes, Fibroblasts & integrin $\alpha_{\mathrm{V}} \beta 3 \rightarrow$ TRPA1/TRPV1 \\
\hline $\begin{array}{l}\text { (ds)RNA/hairpin structures of } \\
\text { self-RNA }\end{array}$ & Tissue damage? & TLR3 \\
\hline
\end{tabular}

alternative ion channel in the 5-HT signaling pathway in TRPV1+ neurons (Imamachi et al., 2009). Indeed, studies of gene deleted animals provided evidence for the role of $5-\mathrm{HT}_{7}$ receptor in mediating acute serotonergic itch via consequent TRPA1 activation (Morita et al., 2015). Moreover, as mentioned above, TRPV4 was also described as a component in the transduction of serotonergic itch in sensory neurons (Akiyama et al., 2016).

The otherwise vasoconstrictive peptide ET-1 acts as an effective endogenously produced itch mediator, although ET-1 can also induce nociception (Hans et al., 2009; Gomes et al., 2012; Kido-Nakahara et al., 2014). Sensory neurons express mainly the ET receptor $\boldsymbol{A}\left(\boldsymbol{E} \boldsymbol{T}_{\boldsymbol{A}}\right)$ (Khodorova et al., 2009) which signals partly via a $\mathrm{G}_{\mathrm{q}}$-related pathway stimulating PLC $\beta$ (Khodorova et al., 2009; Davenport et al., 2016). In nociceptors, $\mathrm{ET}_{\mathrm{A}}$ activation by endothelin results in increase in intracellular $\mathrm{Ca}^{2+}$ concentration which activates PKC resulting in the potentiation of TRPV1 responses (Plant et al., 2007). The pruritic signaling also starts from $\mathrm{ET}_{\mathrm{A}}$ (McQueen et al., 2007), and involves PLC $\beta 3$, but endothelin-evoked itch is independent of TRPV1 (Imamachi et al., 2009). It is strongly reduced by genetic deletion or pharmacological blockade of TRPA1 (Kido-Nakahara et al., 2014), although there is some controversy about the role of this ion channel in ET-1-induced scratching (Liang et al., 2011). Moreover, the role of extracellular signal-regulated kinases ERK1/2 was also proposed in the $\mathrm{ET}_{\mathrm{A}}$ induced pruritic responses. ET-1-induced scratching is negatively regulated by the endothelin-converting enzyme 1 (ECE1) co-expressed with $\mathrm{ET}_{\mathrm{A}}$ in somatosensory neurons (Kido-Nakahara et al., 2014).

As mentioned above, MRGPRs serve not only as markers of the pruriceptive fibers but also as receptors for some nonhistaminergic pruritogens. As their name indicates, they are $G$ protein-coupled receptors that signal mainly via the $G_{q}$ pathway, resulting in $\mathrm{Ca}^{2+}$ release from intracellular stores. The deletion of a gene cluster of $12 \mathrm{Mrgpr}$ genes in mice resulted in impaired itch evoked by selected non-histaminergic pruritogens: the antimalarial drug chloroquine was identified to activate MRGPRA3, and bovine adrenal medulla 8-22 (BAM8-22, a proenkephalin A-derived peptide) and SLIGRL (a peptide product cleaved from the protease activated receptor 2, PAR2) stimulate MRGPRC11. These receptors were shown to signal via $\mathrm{G}_{\mathrm{\alpha q} 11}$ activating TRPA1 (and not TRPV1) (Lembo et al., 2002; Liu et al., 2009, 2011; Wilson et al., 2011; Liu and Dong, 2015). However, a recent study challenged the role of TRPA1 in mediating chloroquine-induced itch, and suggested the role of the calcium-activated chloride channel ANO1/TMEM16A as a downstream target of the chloroquine-induced PLC $\beta$-mediated signaling resulting in depolarization and consequent discharge of sensory fibers (Ru et al., 2017). Importantly, these mouse Mrgpr ligands are also pruritogenic in humans, activating MRGPRX1 
TABLE 2 | Overview of the potential pathogenesis of itch in selected pruritic diseases and pathological conditions.

Disease

Irritant contact dermatitis (ICD)

Allergic contact dermatitis (ACD)

Urticaria

Atopic dermatitis (AD)

Factors potentially involved in the pathogenesis of pruritus

Keratinocyte injury and barrier damage $\rightarrow$ inflammatory response, $T_{h} 1$ cytokines

Allergen specific, T cell mediated inflammatory responses, typically $T_{h} 2$ type $\rightarrow 5-H T \uparrow, E T-1 \uparrow$, TSLP $\uparrow$, CXCL10 1 , IL-33

$\operatorname{lgE}$, degranulation of mast cells, dysregulation of basophils and eosinophils $\rightarrow$ histamine $\uparrow$, other pruritic mediators

Barrier disturbances, vicious itch-scratch cycle $\rightarrow$ irritant and allergen permeation $\uparrow$

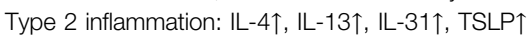

Dysregulation of cutaneous signaling pathways: opioid, cannabinoid, neuropepitide (SP $\rightarrow \mathrm{NKR} 1)$ signaling

Innervation density $\uparrow$

Inflammatory lipid mediators $\uparrow$

Periostin synthesis $\uparrow$ (linked to type 2 inflammation)

\begin{tabular}{|c|c|}
\hline Psoriasis & $\begin{array}{l}\mathrm{T}_{\mathrm{h}} 17 \uparrow \rightarrow \mathrm{IL}-17 \uparrow, \mathrm{IL} 22 \uparrow \\
\mathrm{IL} 31 \uparrow, \mathrm{TSLP} \uparrow, \mathrm{SP} \uparrow, \mathrm{NPY} \downarrow \\
\mathrm{NGF} \uparrow \rightarrow \text { innervation density } \uparrow\end{array}$ \\
\hline Prurigo nodularis & $\begin{array}{l}\text { Innervation density } \uparrow \rightarrow \mathrm{SP} \uparrow, \mathrm{CGRP} \uparrow \\
\text { Eosinophils } \uparrow \text {, mast cells } \uparrow, T \text { cells } \uparrow \rightarrow \mathrm{IL} 4 \uparrow, \mathrm{VIP} \uparrow \text {, histamine } \uparrow \text { prostaglandins } \uparrow\end{array}$ \\
\hline Cutaneous T-cell lymphoma & $\begin{array}{l}\mathrm{IL}-31 \uparrow, \mathrm{IL}-31 \mathrm{RA} \uparrow, \mathrm{OSMR} \beta \uparrow \\
\mathrm{IL}-4 ?, \mathrm{IL}-13 ?, \mathrm{SP} ?\end{array}$ \\
\hline Dermatomyositis & $\mathrm{CD}^{+}$cells $\uparrow \rightarrow \mathrm{IL}-31 \uparrow, \mathrm{IL}-31 \mathrm{RA} \uparrow$ \\
\hline Systemic sclerosis & $\begin{array}{l}\text { Neuropathic component: Destruction of sensory fibers by accumulating collagen, and later regeneration by th } \\
\text { milieu } \\
\text { Mast cells } \uparrow, \text { histamine } \uparrow\end{array}$ \\
\hline Chronic renal failure & $\begin{array}{l}\text { Eosinophils } \uparrow \text {, mast cells } \uparrow \text {, histamine } \uparrow \text {, tryptase } \uparrow \text {, inflammation } \uparrow \\
\text { Peripheral neuropathy } \\
\text { Imbalance of } \mu \text { - and } \kappa \text {-opioid receptor activity }\end{array}$ \\
\hline Cholestatic liver diseases & $\begin{array}{l}\text { Endogenous opioids } \uparrow, \text { histamine } \uparrow, \text { serotonin } \uparrow, \text { lysophosphatidic acid } \uparrow \text { ( } \rightarrow \text { TRPV1), bilirubin } \uparrow, \text { bile acids } \uparrow \\
\text { Lysophosphatidylcholine } \rightarrow \text { TRPV4 (epidermis) } \rightarrow \text { miR-146a } \uparrow \rightarrow \text { neural TRPV1 activation } \uparrow \\
\text { Bile acids } \uparrow \rightarrow \text { TGR5 } \rightarrow \text { TRPA1 (mouse) } \\
\text { Bile acids } \uparrow \rightarrow \text { MRGPRX4 (human) } \\
\text { BAM8-22 } \uparrow \rightarrow \text { MRGPRX1/MRGPRC11 } \rightarrow \rightarrow \text { TRPA1 }\end{array}$ \\
\hline
\end{tabular}

(chloroquine and BAM8-22) and MRGPRX2 (SLIGKV, the human analog of the SLIGRL) (Liu et al., 2009, 2011; Sikand et al., 2011; Liu and Dong, 2015). Moreover, in humans, MRGPRX4 also induces pruritic signal transduction via $\mathrm{G}_{\mathrm{q}} /$ PLC pathway upon activation by bile acids (Yu et al., 2019). Interestingly, in mice, bile acids activate another G-protein coupled receptor, the G-protein-coupled bile acid receptor 1 (TGR5) in sensory afferents, which also signals via TRPA1 and evokes itch (Alemi et al., 2013; Lieu et al., 2014). Next to the above MRGPRs, the activation of MRGPRD by $\beta$-alanine can also induce itch. Similar to the previously mentioned receptors, MRGPRD activates TRPA1, albeit via a PKA-dependent manner (Liu Q. et al., 2012; Wang et al., 2019).

Although several cytokines, especially $\mathrm{T}_{\mathrm{h}} 2$-associated ones, are involved in the development of pruritus and itchy (dermatological) disorders, only some of them can directly excite pruriceptive nerve endings via cytokine receptors. Neural cytokine receptors can influence the responsiveness of the sensory fibers even if their activation does not initiate immediate action potential firing. Therefore, they can contribute to the development of chronic itch characteristic of several of the most prevalent dermatological conditions (Storan et al., 2015). One of the most well-established pruritic cytokines is
IL-31 which activates a subpopulation of sensory neurons via a receptor heterodimer composed of IL-31 receptor A (IL-31RA) and Oncostatin $M$ receptor $\beta$ (OSMR $\beta$ ) (Cevikbas et al., 2014; Datsi et al., 2021). IL-31RA activation induces signal transduction through the activation of ERK1/2 and both TRPV1 and TRPA1 (Cevikbas et al., 2014). Sensory neurons also express receptors of other $\mathrm{T}_{\mathrm{h}} 2$-type cytokines, like IL-4 (IL-4R $\alpha$ ) and IL13 (IL-13R $\alpha 1)$. Interestingly, although IL-4 and IL-13 also activate a small percentage of pruriceptive fibers in both mice and humans, they did not evoke acute itching, in contrast to IL31. However, they sensitized the sensory neurons toward histamine and other pruritogens, and increased the intensity of histamine-evoked itch. These responses were mediated by IL-4Ra and downstream JAK1 signaling (Oetjen et al., 2017). A recent report raised some controversy about the itch-inducing effect of IL-4 and IL-13 demonstrating that they can evoke even acute itch if applied at lower concentration. A potential explanation might be that higher concentration of the cytokines saturates the JAK1 pathway, and induces negative feedback reactions (Campion et al., 2019). Sensory neurons also express the receptor of thymic stromal lymphopoietin (TSLP), which is another pruritic $\mathrm{T}_{\mathrm{h}} 2$-type cytokine produced by various epithelial cells, including epidermal keratinocytes 
(Wilson et al., 2013; Varricchi et al., 2018). It activates a small population of the cutaneous nerve endings expressing the heteromeric TSLP receptor composed of IL7 receptor alpha (IL7R $\alpha)$ and TSLP-specific receptor chain (TSLPR) chains. The activation of TSLP receptor evokes itch via TRPA1 (Wilson et al., 2013). IL-1 receptor accessory protein (IL-1RAcP) and a membrane-bound IL-33-specific ST2 form a heteromeric receptor for IL-33, and both subunits can be found in the membrane of pruriceptive nerve endings. IL-33 is a proinflammatory cytokine, which can activate sensory neurons via ST2 receptor involving both TRPA1 and TRPV1. These IL-33induced signaling pathways evoked itch in an urushiol-induced allergic contact dermatitis model (Liu et al., 2016; Topal et al., 2020). In early phase of $A D$ and contact hypersensitivity model of allergic contact dermatitis, CXC chemokine receptor 3 (CXCR3) was found to be upregulated in pruriceptive neurons as was its ligand CXCL10 in the surrounding tissue. In these models, antagonist of CXCR3 inhibited spontaneous disease-related itch (Qu et al., 2015, 3; Walsh et al., 2019). Pharmacological evidence suggests that CXCR3 may signal via a $\mathrm{Ca}^{2+}$-regulated chloride channel (Qu et al., 2017).

Toll-like receptors (TLRs) belong to pattern recognition receptors that are activated by exogenous pathogen- or endogenous danger-associated molecular patterns (PAMPs or DAMPs, respectively). Expressed in various immune cells and peripheral tissues, they are key players in initiating innate immune responses. Among them, TLR3 and TLR7 are expressed in sensory neurons and have been suggested to play roles in the development of pruritus (Taves and Ji, 2015; Dong and Dong, 2018). TLR3 activation by its ligand polyinosinicpolycytidylic acid (poly I:C) evoked action potential firing in sensory neurons and induced acute scratching behavior. Moreover, TLR3 was found to be important in the development of both histaminergic and non-histaminergic itch as both were markedly decreased in Tlr3 knock out animals (Liu T. et al., 2012). Like TLR3, TLR7 was also detected in peripheral sensory neurons of the DRGs and TLR7 activators evoked acute itching in a TLR7-dependent manner. Moreover, the TLR7 agonist imiquimod induced discharge of DRG neurons in wild type, but not in $\operatorname{Tlr} T^{1-}$ mice (Liu et al., 2010). Although both TLR3 and TLR7 are mostly known to be localized in intracellular membranes, it is proposed that they can be expressed in the surface membrane of the sensory neurons, and are thereby available for extracellular ligands (Taves and Ji, 2015). However, the role of TLR7 was questioned by another study indicating that imiquimod-induced scratching as well as neuronal responses are independent of TLR7, but may be due to the inhibition of background or voltage-gated potassium channels of the somatosensory neurons (Kim et al., 2011; Lee et al., 2012). Moreover, imiquimod was recently shown to directly activate TRPA1 which, in sensory neurons, may initiate immediate acute itch (Esancy et al., 2018; Kemény et al., 2018).

Recently, the extracellular matrix protein periostin was shown to activate the receptor integrin $\boldsymbol{\alpha}_{V} \boldsymbol{\beta}$ on the surface of DRG neurons resulting in itch behavior in mice. The periostin induced, integrin $\alpha_{\mathrm{V}} \beta 3$-dependent itch was strongly reduced in mice lacking TRPA1 and TRPV1 ion channels, and NPPB suggesting that these ion channels and neurotransmitters of the pruriceptive neurons are involved in the periostin evoked itch. However, the signaling pathway connecting the integrin $\alpha_{v} \beta 3$ to TRP channels is still under investigation (Mishra et al., 2020; Hashimoto et al., 2021a).

As mentioned above, the activation of Sphingosine 1phosphate receptor 3 (S1PR3) by S1P can also initiate itch activating TRPA1 via $G_{\beta \gamma}$ signal transduction. However, the same receptor can also activate TRPV1 via PLC dependent signaling but this pathway results in nociception and can only be activated by higher S1P concentration (Hill et al., 2018).

Somatosensory neurons also express Lysophosphatidic acid receptor 5 (LPA5), a receptor for lysophosphatidic acid (LPA), that mediates LPA evoked itch (Kittaka et al., 2017; Yamanoi et al., 2019). In the LPA5 signaling pathway, LPA can be (re-) generated intracellularly mainly via phospholipase $\mathrm{D}$ (PLD), but $\mathrm{PLA}_{2}$ and PLC can be also involved. Finally, intracellular LPA can directly activate TRPV1 and TRPA1 resulting in the excitation of the pruriceptive neurons (Nieto-Posadas et al., 2011; Kittaka et al., 2017).

Currently, cysteinyl leukotriene receptor $2\left(\mathrm{CysLT}_{2} \mathrm{R}\right)$, the receptor of the cysteinyl leukotriene C4 (LTC4), was described as a highly expressed receptor in sensory neurons. $\mathrm{CysLT}_{2} \mathrm{R}$ was detected especially in the subset of NP3 cluster DRG neurons, strongly coexpressed with Il31ra and Nppb. Its activation by LTC4 induced acute scratching behavior via $\mathrm{CysLT}_{2} \mathrm{R}$. Although it was not investigated whether $\operatorname{CysLT}_{2} \mathrm{R}$ activates DRG neurons or not, and the downstream signaling pathway is also largely unknown, LTC4-induced scratching was diminished in Trpv1 knock out mice and in the presence of TRPA1 antagonist suggesting that both ion channels can mediate the effect (Voisin et al., 2021).

Urokinase plasminogen activator receptor (U-PAR) was also reported in a subset of DRG neurons and its agonist serpin E1 evoked $\mathrm{Ca}^{2+}$ transients in DRG neurons as well as itching in mice, but the mechanism of action and the related signaling pathway is largely unknown (Larkin et al., 2021).

\section{Cutaneous Pruritic Crosstalk}

Recent advances in the field have shown that itch does not necessarily start at the level of the nerves, but can also be initiated by non-neuronal elements in the skin. In this section we will list the possible contribution of cutaneous cells to the development of itch through mediator release (skin-nerve axis), as well as the role of factors released by nerves that act locally to propagate both the release of pruritogens and local inflammation (nerve-skin axis) (Figure 1).

\section{Keratinocytes' Contribution to Itch}

Keratinocytes were classically considered to be important in forming and maintaining the skin barrier. This view has been supplemented by numerous observations, including the fact that keratinocytes express sensory receptors, among others TRP channels (Denda et al., 2001; Inoue et al., 2002; Peier et al., 2002; Bodó et al., 2004; Chung et al., 2004) and that they can actively secrete various substances that communicate with neighboring cells and nerve endings, including ATP (Denda and Denda, 2007; Mandadi et al., 2009; Mihara et al., 2011), 


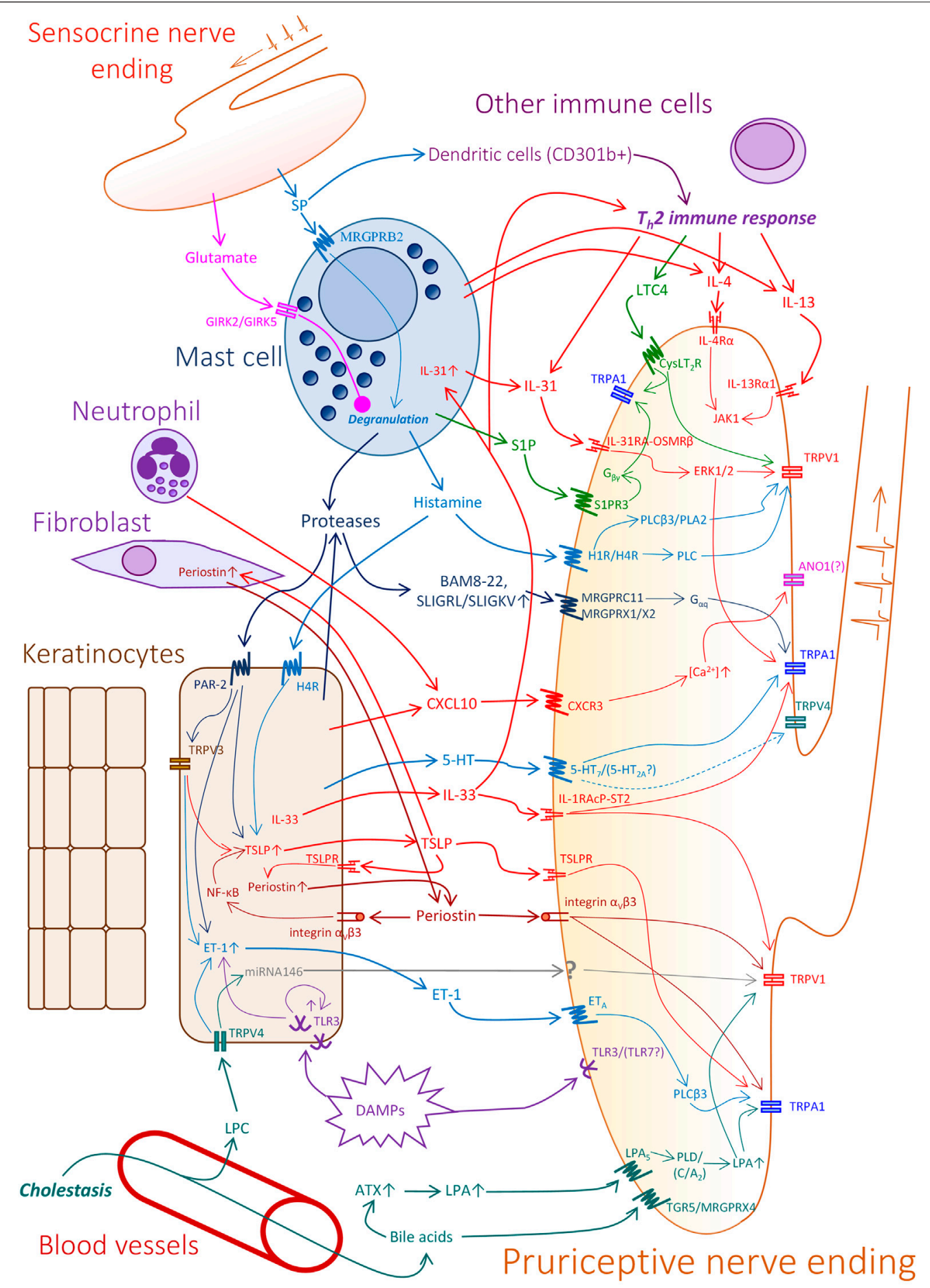

FIGURE 1 | Potential elements and mechanisms in pruritic cutaneous crosstalk. In the skin, products of keratinocytes, mast cells, several immune cells, and additional metabolic and tissue factors can contribute to the excitation of pruriceptive sensory nerve endings. Moreover, sensory terminals can also release pro- and antipruritic factors. Note, that the sensory nerve ending in the figure represents a hypothetic pruriceptor demonstrating the expression of several receptors and signaling (Continued) 
FIGURE 1 | pathways which may be expressed by different individual sensory neurons. For more detailed explanation, please see the text. Abbreviations: 5 HT-Serotonin, 5-HT $T_{2 A} / 7$-Serotonin receptor $2 \mathrm{~A}_{7}$, ANO1-Anoctamine 1, ATX-Autotaxin, CXCL10-C-X-C motif chemokine ligand 10, CXCR3-C-X-C Motif Chemokine Receptor 3, DAMPS -Damage associated molecular patterns, CySLT2R-cysteinyl leukotriene receptor 2, ERK1/2-Extracellular signal-regulated kinase 1/2, ET-1 - Endothelin 1, ET A - Endothelin receptor A, GIRK2/5-glutamate ionotropic receptor kainate type subunit 2/5, IL-13Ra1-Interleukin 13 receptor, alpha 1, IL-1RACP-ST2-IL-1 receptor accessory protein - ST2 heterodimer, IL-31RA-OSMR $\beta$-IL-31 receptor A- Oncostatin M receptor $\beta$ heterodimer, IL-4R $\alpha$ - Interleukin 4 receptor, JAK1 - Janus kinase 1, LPA - Lysophosphatidic acid, LPA ${ }_{5}$ - Lysophosphatidic acid receptor 5, LPC-lysophosphatidylcholine, LTC4-cysteinyl leukotriene C4, MRGPRB2/C11/X1/X2/X4-Mas-related G-protein-coupled receptor B2/C11/X1/X2/X4, NF- $k B$-nuclear factor kappa-lightchain-enhancer of activated B cells, $P L D / C / C \beta 3 / A_{2}$ - phospholipase $D / C / C \beta 3 / A_{2}$, S1P - Sphingosine 1-phosphate, S1P3R-Sphingosine 1-phosphate receptor 3, SP-Substance P, TGR5-G-protein-coupled bile acid receptor 1 (Takeda G protein-coupled receptor 5), TLR3/7-Toll-like receptor 3/7, TRPA1/V1/N3/ V4-Transient receptor potential Ankyrin 1Nanilloid 1Nanilloid 3Nanilloid 4, TSLP-Thymic stromal lymphopoietin, TSLPR-Thymic stromal lymphopoietin receptor.

dopamine (Fuziwara et al., 2005) and glutamate (Fuziwara et al., 2003). Based on these results keratinocytes can be considered as the forefront of the sensory nervous system (Denda et al., 2007).

In terms of itch sensation, the triggers that can elicit the release of pruritogens from keratinocytes are still not fully known. Keratinocytes express multiple receptors that have been implicated in itch induction, including PAR2 (Buhl et al., 2020), TLR3 (Szöllösi et al., 2019), H1 and H4 receptors (Gschwandtner et al., 2008; Schaper et al., 2016), $\mathrm{ET}_{\mathrm{A}}$ and endothelin receptor $\mathrm{B}\left(\mathrm{ET}_{\mathrm{B}}\right)$ (Tsuboi et al., 1995), 5-HT receptors (Lundeberg et al., 2002; Slominski et al., 2003), OSMR $\beta$ (Boniface et al., 2007; Kato et al., 2014), integrin $\alpha_{\mathrm{V}} \beta 3$ (Masuoka et al., 2012), TSLPR (Mishra et al., 2020), as well as neuropeptide receptors (Sandoval-Talamantes et al., 2020), and two members of the transient receptor potential vanilloid (TRPV) family, TRPV3 and 4 (Peier et al., 2002; Sokabe et al., 2010; Mihara et al., 2011; Tóth et al., 2014; Szöllősi et al., 2018). While we have evidence that the receptors listed above are all functionally expressed by keratinocytes, their role in the development and propagation of itch is less well-defined. In general we can classify them into two large groups: receptors that influence the barrier forming function of keratinocytes, and those that cause the cells to secrete factors that can activate pruritic nerve endings. The former may be considered as an indirect mechanism of itch induction, since impaired barrier function leads to increased transepidermal water loss, dry skin, and an increased likelihood of exogenous pruritogens penetrating the stratum corneum (Yosipovitch et al., 2019). The latter can be considered a direct mechanism of itch signaling, where the activated keratinocytes secrete signaling molecules (IL-33, TSLP and ET-1) known to activate pruritic nerve fibers.

The indirect path of itch induction as mentioned above is dependent on the disruption of the epidermal barrier. This is usually accompanied by the production of pro-inflammatory cytokines (e.g. IL-6) and chemokines (e.g. CXCL-8, CCL17/ TARC, CCL19/MIP-3 $\beta$, CCL22/MDC, CCL23/MIP-3, CCL4/ MIP-1 $\beta$ and CXCL1/GRO1 $\alpha$ ) (Cornelissen et al., 2012; Kabashima, 2013; Lee et al., 2013), as well as nerve growth factor (NGF) by keratinocytes. The combined effect of these factors is recruitment of further inflammatory cells to the skin, and in the case of chronic pruritus, increased density of nerve fibers and response in the affected area (Buhl et al., 2020). The disruption of the epidermal barrier can occur through increased keratinocyte proliferation (as caused by agonists of H4R (Glatzer et al., 2013), TLR3 (Szöllősi et al., 2019), periostin (Masuoka et al.,
2012), and neuropeptides (Sandoval-Talamantes et al., 2020)), through disruption of the differentiation process, by the production of matrix metallopeptidase 9 (MMP9), which can drive recruitment of immune cells to the skin [as caused by agonists to H1 (Gschwandtner et al., 2013; Chen J. et al., 2021)], and the increased production of antimicrobial peptides, a common characteristic of inflammatory skin diseases [as seen after OSMR $\beta$ activation (Boniface et al., 2007)]. TRPV3, a nonselective calcium-permeable channel first identified in keratinocytes (Peier et al., 2002), was linked to pruritus based on the consequence of gain-of-function mutations in the channel. These lead to the hairless and pruritic dermatitis phenotype of DS-Nh mice (Yoshioka et al., 2009) and to the development of Olmsted syndrome in humans, which is characterized by palmoplantar keratoderma and periorificial plaques, as well as hair and nail malformities, pain and itch (Lin et al., 2012). Conversely, the activation of TRPV4 accelerates barrier recovery, and the formation of intercellular junctions between keratinocytes since this channel is co-localized to adherent junction proteins such as E-cadherin and $\beta$-catenin. The role of TRPV4 in the development of itch is more nuanced however, since it has also been linked to regulation serotonin and histamine release as well as a consequent development of itch (Chen et al., 2016; Luo et al., 2018; Boudaka et al., 2020).

Of the above listed mediators, their involvement in direct keratinocyte-nerve communication has been proven for $\mathrm{H} 4 \mathrm{R}$ (Schaper et al., 2016), PAR2 (Kempkes et al., 2014; Buhl et al., 2020) TLR3 (Szöllösi et al., 2019) and both TRPV3 (Seo et al., 2020) and TRPV4 (Moore et al., 2013). To date the major pruritic mediators that can directly activate pruritic nerve endings released by keratinocytes are TSLP, periostin, ET-1, IL-33 and most recently BNP. On keratinocytes histamine dominantly acts through the $\mathrm{H} 4$ receptor and increases the release of TSLP subsequently to poly I:C stimulation in both murine and human cells (Schaper et al., 2016). TSLP secretion has also been observed after activation of all the above mentioned receptors with the exception of TRPV4, which solidifies its role as one of the most important skin-derived pruritic mediators (Kinoshita et al., 2009; Wilson et al., 2013; Park et al., 2017). Furthermore, TSLP (and other $\mathrm{T}_{\mathrm{h}} 2$ cytokines) can induce periostin secretion and periostin can stimulate further TSLP release potentially establishing another pruritic positive feedback (Masuoka et al., 2012; Mishra et al., 2020; Hashimoto et al., 2021a). One of the most potent keratinocyte-derived pruritic mediators is ET-1 (Kido-Nakahara et al., 2014), the production of which can be initiated by PAR2 (Buhl et al., 2020), TLR3 (Szöllösi 
et al., 2019), TRPV3 (Zhao et al., 2020), and TRPV4 (Chen et al., 2016) activation. IL-33 is a member of the IL-1 inflammatory cytokine family, and is constitutively expressed in the nucleus of keratinocytes, and acts as an alarmin that is released upon inflammation or cellular damage (Moussion et al., 2008). While first shown to act on cells of the innate and adaptive arm of the immune system [specifically mast cells, type 2 innate lymphoid cells, basophils and type $2 \mathrm{~T}$ helper cells (Kondo et al., 2008)], the receptor of IL-33, ST2 is also expressed on sensory nerve endings in the skin and its activation leads to an itch response in mice, as discussed above (Liu et al., 2016). Moreover, IL-33 is upregulated in atopic dermatitis (AD) lesions which may contribute to its pruritic phenotype (Imai, 2019).

As seen above the contribution of keratinocytes to itch sensation is multifaceted, and this is further complicated by the interplay between these receptors in the keratinocytes themselves. PAR2 has been shown to signal through TRPV3 (Zhao et al., 2020), the expression of TLR3 is increased upon TLR3 activation (forming a positive feedback loop that could be a major factor in the chronification of itch (Szöllösi et al., 2019)), and the effect of histamine is also potentiated through TLR3 (Schaper et al., 2016). This is also compounded by the crosstalk between keratinocytes and immune cells, as detailed below.

\section{Immune Cells}

Mast cells have long been considered to be a central player in the pathogenesis of itch, mainly through their release of histamine. Histamine is the main mediator responsible for acute itch, by activating the $\mathrm{H} 1$ and $\mathrm{H} 4$ receptors on sensory nerves (Shim and Oh, 2008). Mast cells also release a wide array of other signaling molecules including cytokines and chemokines, and have recently been shown to contribute to non-histaminergic itch as well (Meixiong et al., 2019a) through these mediators. The direct role of mast cells in itch transduction is further supported by their close proximity to afferent nerves in the skin (Bienenstock et al., 1991). The most important cytokines known to directly activate pruritogenic nerves are IL-4, IL-13 and IL-31, all of which are associated with $\mathrm{T}_{\mathrm{h}} 2$ cells and which can be released from mast cells, among others. Other sources of these cytokines include natural killer cells, basophils and eosinophils, although the contribution of these latter cell populations to itch is not well defined.

The role of $\mathrm{T}_{\mathrm{h}} 2$ cells in pruritic skin diseases, especially in $\mathrm{AD}$, is well documented (Gandhi et al., 2017), and forms the basis for some of the most effective treatments of itch in AD (Ruzicka et al., 2017; Gooderham et al., 2018; Bawany et al., 2020). Dupilumab inhibits the effect of IL- 4 and IL-13 by blocking the IL-4a subunit which is shared by both cytokines, while Nemolizumab targets IL31RA to block the effect of IL-31 (Ruzicka et al., 2017). IL-4 and IL-13 act both as amplifiers of $\mathrm{T}_{\mathrm{h}} 2$ responses that contribute to the upkeep of the environment that promotes pruritic signaling (Furue et al., 2019), and as direct activators of pruritic nerve endings (Campion et al., 2019). IL-31 acts on both keratinocytes and sensory nerves (Sonkoly et al., 2006), although its direct link to itch is only proven in mice, since in humans it does not induce immediate, only delayed itch responses (Hawro et al., 2014). Nevertheless, Nemolizumab has been proven to be efficacious in the treatment of AD (Ruzicka et al., 2017), which hints that in humans IL-31 acts indirectly to induce itch.

An indirect contribution of the abovementioned cytokines to the development of chronic itch is their contribution to barrier dysfunction, by the downregulation of skin barrier proteins in keratinocytes (Kim et al., 2008). Since this may lead to the release of TSLP that strengthens $\mathrm{T}_{\mathrm{h}} 2$ cell functions (Kitajima et al., 2011), we can once again see a possible positive feedback loop that may lead to the chronification of itch. Keratinocytes may also produce IL-33, which also leads to $\mathrm{T}_{\mathrm{h}} 2$ polarization in $\mathrm{AD}$ (Imai, 2019), and results in IL-31 secretion from mast cells (Petra et al., 2018). Recently, next to its direct pruritogenic effect, the role of the extracellular matrix protein periostin emerged as a regulator of barrier functions, and an amplifier of $\mathrm{T}_{\mathrm{h}} 2$ responses, as well (Hashimoto et al., 2021a).

\section{Neurogenic Pruritus - Role of Sensory Neurons in the Establishment of a Pruritus-Prone Local Milieu}

The crucial role of the cutaneous immune cells and keratinocytes in the establishment of a local pruritic environment via the secretion of mediators that signal toward the itch-detecting sensory fibers in various skin conditions is unquestionable. However, emerging evidence supports the concept that this is not a one-way interaction, but rather a local pruritic intercellular network between the sensory neurons and the peripheral cells, in which the neurons can also actively take part by influencing the function of the neighboring cells, and thereby contributing to the development of an inflamed, pro-pruritic local tissue micromilieu. The "classical" concept of neurogenic inflammation has been known since the '60s, when Miklós Jancsó and his colleagues showed that the excitation of capsaicin-sensitive nerve endings causes local inflammation (Jancsó et al., 1967, 1968). Later research described the "sensocrine" function of the sensory neurons by which they release neuropeptides such as substance P (SP) and calcitonin gene related peptide (CGRP), as well as glutamate, ATP, chemokine ( $\mathrm{C}-\mathrm{C}$ motif) ligand 2 (CCL2), colony stimulating factor 1 (CSF-1) and other mediators, including even microRNAs at the peripheral nerve endings. These sensory neuronderived mediators can influence the local barrier and immune functions as well as inflammatory responses (Shouman and Benarroch, 2021). As time passes, more and more specific "neuron-to-periphery" interactions are identified, and some of them are likely to have an impact on the development of pruritus.

Neuropeptides released from the sensory nerve endings, especially from C-fibers, can target keratinocytes, dermal endothelial cells, mast cells, Langerhans cells, and lymphocytes as well. For example, SP can increase histamine and TNFa release from mast cells, IL-1, IL- 6 and IL- 8 production in keratinocytes, or IL-8 production in dermal microvascular endothelial cells, all contributing to local inflammation (Ansel et al., 1997; Choi and Di Nardo, 2018; Shouman and Benarroch, 2021). In contrast to the inflammatory role of SP, the effect of CGRP is more ambiguous. It can activate mast cells, evoke vasodilation (Ansel et al., 1997; Choi and Di Nardo, 2018; Shouman and Benarroch, 2021), and shift Langerhans cells-initiated immune responses toward $\mathrm{T}_{\mathrm{h}} 2$ direction (Ding et al., 2008), but it was also 
found to inhibit 5-HT- or histamine-induced inflammatory responses (Granstein et al., 2015), as well as the $T_{h} 2$ cytokine production in type 2 innate lymphoid cells (Wallrapp et al., 2019). Somatostatin is also released from the peripheral sensory endings, but it evokes rather anti-inflammatory responses (Szolcsányi et al., 1998; Helyes et al., 2004, 2009).

As described above, $T_{h} 2$ cell mediated immune responses play a crucial role in the development and maintenance of a pruritic tissue environment. It was shown in a mouse AD model that substance P-dependent neurogenic inflammation mediated the stress-evoked shift in the cutaneous cytokine profile toward $\mathrm{T}_{\mathrm{h}} 2$ cytokines (Pavlovic et al., 2008). Moreover, sensory neuronderived SP can regulate allergic responses as well. It was recently described that allergen house dust mite proteases activate TRPV1 expressing sensory neurons resulting in SP release, and SP then induces mast cell degranulation via MRGPRB2 (Serhan et al., 2019). Another recent study also demonstrated that intradermal injection of protease allergens initiated not only immediate itch and pain behavior, but stimulated SP (and inhibited CGRP) release from TRPV1 expressing sensory fibers. The released SP activated the CD301b + dendritic cells and induced their migration to draining lymph nodes, where these cells were responsible for $\mathrm{T}_{\mathrm{h}}$ 2-differentiation. It was found that ablation or pharmacological blockade of allergen responder TRPV1+ sensory neurons decreased allergen-induced $\mathrm{T}_{\mathrm{h}} 2$ cell differentiation and related IL-4 and IL-13 expression (Perner et al., 2020). Moreover, CGRP released from cutaneous sensory nerve endings was also described to stimulate $\mathrm{CD} 301 \mathrm{~b}+$ dendritic cells to produce IL-23 in murine skin, which resulted in increased IL-17A production of $\gamma \delta \mathrm{T}$ cells (Kashem et al., 2015).

Importantly, cutaneous sensory neurons can not only initiate but also suppress this inflammatory, pruritic environment. In contrast to neuropeptides, some non-peptidergic fibers expressing MRGPRD can negatively regulate mast cells via glutamate release, which likely acts via an ionotropic glutamate receptor heterodimer composed of glutamate ionotropic receptor kainate type subunit 2 (GIRK2/GLUR6) and GIRK5 expressed by mast cells (Zhang et al., 2021).

\section{PRURITIC DISEASES}

Pruritus is a common symptom of several dermatological and systemic diseases with the involvement of the above discussed cutaneous immuno-neuronal crosstalk. In the next part of our review, we provide a concise summary of some of these diseases and the potential mechanisms which can lead to the development of the pruritic symptoms (Table 2).

\section{Dermatological Diseases Contact Dermatitis}

There are two forms of contact dermatitis to distinguish: irritant and allergic contact dermatitis (ICD and ACD, respectively). In case of ICD, the primary cause is a (chronic) exposure to irritants that causes epidermal barrier perturbation. Epidermal keratinocytes are the primary targets of the irritants. Upon exposure, they subsequently synthesize and release proinflammatory cytokines that are not biased toward $\mathrm{T}_{\mathrm{h}} 2$ mediated immune responses. Indeed, the infiltrating $\mathrm{T}$ cells rather belong to the $T_{h} 1$ class and especially IL-2, IFN $\gamma$, IL-1 $\alpha$, IL-1 $\beta$, IL-6, CXCL-8, TNFa, GMCSF, and VEGF are upregulated in the skin (Lisby and Baadsgaard, 2006; Lee et al., 2013). Importantly, different irritants can differentially affect cytokine levels, and can evoke various biological responses in keratinocytes ranging from hyperproliferation to necrotic cell death. Itch is a common symptom in ICD, but pain-like sensations (e.g., stinging or burning) are also often observed (Lisby and Baadsgaard, 2006; Bains et al., 2019). In contrast, ACD is a delayed, type 4 hypersensitivity reaction, i.e., an antigen-specific $\mathrm{T}$-cell mediated inflammatory response to repeated exposure. It is composed of two distinct immunological phases, i.e., the sensitization and the elicitation or effector phase. In the sensitization phase, the haptens penetrate the epidermal barrier, and establish direct contacts with various skin components including MHC molecules expressed by epidermal Langerhans cells resulting in the activation of said cells. Activated, allergen-presenting Langerhans cells travel to the draining lymph nodes to be recognized by specific $\mathrm{T}$ cells. This process is associated with a cascade of cytokine production that stimulates the proliferation of the specific allergen-recognizing $\mathrm{T}$ cells which finally enter the circulation in high numbers. Upon a repeated allergen contact, the effector phase is initiated. The activated antigen presenting cells recruit the circulating primed $\mathrm{T}$ cells that will locally be activated by the allergens and will subsequently release large amounts of inflammatory cytokines thereby contributing to the local inflammation. This reaction typically peaks in $12-48 \mathrm{~h}$ after the allergen exposure. This process involves both type 1 and type 2 cytokines, which, beyond the inflammatory responses, can initiate ACD-associated sensory phenomena, like itch (Rustemeyer et al., 2006; Leonard and Guttman-Yassky, 2019).

A recent study compared itch and pain behavior, and scored the accompanying inflammation in mouse hypersensitivity models of ICD and ACD. The authors applied the same topical challenge for both conditions, using the hapten squaric acid dibutylester (SADBE; challenge with $1 \%$ solution on three consecutive days). The two experimental protocols only differed in the sensitization phase, when SADBE was applied to the abdominal skin of the animals belonging to the ACD group, whereas ICD mice as well as members of the control group received acetone. Finally, both group was challenged with $1 \%$ SADBE on the tested skin area (cheek or calf). It was found, that both ICD and ACD are characterized by itch- and pain-related behavior, inflammatory symptoms and pro-inflammatory cytokine production, but in general, both the sensory symptoms as well as the inflammatory features are stronger in ACD than in ICD. However, C-X-C motif chemokine ligand 10 (CXCL10) was elevated only in ACD (Zhang et al., 2019). Moreover, in SADBE-induced murine ACD, chemokine receptor CXCR3, which serves as the receptor of CXCL10, was upregulated in the DRG and its pharmacological inhibition attenuated spontaneous itch, but not pain. Injected CXCL10, on the other hand, evoked itch-, but not pain-related behavior in ACD mice (Qu et al., 2015). 
Importantly, the exact pathomechanism, the cytokine production, and T-cell polarization in contact dermatitis largely depend on the allergen both in humans and in mice (Dhingra et al., 2014; Leonard and Guttman-Yassky, 2019). For example, nickel induces $T_{h} 1$-biased responses with certain $T_{h} 17$ and $\mathrm{T}_{\mathrm{h}} 22$ elements, whereas house dust mite elicits $\mathrm{T}_{\mathrm{h}} 2$-polarized responses with additional $T_{h} 9$ and $T_{h} 17 / T_{h} 22$ activation, and fragrance allergens cause $T_{h} 2 / T_{h} 22$ skewed immune responses (Dhingra et al., 2014; Malik et al., 2017; Leonard and GuttmanYassky, 2019). Allergen-specific reactions were also identified in skin biopsies after food patch tests applied in delayed-type hypersensitivity food reaction. For example, besides $T_{h} 17$ polarization, peanut, but not beef or codfish, was also characterized by increased IL-33 expression (Ungar et al., 2017; Leonard and Guttman-Yassky, 2019). In mouse pruritic ACD models, the generally used oxazolone induced a mixed $\mathrm{T}_{\mathrm{h}} 1 /$ $\mathrm{T}_{h} 2$ response with elevated level of 5-HT, ET-1, and substance $\mathrm{P}$, but not TSLP. In contrast, the poison ivy-driven allergen urushiol resulted in $\mathrm{T}_{\mathrm{h}} 2$-biased responses associated with increased IL-33, TSLP, 5-HT, and ET-1 expression without affecting substance P (Liu et al., 2016, 2019). These mediators are capable of activating their own receptors in the itch-sensitive sensory neurons that transduce the pruritic signals likely via TRPA1 in oxazolone- and urushiol-induced ACD (Liu et al., 2013).

\section{Urticaria}

Chronic urticaria (CU) is characterized by the occurrence of weals (hives), angioedema, or both for more than 6 weeks, and is usually accompanied by severe pruritus (Gonçalo et al., 2021). It is estimated to affect $\sim 1 \%$ of the population, and it may significantly impair quality of life (Gonçalo et al., 2021). Although the signaling pathways involved in the development of itch in $\mathrm{CU}$ are not completely explored, pathological degranulation of dermal mast cells as well as dysregulation of basophil and eosinophil granulocytes and the subsequent histamine release appear to be central players in the process (Hon et al., 2021).

Indeed, the classical symptoms of urticaria are well-modelled by intradermal histamine injection. Besides pruritus, locally applied histamine also causes increased vascular permeability and development of edema (weal), as well as local vasodilation resulting in dermal hyperaemia (erythema), which latest is a consequence of neuropeptide release (SP and CGRP) from the activated mechano-insensitive, peptidergic $\mathrm{C}$ fibers. These symptoms are specifically related to histamine and are not associated to non-histaminergic itch (Andersen et al., 2015). Although urticaria is mainly characterized by a histaminergic nature, clinical data indicate that both histaminergic and nonhistaminergic components may be involved in the development of pruritus in CU. Indeed, second generation antihistamines are recommended to be the first choice to alleviate itch (Hon et al., 2019), and, if they remain ineffective in spite of the elevation of their dose, administration of IgE-neutralizing antibodies (e.g., Omalizumab or the more effective Ligelizumab) (Wedi, 2020), corticosteroids, leukotriene receptor antagonists (e.g., montelukast), Cyclosporine A, or even certain antidepressants and anti-inflammatory drugs should be considered (Hon et al., 2019).
Importantly, recent research suggests that other mast cell and basophil granulocyte-related targets may also become useful tools in the treatment of CU. These include spleen tyrosine kinase (SYK; a down-stream target of the high-affinity IgE receptor FceR1a), Bruton tyrosine kinase (BTK; an important regulator of IgE-independent mast cell activation), CRTh2 (a receptor for PGD2 expressed among others on mast cells), as well as H4 histamine and MRGPRX2 receptors (Hon et al., 2021). Last, but not least, besides the aforementioned biological drugs targeting mostly mast cells and basophils, eosinophiltargeting [e.g., ones neutralizing IL-5 [mepolizumab and reslizumab] or IL-5 receptor (benralizumab)], and other antibodies (interfering with the signaling of IL-1, IL-4, and TNF- $\alpha$ ) also showed promising effects in clinical trials [for details, see (Hon et al., 2021)].

\section{Atopic Dermatitis}

$\mathrm{AD}$ is a chronic, inflammatory skin disease affecting ca. $20 \%$ of children and ca. $10 \%$ of adults in the industrial countries (Langan et al., 2020). Based on the symptoms and certain aspects of the pathogenesis, it can be classified into two major subtypes, i.e., "extrinsic" and "intrinsic" AD (Czarnowicki et al., 2019). The extrinsic endotype is more common. It usually develops on an atopic background, and it is characterized by eosinophilia, high serum IgE level, and greater filaggrin mutation rate as compared to the intrinsic endotype that exhibits female predominance, delayed onset, as well as lack of atopic background, and is characterized by a relatively more preserved barrier function, normal serum IgE level, and an increased prevalence of metal contact hypersensitivity (Czarnowicki et al., 2019). Importantly, the existence of intraendotype variations in the immune polarization and epidermal barrier function is also well-described across different races (Czarnowicki et al., 2019). However, despite of the aforementioned complexity, it is well-evidenced that disturbance of each element of the complex cutaneous barrier (i.e., physicochemical, immunological and microbiological) (Proksch et al., 2008; Jensen and Proksch, 2009) is a key contributor in the development of AD (Bieber, 2008; Griffiths et al., 2017). Although clinical symptoms of the disease may exhibit a great inter-individual heterogeneity (Langan et al., 2020), development of eczematous lesions, intense pruritus, and a chronic or relapsing disease course are characteristic features of $\mathrm{AD}$.

Of great importance, itch is not only one of the most unpleasant symptoms of $\mathrm{AD}$, but, via the "itch-scratch cycle", it also contributes to the pathogenesis of the disease by damaging the epidermal barrier, and facilitating the permeation of allergens and irritants (Mack and Kim, 2018; Furue et al., 2020; Langan et al., 2020; Nakahara et al., 2021). Thus, alleviating itch could be much more than a mere symptomatic treatment in AD. Research efforts of the last decades have highlighted the role of several itch mediators and pathways in AD-related pruritus (Langan et al., 2020; Umehara et al., 2021). Indeed, periostin (Mishra et al., 2020) and type 2 cytokines (e.g., IL-4, IL-13, IL-31, and TSLP) (Yang and Kim, 2019) and most especially, the IL-4-neuronal IL-4 receptor interaction, together with the subsequent JAK-1 
signaling appear to be key players in the process (Cevikbas et al., 2014; Oetjen et al., 2017), whereas histamine and its key pruritic receptors are likely to be of inferior significance (Umehara et al., 2021). Indeed, "classical" anti-histamines targeting H1R failed to be effective as "add-on" therapy in eczema (Matterne et al., 2019), although recently, promising results were published with H4R antagonists (Werfel et al., 2019) and combination of H1R and H4R antagonists (Köchling et al., 2017). On the other hand, dupilumab (a human monoclonal antibody blocking the effects of IL-4 and IL-13 and thereby interfering with the activation of $\mathrm{T}_{\mathrm{h}} 2$ cells and group 2 innate lymphoid cells (Beck et al., 2014; Imai et al., 2021)) monotherapy was greatly efficient in reducing Eczema Area and Severity Index (EASI) and pruritus scores in a double-blind placebo-controlled trial involving patients with moderate-to-severe AD (Beck et al., 2014). Likewise, nemolizumab (CIM331), a humanized antibody against interleukin-31 receptor A could also significantly improve pruritus in patients with moderate-to-severe $\mathrm{AD}$ in a phase 2 , randomized, double-blind, placebo-controlled study (Ruzicka et al., 2017).

Recent pieces of evidence argue that dysregulation of other signaling pathways (e.g., cutaneous cannabinoid (Tóth et al., 2019), and opioidergic signaling (Slominski, 2015; Bigliardi et al., 2016)) may also contribute to $\mathrm{AD}$-related pruritus. Indeed, $\mathrm{CB}_{1}$ and $\mathrm{CB}_{2}$ cannabinoid receptors, as well as $\kappa$ opioid receptor (KOR) were found to be significantly downregulated in the lesional skin of $\mathrm{AD}$ patients suffering from severe itch as compared to the non-itchy, non-lesional skin of the patients (RNAseq) (Nattkemper et al., 2018). In line with these data, KOR, as well as dynorphin A 1-17 and dynorphin A 1-8 were found to be down-regulated in the lesional epidermis of AD patients (Tominaga et al., 2007), and topically applied nalfurafine (a selective KOR agonist) alleviated itch in AD (Inui, 2015; Elliott et al., 2016). Moreover, the serum concentration of $\beta$-endorphin (an endogenous opioid exhibiting higher affinity towards the "pro-pruritic" $\mu$-opioid receptor) was found to be elevated in $\mathrm{AD}$, and its level correlated with the severity of itch (Lee et al., 2006). Taken together, these pieces of evidence suggest that dysregulation of homeostatic cutaneous cannabinoid and opioid signaling may contribute to the development of pruritus in $\mathrm{AD}$.

Importantly, several other peptide and lipid signaling pathways were also suggested to be involved in the development of AD-related itch. Indeed, both the number of mast cell-sensory nerve contacts, as well as the number of SP and CGRP positive nerve fibers were elevated in the lesional epidermis of $\mathrm{AD}$ patients as compared to healthy controls (Järvikallio et al., 2003). Moreover, the NKR1 antagonist aprepitant was found to exert significant anti-pruritic effects in $\mathrm{AD}$ suggesting that the SP-NKR1 pathway is also important in $\mathrm{AD}$-related itch (Ständer et al., 2010). Moreover, 12/15-LOX and COX pathways were also found to be dysregulated in the lesional skin of $\mathrm{AD}$ patients leading to the elevation of the levels of several potentially pruritogenic lipid mediators, including 12-hydroxyeicosatetraenoic acid (12-HETE), leukotriene B4 (LTB4), thromboxane B2 (TXB2), prostaglandin (PG) E2, and PGF2 (Töröcsik et al., 2019).
Last, but not least, it should also be noted that TRPV3 is a potent promoter of the production and release of various proinflammatory regulators on multiple cell types of the human skin, including keratinocytes and sebocytes (Szöllősi et al., 2018; Szántó et al., 2019), and is likely to play a role in dry skin dermatoses (Szántó et al., 2019), including AD as well as AD-related pruritus. Indeed, PAR2 and TRPV3 were shown to be up-regulated in skin biopsies of AD patients (Zhao et al., 2020). Activation of PAR2 on epidermal keratinocytes was shown to influence $\mathrm{Ca}^{2+}$. homeostasis of the cells via STIM1-Orail interaction, resulting in TSLP release leading to itch (Wilson et al., 2013). More recently, it has also been demonstrated that the ability of keratinocyte PAR2 activation to evoke TSLP release and subsequent itch can be abrogated by the genetic deletion of TRPV3, arguing that the two receptors may cooperate in mediating itch in AD (Zhao et al., 2020). Finally, according to a recent study, the IL-31-induced BNP-release from the sensory neurons increases TRPV3 expression and activity on epidermal keratinocytes in a natriuretic peptide receptor 1 (NPR1)dependent manner. Enhanced activity of TRPV3 in turn led to elevated SERPIN E1 [a.k.a. plasminogen activator inhibitor 1; an adipokine expressed in keratinocytes as well (Kovács et al., 2020)] release that evoked itch (Larkin et al., 2021). Thus, abrogation of TRPV3 activity promises to be a powerful tool to alleviate itch in $\mathrm{AD}$.

\section{Psoriasis Vulgaris}

Psoriasis is a common inflammatory skin disease affecting 1-3\% of the world population (Szepietowski and Reich, 2016) characterized by sharply demarcated, erythematous, pruritic plaques covered in grey scales that can cover large areas on the extensor surfaces of the limbs, the trunk, and the scalp (Rendon and Schäkel, 2019). Even though the name derives from the Greek word for itch (psora), pruritus has long been an overlooked aspect of the disease, even though $60-90 \%$ of psoriatic patients report itch as one of their symptoms. Indeed, many report pruritus as the most bothersome of their symptoms (Komiya et al., 2020). The treatment of pruritus in psoriatic disease poses an unmet need, since antihistamines are generally considered to have only moderate effects, and the exact cause of itch remains unknown in psoriatic lesions (Domagała et al., 2017).

Psoriasis can easily be considered an immuno-epithelial disease, since the main driving factor of plaque development is the production of IL-17 and IL-22 by $\mathrm{T}_{\mathrm{h}} 17$ cells, which is initiated by TNFa and IL-23 from dendritic cells (Zheng et al., 2007). These cytokines have not been linked directly to pruritus, and it is likely that itch develops as a secondary consequence of the disease, instead of being a primary symptom that leads to the development of the psoriatic plaques. Nevertheless monoclonal antibody treatment targeting IL-17 has been reported to improve itch in psoriasis (Bushmakin et al., 2015; Strober et al., 2016; Kimball et al., 2018).

The role of multiple pruritic mediators have been investigated in psoriasis, including neuropeptides, nerve growth factor, IL-31, and TSLP (Komiya et al., 2020). Neuropeptides, specifically SP and Neuropeptide Y (NPY), have been implicated in the pruritus found in psoriasis. The levels of SP (Saraceno et al., 2006), as well 
as the number of SP + fibers in pruritic psoriatic lesions (Nakamura et al., 2003) is increased, and serlopitant, an antagonist of the neurokinin-1 receptor, was effective against chronic itch (Yosipovitch et al., 2018). Interestingly, the effect of SP on murine dorsal root ganglia was found to be more dependent on MrgprA1 (Azimi et al., 2017), so it is possible that in humans SP also acts on MRGPRX2, which is also highly expressed in psoriatic lesions (Nattkemper et al., 2018). NPY, on the other hand is found at lower levels in psoriatic patients with pruritus (Reich et al., 2007), which is possibly explained by the finding that it suppresses mechanical itch transmission in wildtype mice (Acton et al., 2019). NGF expression was also found to be higher in psoriatic lesions, as well as the expression of the NGF receptor tropomyosin-receptor $\mathrm{A}$, both of which correlated with the intensity of pruritus (Nakamura et al., 2003).

Multiple lines of evidence support the role of two classically ADlinked cytokines, TSLP and IL-31 in psoriasis. The serum level of both TSLP and IL-31 is elevated in patients with pruritic psoriasis (Narbutt et al., 2013; Suwarsa et al., 2019), as well the number of IL31-immunoreactive mast cells at lesional sites (Niyonsaba et al., 2010), while TSLP expression is increased in the epidermis of psoriatic lesions (Volpe et al., 2014). TSLP has also been linked more directly to scalp psoriasis (Volpe et al., 2014).

The sphingolipid metabolite $\mathrm{S} 1 \mathrm{P}$ is also associated to psoriasis. S1P, similar to IL-23, primes the maturation of $T_{h} 17$ cells via S1PR1 (Huang et al., 2007; Liao et al., 2007). Indeed, in psoriasis, elevated plasma S1P level was reported (Checa et al., 2015; Myśliwiec et al., 2017), which may stimulate pruriceptive fibers via S1PR3 (Hill et al., 2018), as discussed above.

The involvement of the nervous system in the pathogenesis of the disease has been suspected for some time. Multiple reports (Raychaudhuri and Farber, 1993; Zhu et al., 2016; Onderdijk et al., 2017; Keçici et al., 2018; Qin et al., 2021) showed that denervation of the skin on one side of the body can lead to the clearance of the lesions, and that stress can exacerbate the disease (Harvima et al., 1993; Singh et al., 1999). The mechanisms behind these observations were considered to be both increased local production of neuropeptides (Hosoi et al., 1993), and changes in the density of innervation in psoriatic lesions. Interestingly, both increased (Naukkarinen et al., 1991) and decreased innervation have been reported (Pergolizzi et al., 1998), as well as some reports that found no significant differences (Di Francesco et al., 1978; Armagni et al., 1979). Since, as mentioned above epidermal keratinocytes in psoriasis produce increased levels of NGF (Pincelli, 2000), it is logical to assume that this would influence the growth of nerves (Kou et al., 2012). Applying a selective optogenetic stimulation of TRPV1+ cutaneous nerve endings in mice resulted in the development of type 17 inflammatory response associated with histological features that highly resembled the imiquimod-induced psoriasiform lesions. The ablation of TRPV1+ sensory fibers attenuated these responses clearly indicating that psoriasiform symptoms can develop on neurogenic inflammatory background (Cohen et al., 2019).

\section{Prurigo Nodularis}

Prurigo nodularis is a chronic inflammatory skin disease characterized by multiple extremely pruritic lesions commonly found on the trunk and the extensor surfaces of the extremities (Mullins et al., 2021). Prurigo nodularis commonly occurs with other diseases, including $\mathrm{AD}$, xerosis cutis, excoriation disorder, hypertension, type II diabetes mellitus, chronic kidney disease, HIV infection, substance-use disorders, mood disorders, and obesity (Mullins et al., 2021; Pereira et al., 2021). The exact pathophysiology of the disease is still unknown, but a strong neural component is likely based on increased number of protein gene product 9.5 immunoreactive nerve fibers and increased expression of SP and CGRP in the lesions (Abadía Molina et al., 1992; Lee and Shumack, 2005). Both neuropeptides stimulate local immune responses and promote endothelial cell proliferation through the release of vascular endothelial growth factor, and further increase in the number of nerve fibers through NGF production (Choi and Di Nardo, 2018). In terms of the immune system, lesional skin in PN contains a dense infiltrate of eosinophils, mast cells and T cells. These cells contribute multiple cytokines to the inflammatory milieu of the lesions, including IL4 and VIP from eosinophils (who can also contribute NGF and SP) (Johansson et al., 2000), IL-31 from T lymphocytes and macrophages (Hashimoto et al., 2021b) and histamine and prostaglandins from mast cells (Zeidler et al., 2018).

\section{Cutaneous T-Cell Lymphoma}

Cutaneous T-cell lymphoma is typically divided into two common subtypes: mycosis fungoides (MF) and its leukemic variant, Sézary syndrome (SS). Pruritus affects a large population (approximately $88 \%$ ) of both subtypes, and the severity of itch increases in late-stage disease, as well as being higher in general in SS (Vij and Duvic, 2012; Nattkemper et al., 2016). Pruritus in these patients responds poorly to treatment, which is unsurprising considering the fact the exact mechanism behind it is still unknown. Various mediators have implicated, although mostly based on empirical experience in a limited number of patients.

IL-31 levels are higher in sera of patients with MF and SS (Ohmatsu et al., 2012; Malek et al., 2015), although other results show contradictory results (Möbs et al., 2015). It is also unclear whether the IL-31 serum levels correlate with disease or pruritus severity (Malek et al., 2015). IL-31 expression locally in the skin is also increased, as well as the level of IL-31RA and OSMR $\beta$ (Nattkemper et al., 2016).

IL-4 and IL-13 may also play important roles in itch in these patients, since dupilimab significantly reduced itch in a patient with SS (Steck et al., 2020). SP may also be involved in itch in both $\mathrm{SS}$ and $\mathrm{MF}$, since multiple reports show that the $\mathrm{NK}_{1}$ receptor antagonist aprepritant showed some efficacy in alleviating pruritus (Duval and Dubertret, 2009; Booken et al., 2011; Ladizinski et al., 2012; Torres et al., 2012; Song et al., 2017).

\section{Selected Systemic Diseases and Pathological Conditions Dermatomyositis}

Dermatomyositis (DM) is a rare heterogeneous systemic autoimmune connective tissue disease, which is a subtype of idiopathic inflammatory myopathies. DM might have a wide 
variety of clinical manifestations including lung, joint, esophageal and cardiac findings; however, its hallmark features are the characteristic skin manifestations and progressive symmetrical muscle weakness (Griger et al., 2017). Based on data from question surveys, the majority of the patients (84.6-90.4\%) suffers from pruritus (Shirani et al., 2004; Kim et al., 2018) which has a significant impact on quality of life (QoL). It seems that the severity of pruritus significantly correlates with disease activity, but the pathogenesis of DM-related itch is poorly understood. One small retrospective study (Khanna et al., 2020) found that there is a trend between histopathologic presence of eosinophils in skin biopsies, and pruritus. Recently, it was shown that IL-31 and IL-31RA gene expression in lesional skin was upregulated compared with either non-lesional skin or that from healthy controls (Kim et al., 2018). IL-31 mRNA expression also positively correlated with itch score and immunoreactivity for IL31 and IL-31RA was greater in lesional skin. Furthermore, lesional DM skin contained significantly more IL-31producing cells, of which $\mathrm{CD} 4^{+}$cells were the most abundant IL-31-expressing cell type (Kim et al., 2018). Importantly, lenabasum (a.k.a. JBT-101 or ajulemic acid), an investigational, non-psychotropic, orally bioavailable $\mathrm{CB}_{2}$ receptor agonist with remarkable anti-inflammatory potential, was recently found to significantly downregulate IL-31 in CpG-stimulated PBMCs in vitro (Kim et al., 2018). These data indicate that lenabasum may have potential as a new therapy for DM and DM-related itch; its efficiency is also currently being tested in a phase 3 clinical trial (NCT03813160).

\section{Systemic Sclerosis}

Systemic sclerosis (SSc) is a rare and complex chronic autoimmune connective tissue disease characterized by Raynaud's phenomenon (RP), nailfold capillary changes, excessive production of collagen, manifested as skin thickening and fibrosis of internal organs such as the lungs, heart, gastrointestinal tract, and kidneys. Clinically, patients can be subdivided into limited cutaneous SSc (lcSSc) and diffuse cutaneous SSc $(\mathrm{dcSSc})$ forms. Pruritus represents a common, but infrequently reported skin symptom in SSc, with a prevalence of 43-62\% (El-Baalbaki et al., 2010; Razykov et al., 2013; Théréné et al., 2017). It is significantly associated with greater skin and gastrointestinal involvement (Razykov et al., 2013) as well as worse mental status, physical function, and disability (El-Baalbaki et al., 2010).

The pathophysiology of pruritus in patients with SSc is unknown. Pruritus could arise either from 1) abnormalities of nerve fiber endings in SSc skin, 2) from the presence of an excess of mast cells, and/or 3) from the release of local mediators in the skin. The role of chemokines (derived not only from mast cells, but possibly also from other perivascular immune cells) on SSc itch is also of interest (Frech and Baron, 2013). Previous clinical observations in SSc, namely that pruritus is associated with sensory symptoms that predominate in the extremities and non-sclerotic areas, argue for a neuropathic component of pruritus (Théréné et al., 2017). The compression of small nerve fibers by thickened and/or dense collagen might contribute to the neuropathic component. A reduction of sensory and autonomic innervation in both sclerotic and apparently uninvolved skin has been reported in SSc (Provitera et al., 2005) with mast cell association early in the pathologic process. In addition, an inflammatory and immunological component of neuropathic pruritus had also been adduced by regeneration of C-fibers after destruction by collagen deposition and increasing sensitization of itch fibers by inflammatory mediators (Haber et al., 2016). On the other hand, elevated levels of histamine were found in $56 \%$ of patients with SSc and was more common in patients with diffuse disease (74\%), in contrast to limited disease (31\%), thus mast cells and histamine could also be the part of the pathogenesis of SSc-related itch (Falanga et al., 1990).

\section{Chronic Renal Failure}

Chronic renal failure is a worldwide public health problem with a global prevalence rate of $13.4 \%$ (Hill et al., 2016). Based on data of a multicenter study from 18,801 hemodialysis patients, moderate to extreme pruritus was experienced by $42 \%$ (Pisoni et al., 2006). The importance of pruritus is underlined not only because of poorer quality of life of the patients, but pruritus in HD patients was significantly associated with a $17 \%$ higher mortality risk (Pisoni et al., 2006). Although the association between chronic renal failure and skin itching has been recognized for more than a century, the exact pathogenesis of pruritus in renal failure remains poorly understood. It seems that uremic pruritus cannot be caused by a single factor, whereas many metabolic factors have been implicated in the pathogenesis of itching. Based on the existing literature, 4 general theories have emerged: 1) toxin deposition, 2) peripheral neuropathy, 3) immune system dysregulation, and 4) opioid imbalance (Verduzco and Shirazian, 2020).

The initial theory of chronic renal failure associated pruritus pathogenesis is deposition of pruritogenic toxins in the skin, like uremic compounds, vitamin A, calcium, phosphorus, and magnesium. This theory is mainly based on early observations, like pruritus is associated with underdialysis, improvement of pruritus after treatment of high calcium, parathormone and phosphorus level (Hampers et al., 1968; Hiroshige et al., 1995; Kimata et al., 2014; Mettang and Kremer, 2015), but further studies have not confirmed these associations (Shirazian et al., 2013). It is currently thought that underdialysis and toxin deposition may cause pruritus in a subset of patients, which should resolve with adequate dialysis. The second theory is based on the fact that in patients with chronic dialysis, there is a high prevalence of peripheral neuropathy and autonomic dysfunction, which could lead to abnormal skin innervation and nerve conduction resulting itch sensation. The pruritus in uremic patients occurred significantly more frequently in patients with paresthesia (Verduzco and Shirazian, 2020) and gabapentin, a drug approved for the treatment of epilepsy and neuropathic pain significantly reduced pruritus score, supporting the neuropathic hypothesis of uremic pruritus (Gunal et al., 2004).

The elevated levels of pro-inflammatory cytokines and inflammatory markers (C-reactive protein, IL-6, and IL-2) in patients with severe pruritus argue for the hypothesis that dysregulation of the immune system underlies pruritus in 
kidney disease (Kimmel et al., 2006; Narita et al., 2006). It is further supported by the fact that after kidney transplantation patients do not complain about pruritus as long as immunosuppressive therapy, including cyclosporine or tacrolimus is administered, even when a substantial loss of transplant function has occurred (Mettang et al., 2002). In addition, in small randomized trials thalidomide and tacrolimus ointment were effective in the therapy of uremic pruritus (Silva et al., 1994; Pauli-Magnus et al., 2000). However the effectivity of this latter compound was not proved by another vehicle controlled study (Duque et al., 2005). Increased levels of eosinophils, mast cells, histamine and tryptase have also been found in patients with uremic pruritus, which might draw attention to this hypothesis (Francos et al., 1991; Dugas-Breit et al., 2005).

Finally, the alteration of the opioid pathway, modulation of its receptors and cellular processes might also affect chronic renal failure associated pruritus. Overstimulation of central $\mu$-opioid receptors, antagonism of peripheral $\kappa$-opioid receptors, or an imbalance of stimulation and antagonism of $\mu$ - and $\kappa$-opioid receptors causes itching (Tey and Yosipovitch, 2011; Verduzco and Shirazian, 2020). In a recently published double blind, randomized trial, difelikefalin, a peripherally restricted and selective agonist of $\kappa$ opioid receptors, had a significant reduction in itch intensity and improved itch-related quality of life as compared with those who received placebo in patients undergoing hemodialysis who had moderate-to-severe pruritus (Fishbane et al., 2020). In addition, nalfurafine hydrochloride, an к-opioid-selective agonist, has been officially approved for resistant pruritus in HD patients on the basis of a wellevidenced clinical trial in Japan (Inui, 2015).

\section{Cholestatic Liver Diseases}

Pruritus is a common and debilitating symptom in patients with cholestatic liver pathology such as cholangiocellular (primary biliary cholangitis, primary sclerosing cholangitis), obstructive biliary (gallstone diseases, pancreatic head carcinoma, etc.) and hepatocellular (pregnancy related cholestasis, viral hepatitis) diseases. The pathogenesis of itch in cholestatic disease remains elusive and is likely multifactorial, while the mechanisms of HCVassociated pruritus are attributed to HCV induced cholestasis and the induction of interferon stimulated genes as a result of viral overload (Alhmada et al., 2017). Numerous candidate pruritogens are present in bile and upregulated in cholestatic patients, including endogenous opioids, histamine, serotonin, lysophosphatidic acid (LPA), bilirubin, and bile acids (BA) (Beuers et al., 2014). These substances might interact with the nerve endings of the skin and induce the sensation of itching. One of these key factors is Autotaxin (ATX), whose elevated activity in patients' sera may be a consequence of HCV-induced chronic liver diseases and has a crucial role in the synthesis of LPA (Ikeda et al., 2009). Under pathological conditions elevated bile salts in patient's tissues and sera are able to signal the activation of ATXLPA signaling (Nguyen et al., 2014), leading to the accumulation of LPA, which can initiate the pruritus via its receptor $\mathrm{LPA}_{5}$ (Yamanoi et al., 2019). LPA is able to trigger the activation of TRPV1 and TRPA1 (Nieto-Posadas et al., 2011; Kittaka et al., 2017) and regulation of LPA by PI3k, protein kinase $\mathrm{A}$ (PKA) and C
(PKC)-dependent mechanisms has been reported (Kassmann et al., 2013). Most recently, the LPA precursor lysophosphatidylcholine (LPC) was shown to directly bind to and activate epidermal TRPV4 resulting in the release of a micro RNA (miR-146a) which activates pruriceptive cutaneous nerve endings eliciting itch. The miR-146 evoked neural activation depended on TRPV1 activation, although the exact mechanism is not discovered yet. Importantly from a clinical point of view, elevated levels of LPC and miR-146 were found in pruritic primary biliary cholangitis patients compared to non-itching patients and the concentration of both LPC and miR-146a correlated with the severity of itch, although in another sample, there was no significant difference between primary biliary cholangitis patients and healthy subjects (Chen Y. et al., 2021).

Furthermore, animal experiments revealed that BAs activate TGR5 on sensory nerves. TGR5 is a $\mathrm{G}_{\mathrm{s}}$ protein coupled bile acid receptor that is known to regulate metabolic processes in several tissues (Guo et al., 2016), which stimulates the release of neuropeptides in the spinal cord that transmit itch and analgesia (Alemi et al., 2013). It was found that TRPA1 is involved in this BA-evoked, TGR5-dependent pruritus in mice (Lieu et al., 2014). However, recently, experiments based on expression characterizations as well as functional assays revealed that TGR5 is not expressed in human DRG neurons and does not directly mediate itch sensation in human (Yu et al., 2019). Instead, it was proved, using humanized mouse models and calcium imaging, that the human sensory neuron-expressed MRGPRX4 is a novel bile acid receptor. The data suggest that targeting MRGPRX4 is a promising strategy for alleviating cholestatic itch (Meixiong et al., 2019b; Yu et al., 2019). Moreover, in a mouse biliary duct ligation model of cholestasis, that induced spontaneous itching, an increased expression of BAM8-22 was detected in the skin, and its receptor MRGPRX1/MRGPRC11 and the related TRPA1 were also upregulated in the sensory neurons of the DRGs. In this model, the number of the BAM8-22 responsive neurons was increased and BAM8-22 seemed to potentiate the spontaneous itching behavior suggesting that peripheral BAM8-22 may also mediate cholestatic itch (Sanjel et al., 2019). However, the recent recommendations for the treatment of cholestasis associated pruritus are based on 1) ursodeoxycholic acid (UDCA), which enhances biliary secretion of bile salts and other cholephiles; 2 ) the non-absorbable anion exchange resin cholestyramine, which binds a wide variety of amphiphilic molecules in the small intestinal lumen, increasing the bile excretion; 3 ) the potent pregnane $\mathrm{X}$ receptor agonist rifampicin, altering the metabolism of the presumed pruritogens in the liver and/or the gut by biotransformation and 4) opioid antagonists such as naltrexone and serotonin reuptake inhibitors such as sertraline, affecting the endogenous opioidergic and serotonergic system (European Association for the Study of the Liver, 2009; Bergasa, 2011; Kremer et al., 2011; Beuers et al., 2014).

\section{THERAPEUTIC CONCLUSIONS}

No universal itch-specific therapy has been established to date. The European guideline on chronic pruritus recommends several 
therapeutic options including diseases specific and various sympthomatic interventions based on a careful diagnosis and several individual factors (Weisshaar et al., 2019). The application of these diverse clinical approaches in different diseases and increasing evidence from recent research suggest that the antipruritic philosophers' stone probably does not even exist. Inefficiency of antihistamines is well-established in several cases, and often-used immunosuppressants, for example glucocorticoids or calcineurin inhibitors are far from being specific in targeting pruritus or any specific pruritic disorders. They evoke their beneficial effect by generally suppressing immune responses, including several local immune-neuronal interactions characteristic for individual pathologies (Buddenkotte and Steinhoff, 2010). Specifically targeting this intercellular crosstalk locally in the skin may provide a highly specific and effective therapeutic approach with fewer side effects. The possible targets can be the pruritic mediators, their receptors and the related signaling pathways carefully chosen in light of the underlying pathology. The putative efficiency of such a selective approach is supported by several successful attempts using monoclonal neutralizing antibodies targeting $\mathrm{T}_{\mathrm{h}} 2$ and $\mathrm{T}_{\mathrm{h}} 17$ cytokines or their receptors e.g., in the treatment of $\mathrm{AD}$ and psoriasis, respectively (Fourzali et al., 2020; Zhang and He, 2020; Garcovich et al., 2021). The related signal transduction of these receptors can also be successfully targeted e.g., by JAK or phosphodiesterase 4 inhibitors (Fourzali et al., 2020; Soeberdt et al., 2020). Future alternative targets may be neural receptors (e.g., MRGPRs), signaling molecules, and ion channels (e.g., TRP channels) involved in the transduction of itch (Buddenkotte and Steinhoff, 2010; Tóth et al., 2015; Moore et al., 2018; Xie and Hu, 2018; Golpanian and Yosipovitch, 2020). However, the investigation of the specificity of these novel methods requires a cautious approach since certain molecular elements may

\section{REFERENCES}

Abadía Molina, F., Burrows, N. P., Jones, R. R., Terenghi, G., and Polak, J. M. (1992). Increased Sensory Neuropeptides in Nodular Prurigo: a Quantitative Immunohistochemical Analysis. Br. J. Dermatol. 127, 344-351. doi:10.1111/j. 1365-2133.1992.tb00452.x

Acton, D., Ren, X., Di Costanzo, S., Dalet, A., Bourane, S., Bertocchi, I., et al. (2019). Spinal Neuropeptide Y1 Receptor-Expressing Neurons Form an Essential Excitatory Pathway for Mechanical Itch. Cell Rep 28, 625-e6. e6. doi:10. 1016/j.celrep.2019.06.033

Akiyama, T., Carstens, M. I., and Carstens, E. (2010). Enhanced Scratching Evoked by PAR-2 Agonist and 5-HT but Not Histamine in a Mouse Model of Chronic Dry Skin Itch. Pain 151, 378-383. doi:10.1016/j.pain.2010.07.024

Akiyama, T., Ivanov, M., Nagamine, M., Davoodi, A., Carstens, M. I., Ikoma, A., et al. (2016). Involvement of TRPV4 in Serotonin-Evoked Scratching. J. Invest. Dermatol. 136, 154-160. doi:10.1038/JID.2015.388

Alemi, F., Kwon, E., Poole, D. P., Lieu, T., Lyo, V., Cattaruzza, F., et al. (2013). The TGR5 Receptor Mediates Bile Acid-Induced Itch and Analgesia. J. Clin. Invest. 123, 1513-1530. doi:10.1172/JCI64551

Alhmada, Y., Selimovic, D., Murad, F., Hassan, S. L., Haikel, Y., Megahed, M., et al. (2017). Hepatitis C Virus-Associated Pruritus: Etiopathogenesis and Therapeutic Strategies. World J. Gastroenterol. 23, 743-750. doi:10.3748/wjg.v23.i5.743

Andersen, H. H., Elberling, J., and Arendt-Nielsen, L. (2015). Human Surrogate Models of Histaminergic and Non-histaminergic Itch. Acta Derm Venereol. 95, 771-777. doi:10.2340/00015555-2146 overlap with different sensory transduction systems. For example, TRPV1 and TRPA1 are known not only as pruritic ion channels, but they also take part in temperature sensation and regulation, as well as in nociception (Vriens et al., 2014; Moore et al., 2018). Therefore, better understanding of the cutaneous pruritic interactions and identification of novel therapeutic targets are of great importance in current pruritus research.

\section{AUTHOR CONTRIBUTIONS}

AGS and BIT contributed to the conceptualization and design. AGS, $\mathrm{AO}, \mathrm{EL}, \mathrm{ZG}$, and BIT wrote sections and drafted the original manuscript. AGS, AO, ZG, and BIT reviewed and edited the final version. BIT was responsible for project administration and funding acquisition. All authors have critically reviewed and approved the final version of the manuscript. All listed authors qualify for authorship and all authors qualifying for authorship are listed above.

\section{FUNDING}

The presented work was supported by Hungarian research grants of the National Research, Development and Innovation Office (NRDIO 120187, 134235, 134725, 134791, 134993, EFOP-3.6.3VEKOP-16-2017-00009, and GINOP-2.3.2-15-2016-00050). AGS, AO, and BIT were awarded the János Bolyai Research Scholarship of the Hungarian Academy of Sciences. AGS, AO, and BIT were supported by the New National Excellence Program of the Ministry for Innovation and Technology from the source of the National Research, Development and Innovation Fund (ÚNKP-20-5-DE-100, ÚNKP-21-5-DE-465 and ÚNKP-21-5DE-491, respectively).

Ansel, J. C., Armstrong, C. A., Song, I., Quinlan, K. L., Olerud, J. E., Caughman, S. W., et al. (1997). Interactions of the Skin and Nervous System. J. Investig. Dermatol. Symp. Proc. 2, 23-26. doi:10.1038/jidsymp.1997.6

Armagni, C., di Francesco, C., Schaltegger, H., and Krebs, A. (1979). Electron Microscopy Studies on Dermal Nerves in Psoriatic Plaques. Acta Derm Venereol. Suppl. (Stockh) 87, 68-70.

Azimi, E., Reddy, V. B., Pereira, P. J. S., Talbot, S., Woolf, C. J., and Lerner, E. A. (2017). Substance P Activates Mas-Related G Protein-Coupled Receptors to Induce Itch. J. Allergy Clin. Immunol. 140, 447-e3. e3. doi:10.1016/j.jaci.2016. 12.980

Bains, S. N., Nash, P., and Fonacier, L. (2019). Irritant Contact Dermatitis. Clin. Rev. Allergy Immunol. 56, 99-109. doi:10.1007/s12016-018-8713-0

Barry, D. M., Li, H., Liu, X. Y., Shen, K. F., Liu, X. T., Wu, Z. Y., et al. (2016). Critical Evaluation of the Expression of Gastrin-Releasing Peptide in Dorsal Root Ganglia and Spinal Cord. Mol. Pain 12. doi:10.1177/ 1744806916643724

Barry, D. M., Liu, X. T., Liu, B., Liu, X. Y., Gao, F., Zeng, X., et al. (2020). Exploration of Sensory and Spinal Neurons Expressing Gastrin-Releasing Peptide in Itch and Pain Related Behaviors. Nat. Commun. 11, 1397. doi:10. 1038/s41467-020-15230-y

Bawany, F., Franco, A. I., and Beck, L. A. (2020). Dupilumab: One Therapy to Treat Multiple Atopic Diseases. JAAD Case Rep. 6, 1150-1152. doi:10.1016/j.jdcr. 2020.08.036

Beck, L. A., Thaçi, D., Hamilton, J. D., Graham, N. M., Bieber, T., Rocklin, R., et al. (2014). Dupilumab Treatment in Adults with Moderate-To-Severe Atopic Dermatitis. N. Engl. J. Med. 371, 130-139. doi:10.1056/NEJMoa1314768 
Bergasa, N. V. (2011). The Itch of Liver Disease. Semin. Cutan. Med. Surg. 30, 93-98. doi:10.1016/j.sder.2011.04.009

Beuers, U., Kremer, A. E., Bolier, R., and Elferink, R. P. (2014). Pruritus in Cholestasis: Facts and Fiction. Hepatology 60, 399-407. doi:10.1002/hep.26909

Bieber, T. (2008). Atopic Dermatitis. N. Engl. J. Med. 358, 1483-1494. doi:10.1056/ NEJMra074081

Bienenstock, J., MacQueen, G., Sestini, P., Marshall, J. S., Stead, R. H., and Perdue, M. H. (1991). Mast Cell/nerve Interactions In Vitro and In Vivo. Am. Rev. Respir. Dis. 143, S55-S58. doi:10.1164/ajrccm/143.3_Pt_2.S55

Bigliardi, P. L., Dancik, Y., Neumann, C., and Bigliardi-Qi, M. (2016). Opioids and Skin Homeostasis, Regeneration and Ageing - What's the Evidence? Exp. Dermatol. 25, 586-591. doi:10.1111/exd.13021

Bíró, T., Tóth, B. I., Marincsák, R., Dobrosi, N., Géczy, T., and Paus, R. (2007). TRP Channels as Novel Players in the Pathogenesis and Therapy of Itch. Biochim. Biophys. Acta (Bba) - Mol. Basis Dis. 1772, 1004-1021. doi:10.1016/j.bbadis. 2007.03.002

Bodó, E., Kovács, I., Telek, A., Varga, A., Paus, R., Kovács, L., et al. (2004). Vanilloid Receptor-1 (VR1) Is Widely Expressed on Various Epithelial and Mesenchymal Cell Types of Human Skin. J. Invest. Dermatol. 123, 410-413. doi:10.1111/j. 0022-202X.2004.23209.x

Boniface, K., Diveu, C., Morel, F., Pedretti, N., Froger, J., Ravon, E., et al. (2007). Oncostatin M Secreted by Skin Infiltrating $\mathrm{T}$ Lymphocytes Is a Potent Keratinocyte Activator Involved in Skin Inflammation. J. Immunol. 178, 4615-4622. doi:10.4049/jimmunol.178.7.4615

Booken, N., Heck, M., Nicolay, J. P., Klemke, C. D., Goerdt, S., and Utikal, J. (2011). Oral Aprepitant in the Therapy of Refractory Pruritus in Erythrodermic Cutaneous T-Cell Lymphoma. Br. J. Dermatol. 164, 665-667. doi:10.1111/j. 1365-2133.2010.10108.x

Boudaka, A., Al-Yazeedi, M., and Al-Lawati, I. (2020). Role of Transient Receptor Potential Vanilloid 4 Channel in Skin Physiology and Pathology. Sultan Qaboos Univ. Med. J. 20, e138-e146. doi:10.18295/squmj.2020.20.02.003

Buddenkotte, J., and Steinhoff, M. (2010). Pathophysiology and Therapy of Pruritus in Allergic and Atopic Diseases. Allergy 65, 805-821. doi:10.1111/j. 1398-9995.2010.01995.x

Buhl, T., Ikoma, A., Kempkes, C., Cevikbas, F., Sulk, M., Buddenkotte, J., et al. (2020). Protease-Activated Receptor-2 Regulates Neuro-Epidermal Communication in Atopic Dermatitis. Front. Immunol. 11, 1740. doi:10.3389/fimmu.2020.01740

Bushmakin, A. G., Mamolo, C., Cappelleri, J. C., and Stewart, M. (2015). The Relationship between Pruritus and the Clinical Signs of Psoriasis in Patients Receiving Tofacitinib. J. Dermatolog Treat. 26, 19-22. doi:10.3109/09546634. 2013.861891

Campion, M., Smith, L., Gatault, S., Métais, C., Buddenkotte, J., and Steinhoff, M. (2019). Interleukin-4 and Interleukin-13 Evoke Scratching Behaviour in Mice. Exp. Dermatol. 28, 1501-1504. doi:10.1111/exd.14034

Caterina, M. J., Leffler, A., Malmberg, A. B., Martin, W. J., Trafton, J., PetersenZeitz, K. R., et al. (2000). Impaired Nociception and Pain Sensation in Mice Lacking the Capsaicin Receptor. Science 288, 306-313. doi:10.1126/science.288. 5464.306

Cavanaugh, D. J., Lee, H., Lo, L., Shields, S. D., Zylka, M. J., Basbaum, A. I., et al. (2009). Distinct Subsets of Unmyelinated Primary Sensory Fibers Mediate Behavioral Responses to Noxious thermal and Mechanical Stimuli. Proc. Natl. Acad. Sci. U S A. 106, 9075-9080. doi:10.1073/pnas.0901507106

Cevikbas, F., Wang, X., Akiyama, T., Kempkes, C., Savinko, T., Antal, A., et al. (2014). A Sensory Neuron-Expressed IL-31 Receptor Mediates T Helper Celldependent Itch: Involvement of TRPV1 and TRPA1. J. Allergy Clin. Immunol. 133, 448-460. doi:10.1016/j.jaci.2013.10.048

Checa, A., Xu, N., Sar, D. G., Haeggström, J. Z., Ståhle, M., and Wheelock, C. E. (2015). Circulating Levels of Sphingosine-1-Phosphate Are Elevated in Severe, but Not Mild Psoriasis and Are Unresponsive to Anti-TNF- $\alpha$ Treatment. Sci. Rep. 5, 12017. doi:10.1038/srep12017

Chen, J., Zhu, Z., Li, Q., Lin, Y., Dang, E., Meng, H., et al. (2021a). Neutrophils Enhance Cutaneous Vascular Dilation and Permeability to Aggravate Psoriasis by Releasing Matrix Metallopeptidase 9. J. Invest. Dermatol. 141, 787-799. doi:10.1016/j.jid.2020.07.028

Chen, Y., Fang, Q., Wang, Z., Zhang, J. Y., MacLeod, A. S., Hall, R. P., et al. (2016). Transient Receptor Potential Vanilloid 4 Ion Channel Functions as a Pruriceptor in Epidermal Keratinocytes to Evoke Histaminergic Itch. J. Biol. Chem. 291, 10252-10262. doi:10.1074/jbc.M116.716464
Chen, Y., Wang, Z.-L., Yeo, M., Zhang, Q.-J., López-Romero, A. E., Ding, H.-P., et al. (2021b). Epithelia-Sensory Neuron Cross Talk Underlies Cholestatic Itch Induced by Lysophosphatidylcholine. Gastroenterology 161, 301-317. doi:10. 1053/j.gastro.2021.03.049

Chiu, I. M., Barrett, L. B., Williams, E. K., Strochlic, D. E., Lee, S., Weyer, A. D., et al. (2014). Transcriptional Profiling at Whole Population and Single Cell Levels Reveals Somatosensory Neuron Molecular Diversity. eLife 3, e04660. doi:10. 7554/eLife.04660

Cho, H., Yang, Y. D., Lee, J., Lee, B., Kim, T., Jang, Y., et al. (2012). The CalciumActivated Chloride Channel Anoctamin 1 Acts as a Heat Sensor in Nociceptive Neurons. Nat. Neurosci. 15, 1015-1021. doi:10.1038/nn.3111

Choi, J. E., and Di Nardo, A. (2018). Skin Neurogenic Inflammation. Semin. Immunopathol 40, 249-259. doi:10.1007/s00281-018-0675-z

Chung, M. K., Lee, H., Mizuno, A., Suzuki, M., and Caterina, M. J. (2004). TRPV3 and TRPV4 Mediate Warmth-Evoked Currents in Primary Mouse Keratinocytes. J. Biol. Chem. 279, 21569-21575. doi:10.1074/jbc.M401872200

Cohen, J. A., Edwards, T. N., Liu, A. W., Hirai, T., Jones, M. R., Wu, J., et al. (2019). Cutaneous TRPV1+ Neurons Trigger Protective Innate Type 17 Anticipatory Immunity. Cell 178, 919-e14. e14. doi:10.1016/j.cell.2019.06.022

Cornelissen, C., Marquardt, Y., Czaja, K., Wenzel, J., Frank, J., Lüscher-Firzlaff, J., et al. (2012). IL-31 Regulates Differentiation and Filaggrin Expression in Human Organotypic Skin Models. J. Allergy Clin. Immunol. 129, 426433-426438. e1-8. doi:10.1016/j.jaci.2011.10.042

Czarnowicki, T., He, H., Krueger, J. G., and Guttman-Yassky, E. (2019). Atopic Dermatitis Endotypes and Implications for Targeted Therapeutics. J. Allergy Clin. Immunol. 143, 1-11. doi:10.1016/j.jaci.2018.10.032

da Costa, D. S., Meotti, F. C., Andrade, E. L., Leal, P. C., Motta, E. M., and Calixto, J. B. (2010). The Involvement of the Transient Receptor Potential A1 (TRPA1) in the Maintenance of Mechanical and Cold Hyperalgesia in Persistent Inflammation. Pain 148, 431-437. doi:10.1016/j.pain.2009.12.002

Datsi, A., Steinhoff, M., Ahmad, F., Alam, M., and Buddenkotte, J. (2021). Interleukin-31: The "itchy" Cytokine in Inflammation and Therapy. Allergy 76, 2982-2997. doi:10.1111/all.14791

Davenport, A. P., Hyndman, K. A., Dhaun, N., Southan, C., Kohan, D. E., Pollock, J. S., et al. (2016). Endothelin. Pharmacol. Rev. 68, 357-418. doi:10.1124/pr.115.011833

Denda, M., and Denda, S. (2007). Air-exposed Keratinocytes Exhibited Intracellular Calcium Oscillation. Skin Res. Technol. 13, 195-201. doi:10. $1111 / j .1600-0846.2007 .00210 . x$

Denda, M., Fuziwara, S., Inoue, K., Denda, S., Akamatsu, H., Tomitaka, A., et al. (2001). Immunoreactivity of VR1 on Epidermal Keratinocyte of Human Skin. Biochem. Biophys. Res. Commun. 285, 1250-1252. doi:10.1006/bbrc.2001.5299

Denda, M., Nakatani, M., Ikeyama, K., Tsutsumi, M., and Denda, S. (2007). Epidermal Keratinocytes as the Forefront of the Sensory System. Exp. Dermatol. 16, 157-161. doi:10.1111/j.1600-0625.2006.00529.x

Derouiche, S., Takayama, Y., Murakami, M., and Tominaga, M. (2018). TRPV4 Heats up ANO1-dependent Exocrine Gland Fluid Secretion. FASEB J. 32, 1841-1854. doi:10.1096/fj.201700954R

Dhingra, N., Shemer, A., Correa da Rosa, J., Rozenblit, M., Fuentes-Duculan, J., Gittler, J. K., et al. (2014). Molecular Profiling of Contact Dermatitis Skin Identifies Allergen-dependent Differences in Immune Response. J. Allergy Clin. Immunol. 134, 362-372. doi:10.1016/j.jaci.2014.03.009

Di Francesco, C., Meier, C., Schaltegger, H., and Krebs, A. (1978). Qualitative and Quantitative Investigations of the Skin Nerves of Patients with Psoriasis Lightand Electronmicroscopical Study (Author's Transl). Arch. Dermatol. Res. 262, 177-184. doi:10.1007/BF00455388

Ding, W., Stohl, L. L., Wagner, J. A., and Granstein, R. D. (2008). Calcitonin GeneRelated Peptide Biases Langerhans Cells toward Th2-type Immunity. J. Immunol. 181, 6020-6026. doi:10.4049/jimmunol.181.9.6020

Domagała, A., Szepietowski, J., and Reich, A. (2017). Antihistamines in the Treatment of Pruritus in Psoriasis. Postepy Dermatol. Alergol 34, 457-463. doi:10.5114/ada.2017.71112

Dong, X., and Dong, X. (2018). Peripheral and Central Mechanisms of Itch. Neuron 98, 482-494. doi:10.1016/j.neuron.2018.03.023

Dong, X., Han, S., Zylka, M. J., Simon, M. I., and Anderson, D. J. (2001). A Diverse Family of GPCRs Expressed in Specific Subsets of Nociceptive Sensory Neurons. Cell 106, 619-632. doi:10.1016/s0092-8674(01)00483-4

Dugas-Breit, S., Schöpf, P., Dugas, M., Schiffl, H., Ruëff, F., and Przybilla, B. (2005). Baseline Serum Levels of Mast Cell Tryptase Are Raised in Hemodialysis 
Patients and Associated with Severity of Pruritus. J. Dtsch Dermatol. Ges 3, 343-347. doi:10.1111/j.1610-0387.2005.05706.x

Duque, M. I., Yosipovitch, G., Fleischer, A. B., Willard, J., and Freedman, B. I. (2005). Lack of Efficacy of Tacrolimus Ointment $0.1 \%$ for Treatment of Hemodialysis-Related Pruritus: a Randomized, Double-Blind, Vehicle-Controlled Study. J. Am. Acad. Dermatol. 52, 519-521. doi:10.1016/j.jaad.2004.08.050

Duval, A., and Dubertret, L. (2009). Aprepitant as an Antipruritic Agent? N. Engl. J. Med. 361, 1415-1416. doi:10.1056/NEJMc0906670

El-Baalbaki, G., Razykov, I., Hudson, M., Bassel, M., Baron, M., Thombs, B. D., et al. (2010). Association of Pruritus with Quality of Life and Disability in Systemic Sclerosis. Arthritis Care Res. (Hoboken) 62, 1489-1495. doi:10.1002/ acr.20257

Elliott, G., Vanwersch, R., Soeberdt, M., Metze, D., Lotts, T., Ständer, S., et al. (2016). Topical Nalfurafine Exhibits Anti-inflammatory and Anti-pruritic Effects in a Murine Model of AD. J. Dermatol. Sci. 84, 351-354. doi:10. 1016/j.jdermsci.2016.09.008

Esancy, K., Condon, L., Feng, J., Kimball, C., Curtright, A., and Dhaka, A. (2018). A Zebrafish and Mouse Model for Selective Pruritus via Direct Activation of TRPA1. Elife 7. doi:10.7554/eLife.32036

European Association for the Study of the Liver (2009). EASL Clinical Practice Guidelines: Management of Cholestatic Liver Diseases. J. Hepatol. 51, 237-267. doi:10.1016/j.jhep.2009.04.009

Falanga, V., Soter, N. A., Altman, R. D., and Kerdel, F. A. (1990). Elevated Plasma Histamine Levels in Systemic Sclerosis (Scleroderma). Arch. Dermatol. 126, 336-338. doi:10.1001/archderm.1990.01670270068011

Fishbane, S., Jamal, A., Munera, C., Wen, W., and Menzaghi, F.KALM-1 Trial Investigators (2020). A Phase 3 Trial of Difelikefalin in Hemodialysis Patients with Pruritus. N. Engl. J. Med. 382, 222-232. doi:10.1056/NEJMoa1912770

Fleming, M. S., Ramos, D., Han, S. B., Zhao, J., Son, Y. J., and Luo, W. (2012). The Majority of Dorsal Spinal Cord Gastrin Releasing Peptide Is Synthesized Locally whereas Neuromedin B Is Highly Expressed in Pain- and Itch-Sensing Somatosensory Neurons. Mol. Pain 8, 52. doi:10.1186/1744-8069-8-52

Fourzali, K., Golpanian, R. S., and Yosipovitch, G. (2020). Emerging Drugs for the Treatment of Chronic Pruritic Diseases. Expert Opin. Emerg. Drugs 25, 273-284. doi:10.1080/14728214.2020.1801632

Francos, G. C., Kauh, Y. C., Gittlen, S. D., Schulman, E. S., Besarab, A., Goyal, S., et al. (1991). Elevated Plasma Histamine in Chronic Uremia. Effects of Ketotifen on Pruritus. Int. J. Dermatol. 30, 884-889. doi:10.1111/j.13654362.1991.tb04360.x

Frech, T. M., and Baron, M. (2013). Understanding Itch in Systemic Sclerosis in Order to Improve Patient Quality of Life. Clin. Exp. Rheumatol. 31, $81-88$.

Furue, K., Ulzii, D., Tanaka, Y., Ito, T., Tsuji, G., Kido-Nakahara, M., et al. (2020). Pathogenic Implication of Epidermal Scratch Injury in Psoriasis and Atopic Dermatitis. J. Dermatol. 47, 979-988. doi:10.1111/1346-8138.15507

Furue, M., Ulzii, D., Vu, Y. H., Tsuji, G., Kido-Nakahara, M., and Nakahara, T. (2019). Pathogenesis of Atopic Dermatitis: Current Paradigm. Iran J. Immunol. 16, 97-107. doi:10.22034/IJI.2019.80253

Fuziwara, S., Inoue, K., and Denda, M. (2003). NMDA-type Glutamate Receptor Is Associated with Cutaneous Barrier Homeostasis. J. Invest. Dermatol. 120, 1023-1029. doi:10.1046/j.1523-1747.2003.12238.x

Fuziwara, S., Suzuki, A., Inoue, K., and Denda, M. (2005). Dopamine D2-like Receptor Agonists Accelerate Barrier Repair and Inhibit the Epidermal Hyperplasia Induced by Barrier Disruption. J. Invest. Dermatol. 125, 783-789. doi:10.1111/j.0022-202X.2005.23873.x

Gandhi, N. A., Pirozzi, G., and Graham, N. M. H. (2017). Commonality of the IL-4/ IL-13 Pathway in Atopic Diseases. Expert Rev. Clin. Immunol. 13, 425-437. doi:10.1080/1744666X.2017.1298443

Garcovich, S., Maurelli, M., Gisondi, P., Peris, K., Yosipovitch, G., and Girolomoni, G. (2021). Pruritus as a Distinctive Feature of Type 2 Inflammation. Vaccines (Basel) 9, 303. doi:10.3390/vaccines 9030303

Glatzer, F., Gschwandtner, M., Ehling, S., Rossbach, K., Janik, K., Klos, A., et al. (2013). Histamine Induces Proliferation in Keratinocytes from Patients with Atopic Dermatitis through the Histamine 4 Receptor. J. Allergy Clin. Immunol. 132, 1358-1367. doi:10.1016/j.jaci.2013.06.023

Golpanian, R. S., and Yosipovitch, G. (2020). Current and Emerging Systemic Treatments Targeting the Neural System for Chronic Pruritus. Expert Opin. Pharmacother. 21, 1629-1636. doi:10.1080/14656566.2020.1775815
Gomes, L. O., Hara, D. B., and Rae, G. A. (2012). Endothelin-1 Induces Itch and Pain in the Mouse Cheek Model. Life Sci. 91, 628-633. doi:10.1016/j.lfs.2012.03.020

Gonçalo, M., Gimenéz-Arnau, A., Al-Ahmad, M., Ben-Shoshan, M., Bernstein, J. A., Ensina, L. F., et al. (2021). The Global burden of Chronic Urticaria for the Patient and Society*. Br. J. Dermatol. 184, 226-236. doi:10.1111/bjd.19561

Gooderham, M. J., Hong, H. C., Eshtiaghi, P., and Papp, K. A. (2018). Dupilumab: A Review of its Use in the Treatment of Atopic Dermatitis. J. Am. Acad. Dermatol. 78, S28-S36. doi:10.1016/j.jaad.2017.12.022

Granstein, R. D., Wagner, J. A., Stohl, L. L., and Ding, W. (2015). Calcitonin GeneRelated Peptide: Key Regulator of Cutaneous Immunity. Acta Physiol. (Oxf) 213, 586-594. doi:10.1111/apha.12442

Griffiths, C. E., van de Kerkhof, P., and Czarnecka-Operacz, M. (2017). Psoriasis and Atopic Dermatitis. Dermatol. Ther. (Heidelb) 7, 31-41. doi:10.1007/s13555016-0167-9

Griger, Z., Nagy-Vincze, M., and Dankó, K. (2017). Pharmacological Management of Dermatomyositis. Expert Rev. Clin. Pharmacol. 10, 1109-1118. doi:10.1080/ 17512433.2017.1353910

Gschwandtner, M., Mildner, M., Mlitz, V., Gruber, F., Eckhart, L., Werfel, T., et al. (2013). Histamine Suppresses Epidermal Keratinocyte Differentiation and Impairs Skin Barrier Function in a Human Skin Model. Allergy 68, 37-47. doi:10.1111/all.12051

Gschwandtner, M., Purwar, R., Wittmann, M., Bäumer, W., Kietzmann, M., Werfel, T., et al. (2008). Histamine Upregulates Keratinocyte MMP-9 Production via the Histamine H1 Receptor. J. Invest. Dermatol. 128, 2783-2791. doi:10.1038/jid.2008.153

Gunal, A. I., Ozalp, G., Yoldas, T. K., Gunal, S. Y., Kirciman, E., and Celiker, H. (2004). Gabapentin Therapy for Pruritus in Haemodialysis Patients: a Randomized, Placebo-Controlled, Double-Blind Trial. Nephrol. Dial. Transpl. 19, 3137-3139. doi:10.1093/ndt/gfh496

Guo, C., Chen, W. D., and Wang, Y. D. (2016). TGR5, Not Only a Metabolic Regulator. Front. Physiol. 7, 646. doi:10.3389/fphys.2016.00646

Haber, J. S., Valdes-Rodriguez, R., and Yosipovitch, G. (2016). Chronic Pruritus and Connective Tissue Disorders: Review, Gaps, and Future Directions. Am. J. Clin. Dermatol. 17, 445-449. doi:10.1007/s40257-016-0201-9

Hampers, C. L., Katz, A. I., Wilson, R. E., and Merrill, J. P. (1968). Disappearance of "Uremic" Itching after Subtotal Parathyroidectomy. N. Engl. J. Med. 279, 695-697. doi:10.1056/NEJM196809262791307

Han, L., Ma, C., Liu, Q., Weng, H. J., Cui, Y., Tang, Z., et al. (2013). A Subpopulation of Nociceptors Specifically Linked to Itch. Nat. Neurosci. 16, 174-182. doi: $10.1038 / \mathrm{nn} .3289$

Han, S. K., Mancino, V., and Simon, M. I. (2006). Phospholipase Cbeta 3 Mediates the Scratching Response Activated by the Histamine H1 Receptor on C-Fiber Nociceptive Neurons. Neuron 52, 691-703. doi:10.1016/j.neuron.2006.09.036

Hans, G., Schmidt, B. L., and Strichartz, G. (2009). Nociceptive Sensitization by Endothelin-1. Brain Res. Rev. 60, 36-42. doi:10.1016/j.brainresrev.2008.12.008

Harvima, I. T., Viinamäki, H., Naukkarinen, A., Paukkonen, K., Neittaanmäki, H., Harvima, R. J., et al. (1993). Association of Cutaneous Mast Cells and Sensory Nerves with Psychic Stress in Psoriasis. Psychother Psychosom 60, 168-176. doi: $10.1159 / 000288690$

Hashimoto, T., Mishra, S. K., Olivry, T., and Yosipovitch, G. (2021a). Periostin, an Emerging Player in Itch Sensation. J. Invest. Dermatol. 141, 2338-2343. doi:10. 1016/j.jid.2021.03.009

Hashimoto, T., Nattkemper, L. A., Kim, H. S., Kursewicz, C. D., Fowler, E., Shah, S. M., et al. (2021b). Itch Intensity in Prurigo Nodularis Is Closely Related to Dermal Interleukin-31, Oncostatin M, IL-31 Receptor Alpha and Oncostatin M Receptor Beta. Exp. Dermatol. 30, 804-810. doi:10.1111/exd.14279

Hawro, T., Saluja, R., Weller, K., Altrichter, S., Metz, M., and Maurer, M. (2014). Interleukin-31 Does Not Induce Immediate Itch in Atopic Dermatitis Patients and Healthy Controls after Skin challenge. Allergy 69, 113-117. doi:10.1111/all. 12316

Held, K., and Tóth, B. I. (2021). TRPM3 in Brain (Patho)Physiology. Front Cel Dev Biol 9, 635659. doi:10.3389/fcell.2021.635659

Helyes, Z., Pintér, E., Sándor, K., Elekes, K., Bánvölgyi, A., Keszthelyi, D., et al. (2009). Impaired Defense Mechanism against Inflammation, Hyperalgesia, and Airway Hyperreactivity in Somatostatin 4 Receptor Gene-Deleted Mice. Proc. Natl. Acad. Sci. U S A. 106, 13088-13093. doi:10.1073/pnas.0900681106

Helyes, Z., Szabó, A., Németh, J., Jakab, B., Pintér, E., Bánvölgyi, A., et al. (2004). Antiinflammatory and Analgesic Effects of Somatostatin Released from 
Capsaicin-Sensitive Sensory Nerve Terminals in a Freund's Adjuvant-Induced Chronic Arthritis Model in the Rat. Arthritis Rheum. 50, 1677-1685. doi:10. 1002/art.20184

Hill, N. R., Fatoba, S. T., Oke, J. L., Hirst, J. A., O'Callaghan, C. A., Lasserson, D. S., et al. (2016). Global Prevalence of Chronic Kidney Disease - A Systematic Review and Meta-Analysis. PLoS One 11, e0158765. doi:10.1371/journal.pone. 0158765

Hill, R. Z., Morita, T., Brem, R. B., and Bautista, D. M. (2018). S1PR3 Mediates Itch and Pain via Distinct TRP Channel-dependent Pathways. J. Neurosci. 38, 7833-7843. doi:10.1523/JNEUROSCI.1266-18.2018

Hiroshige, K., Kabashima, N., Takasugi, M., and Kuroiwa, A. (1995). Optimal Dialysis Improves Uremic Pruritus. Am. J. Kidney Dis. 25, 413-419. doi:10. 1016/0272-6386(95)90102-7

Hon, K. L., Leung, A. K. C., Ng, W. G. G., and Loo, S. K. (2019). Chronic Urticaria: An Overview of Treatment and Recent Patents. Recent Pat Inflamm. Allergy Drug Discov. 13, 27-37. doi:10.2174/1872213X13666190328164931

Hon, K. L., Li, J. T. S., Leung, A. K. C., and Lee, V. W. Y. (2021). Current and Emerging Pharmacotherapy for Chronic Spontaneous Urticaria: a Focus on Non-biological Therapeutics. Expert Opin. Pharmacother. 22, 497-509. doi:10. 1080/14656566.2020.1829593

Hosoi, J., Murphy, G. F., Egan, C. L., Lerner, E. A., Grabbe, S., Asahina, A., et al. (1993). Regulation of Langerhans Cell Function by Nerves Containing Calcitonin Gene-Related Peptide. Nature 363, 159-163. doi:10.1038/363159a0

Huang, M. C., Watson, S. R., Liao, J. J., and Goetzl, E. J. (2007). Th17 Augmentation in OTII TCR Plus T Cell-Selective Type 1 Sphingosine 1-phosphate Receptor Double Transgenic Mice. J. Immunol. 178, 6806-6813. doi:10.4049/jimmunol. 178.11.6806

Ikeda, H., Watanabe, N., Nakamura, K., Kume, Y., Nakai, Y., Fujishiro, M., et al. (2009). Significance of Serum Autotaxin Activity in Gastrointestinal Disease. Rinsho Byori 57, 445-449.

Ikoma, A., Handwerker, H., Miyachi, Y., and Schmelz, M. (2005). Electrically Evoked Itch in Humans. Pain 113, 148-154. doi:10.1016/j.pain.2004.10.003

Ikoma, A., Steinhoff, M., Ständer, S., Yosipovitch, G., and Schmelz, M. (2006). The Neurobiology of Itch. Nat. Rev. Neurosci. 7, 535-547. doi:10.1038/nrn1950

Imai, Y. (2019). Interleukin-33 in Atopic Dermatitis. J. Dermatol. Sci. 96, 2-7. doi:10.1016/j.jdermsci.2019.08.006

Imai, Y., Kusakabe, M., Nagai, M., Yasuda, K., and Yamanishi, K. (2021). Dupilumab Effects on Innate Lymphoid Cell and Helper T Cell Populations in Patients with Atopic Dermatitis. JID Innov. 1, 100003. doi:10.1016/j.xjidi. 2021.100003

Imamachi, N., Park, G. H., Lee, H., Anderson, D. J., Simon, M. I., Basbaum, A. I., et al. (2009). TRPV1-expressing Primary Afferents Generate Behavioral Responses to Pruritogens via Multiple Mechanisms. Proc. Natl. Acad. Sci. U S A. 106, 11330-11335. doi:10.1073/pnas.0905605106

Inoue, K., Koizumi, S., Fuziwara, S., Denda, S., Inoue, K., and Denda, M. (2002). Functional Vanilloid Receptors in Cultured normal Human Epidermal Keratinocytes. Biochem. Biophys. Res. Commun. 291, 124-129. doi:10.1006/ bbrc. 2002.6393

Inui, S. (2015). Nalfurafine Hydrochloride to Treat Pruritus: a Review. Clin. Cosmet. Investig. Dermatol. 8, 249-255. doi:10.2147/CCID.S55942

Jancsó, N., Jancsó-gábor, A., and Szolcsányi, J. (1967). Direct Evidence for Neurogenic Inflammation and its Prevention by Denervation and by Pretreatment with Capsaicin. Br. J. Pharmacol. Chemother. 31, 138-151. doi:10.1111/j.1476-5381.1967.tb01984.x

Jancsó, N., Jancsó-gábor, A., and Szolcsányi, J. (1968). The Role of Sensory Nerve Endings in Neurogenic Inflammation Induced in Human Skin and in the Eye and Paw of the Rat. Br. J. Pharmacol. Chemother. 33, 32-41. doi:10.1111/j.14765381.1968.tb00471.x

Järvikallio, A., Harvima, I. T., and Naukkarinen, A. (2003). Mast Cells, Nerves and Neuropeptides in Atopic Dermatitis and Nummular Eczema. Arch. Dermatol. Res. 295, 2-7. doi:10.1007/s00403-002-0378-z

Jensen, J. M., and Proksch, E. (2009). The Skin's Barrier. G Ital. Dermatol. Venereol. 144, 689-700.

Jian, T., Yang, N., Yang, Y., Zhu, C., Yuan, X., Yu, G., et al. (2016). TRPV1 and PLC Participate in Histamine H4 Receptor-Induced Itch. Neural Plast. 2016, 1682972. doi:10.1155/2016/1682972

Johansson, O., Liang, Y., Marcusson, J. A., and Reimert, C. M. (2000). Eosinophil Cationic Protein- and Eosinophil-Derived Neurotoxin/eosinophil Protein
X-Immunoreactive Eosinophils in Prurigo Nodularis. Arch. Dermatol. Res. 292, 371-378. doi:10.1007/s004030000142

Julius, D. (2013). TRP Channels and Pain. Annu. Rev. Cell Dev. Biol. 29, 355-384. doi:10.1146/annurev-cellbio-101011-155833

Kabashima, K. (2013). New Concept of the Pathogenesis of Atopic Dermatitis: Interplay Among the Barrier, Allergy, and Pruritus as a trinity. J. Dermatol. Sci. 70, 3-11. doi:10.1016/j.jdermsci.2013.02.001

Kashem, S. W., Riedl, M. S., Yao, C., Honda, C. N., Vulchanova, L., and Kaplan, D. H. (2015). Nociceptive Sensory Fibers Drive Interleukin-23 Production from CD301b+ Dermal Dendritic Cells and Drive Protective Cutaneous Immunity. Immunity 43, 515-526. doi:10.1016/j.immuni.2015.08.016

Kassmann, M., Harteneck, C., Zhu, Z., Nürnberg, B., Tepel, M., and Gollasch, M. (2013). Transient Receptor Potential Vanilloid 1 (TRPV1), TRPV4, and the Kidney. Acta Physiol. (Oxf) 207, 546-564. doi:10.1111/apha.12051

Kato, A., Fujii, E., Watanabe, T., Takashima, Y., Matsushita, H., Furuhashi, T., et al. (2014). Distribution of IL-31 and its Receptor Expressing Cells in Skin of Atopic Dermatitis. J. Dermatol. Sci. 74, 229-235. doi:10.1016/j.jdermsci.2014.02.009

Kelemen, B., Pinto, S., Kim, N., Lisztes, E., Hanyicska, M., Vladár, A., et al. (2021). The TRPM3 Ion Channel Mediates Nociception but Not Itch Evoked by Endogenous Pruritogenic Mediators. Biochem. Pharmacol. 183, 114310. doi:10.1016/j.bcp.2020.114310

Kemény, Á., Kodji, X., Horváth, S., Komlódi, R., Szőke, É., Sándor, Z., et al. (2018). TRPA1 Acts in a Protective Manner in Imiquimod-Induced Psoriasiform Dermatitis in Mice. J. Invest. Dermatol. 138, 1774-1784. doi:10.1016/j.jid.2018.02.040

Kempkes, C., Buddenkotte, J., Cevikbas, F., Buhl, T., and Steinhoff, M. (2014). "Role of PAR-2 in Neuroimmune Communication and Itch," in Itch: Mechanisms And Treatment Frontiers in Neuroscience. Editors E. Carstens and T. Akiyama (Boca Raton (FL): CRC Press/Taylor \& Francis). Available at: http://www.ncbi.nlm.nih.gov/books/NBK200911/(Accessed April 12, 2021).

Keçici, A. S., Göktay, F., Tutkavul, K., Güneş, P., and Yaşar, Ş. (2018). Unilateral Improvement of Nail Psoriasis with Denervation Injury. Clin. Exp. Dermatol. 43, 339-341. doi:10.1111/ced.13337

Khanna, U., Vaughan, H., North, J., and Haemel, A. (2020). Quantitative Assessment of Eosinophils in Dermatomyositis Skin Biopsies with Correlation of Eosinophils to Pruritus and Other Clinical Features. Am. J. Dermatopathol 43, 287-290. doi:10.1097/DAD.0000000000001765

Khodorova, A., Montmayeur, J. P., and Strichartz, G. (2009). Endothelin Receptors and Pain. J. Pain 10, 4-28. doi:10.1016/j.jpain.2008.09.009

Kido-Nakahara, M., Buddenkotte, J., Kempkes, C., Ikoma, A., Cevikbas, F., Akiyama, T., et al. (2014). Neural Peptidase Endothelin-Converting Enzyme 1 Regulates Endothelin 1-induced Pruritus. J. Clin. Invest. 124, 2683-2695. doi:10.1172/JCI67323

Kim, B. E., Leung, D. Y., Boguniewicz, M., and Howell, M. D. (2008). Loricrin and Involucrin Expression Is Down-Regulated by Th2 Cytokines through STAT-6. Clin. Immunol. 126, 332-337. doi:10.1016/j.clim.2007.11.006

Kim, B. M., Lee, S. H., Shim, W. S., and Oh, U. (2004). Histamine-induced Ca(2+) Influx via the PLA(2)/lipoxygenase/TRPV1 Pathway in Rat Sensory Neurons. Neurosci. Lett. 361, 159-162. doi:10.1016/j.neulet.2004.01.019

Kim, H. J., Zeidi, M., Bonciani, D., Pena, S. M., Tiao, J., Sahu, S., et al. (2018). Itch in Dermatomyositis: the Role of Increased Skin Interleukin-31. Br. J. Dermatol. 179, 669-678. doi:10.1111/bjd.16498

Kim, S. J., Park, G. H., Kim, D., Lee, J., Min, H., Wall, E., et al. (2011). Analysis of Cellular and Behavioral Responses to Imiquimod Reveals a Unique Itch Pathway in Transient Receptor Potential Vanilloid 1 (TRPV1)-Expressing Neurons. Proc. Natl. Acad. Sci. U S A. 108, 3371-3376. doi:10.1073/pnas.1019755108

Kimata, N., Fuller, D. S., Saito, A., Akizawa, T., Fukuhara, S., Pisoni, R. L., et al. (2014). Pruritus in Hemodialysis Patients: Results from the Japanese Dialysis Outcomes and Practice Patterns Study (JDOPPS). Hemodial Int. 18, 657-667. doi:10.1111/hdi.12158

Kimball, A. B., Luger, T., Gottlieb, A., Puig, L., Kaufmann, R., Burge, R., et al. (2018). Long-term Impact of Ixekizumab on Psoriasis Itch Severity: Results from a Phase III Clinical Trial and Long-Term Extension. Acta Derm Venereol. 98, 98-102. doi:10.2340/00015555-2801

Kimmel, M., Alscher, D. M., Dunst, R., Braun, N., Machleidt, C., Kiefer, T., et al. (2006). The Role of Micro-inflammation in the Pathogenesis of Uraemic Pruritus in Haemodialysis Patients. Nephrol. Dial. Transpl. 21, 749-755. doi:10.1093/ndt/gfi204

Kinoshita, H., Takai, T., Le, T. A., Kamijo, S., Wang, X. L., Ushio, H., et al. (2009). Cytokine Milieu Modulates Release of Thymic Stromal Lymphopoietin from 
Human Keratinocytes Stimulated with Double-Stranded RNA. J. Allergy Clin. Immunol. 123, 179-186. doi:10.1016/j.jaci.2008.10.008

Kitajima, M., Lee, H. C., Nakayama, T., and Ziegler, S. F. (2011). TSLP Enhances the Function of Helper Type 2 Cells. Eur. J. Immunol. 41, 1862-1871. doi:10. 1002/eji.201041195

Kittaka, H., Uchida, K., Fukuta, N., and Tominaga, M. (2017). Lysophosphatidic Acid-Induced Itch Is Mediated by Signalling of LPA5 Receptor, Phospholipase D and TRPA1/TRPV1. J. Physiol. 595, 2681-2698. doi:10.1113/JP273961

Köchling, H., Schaper, K., Wilzopolski, J., Gutzmer, R., Werfel, T., Bäumer, W., et al. (2017). Combined Treatment with H1 and H4 Receptor Antagonists Reduces Inflammation in a Mouse Model of Atopic Dermatitis. J. Dermatol. Sci. 87, 130-137. doi:10.1016/j.jdermsci.2017.04.004

Komiya, E., Tominaga, M., Kamata, Y., Suga, Y., and Takamori, K. (2020). Molecular and Cellular Mechanisms of Itch in Psoriasis. Int. J. Mol. Sci. 21. doi:10.3390/ijms21218406

Kondo, Y., Yoshimoto, T., Yasuda, K., Futatsugi-Yumikura, S., Morimoto, M., Hayashi, N., et al. (2008). Administration of IL-33 Induces Airway Hyperresponsiveness and Goblet Cell Hyperplasia in the Lungs in the Absence of Adaptive Immune System. Int. Immunol. 20, 791-800. doi:10. 1093/intimm/dxn037

Kou, K., Nakamura, F., Aihara, M., Chen, H., Seto, K., Komori-Yamaguchi, J., et al. (2012). Decreased Expression of semaphorin-3A, a Neurite-Collapsing Factor, Is Associated with Itch in Psoriatic Skin. Acta Derm Venereol. 92, 521-528. doi:10.2340/00015555-1350

Kovács, D., Fazekas, F., Oláh, A., and Töröcsik, D. (2020). Adipokines in the Skin and in Dermatological Diseases. Ijms 21, 9048. doi:10.3390/ijms21239048

Kremer, A. E., Oude Elferink, R. P., and Beuers, U. (2011). Pathophysiology and Current Management of Pruritus in Liver Disease. Clin. Res. Hepatol. Gastroenterol. 35, 89-97. doi:10.1016/j.clinre.2010.10.007

Kupari, J., Usoskin, D., Parisien, M., Lou, D., Hu, Y., Fatt, M., et al. (2021). Single Cell Transcriptomics of Primate Sensory Neurons Identifies Cell Types Associated with Chronic Pain. Nat. Commun. 12, 1510. doi:10.1038/s41467-021-21725-z

Ladizinski, B., Bazakas, A., and Olsen, E. A. (2012). Aprepitant: a Novel Neurokinin-1 Receptor/substance P Antagonist as Antipruritic Therapy in Cutaneous T-Cell Lymphoma. J. Am. Acad. Dermatol. 67, e198-9. doi:10.1016/ j.jaad.2012.02.008

LaMotte, R. H., Dong, X., and Ringkamp, M. (2014). Sensory Neurons and Circuits Mediating Itch. Nat. Rev. Neurosci. 15, 19-31. doi:10.1038/nrn3641

LaMotte, R. H., Shimada, S. G., and Sikand, P. (2011). Mouse Models of Acute, Chemical Itch and Pain in Humans. Exp. Dermatol. 20, 778-782. doi:10.1111/j. 1600-0625.2011.01367.x

Langan, S. M., Irvine, A. D., and Weidinger, S. (2020). Atopic Dermatitis. Lancet 396, 345-360. doi:10.1016/S0140-6736(20)31286-1

Larkin, C., Chen, W., Szabó, I. L., Shan, C., Dajnoki, Z., Szegedi, A., et al. (2021). Novel Insights into the TRPV3-Mediated Itch in Atopic Dermatitis. J. Allergy Clin. Immunol. 147, 1110-e5. e5. doi:10.1016/j.jaci.2020.09.028

Leader, B., Carr, C. W., and Chen, S. C. (2015). Pruritus Epidemiology and Quality of Life. Handb Exp. Pharmacol. 226, 15-38. doi:10.1007/978-3-662-44605-8_2

Lee, C. H., Chuang, H. Y., Shih, C. C., Jong, S. B., Chang, C. H., and Yu, H. S. (2006). Transepidermal Water Loss, Serum IgE and Beta-Endorphin as Important and Independent Biological Markers for Development of Itch Intensity in Atopic Dermatitis. Br. J. Dermatol. 154, 1100-1107. doi:10.1111/j.1365-2133.2006. 07191.x

Lee, H. Y., Stieger, M., Yawalkar, N., and Kakeda, M. (20132013). Cytokines and Chemokines in Irritant Contact Dermatitis. Mediators Inflamm. 2013, 1-7. doi:10.1155/2013/916497

Lee, J., Kim, T., Hong, J., Woo, J., Min, H., Hwang, E., et al. (2012). Imiquimod Enhances Excitability of Dorsal Root Ganglion Neurons by Inhibiting Background (K(2P)) and Voltage-Gated (K(v)1.1 and K(v)1.2) Potassium Channels. Mol. Pain 8, 2. doi:10.1186/1744-8069-8-2

Lee, M. R., and Shumack, S. (2005). Prurigo Nodularis: a Review. Australas. J. Dermatol. 46, 211-220. quiz 219-220. doi:10.1111/j.1440-0960.2005.00187.x

Lembo, P. M., Grazzini, E., Groblewski, T., O'Donnell, D., Roy, M. O., Zhang, J., et al. (2002). Proenkephalin A Gene Products Activate a New Family of Sensory Neuron--specific GPCRs. Nat. Neurosci. 5, 201-209. doi:10.1038/nn815

Leonard, A., and Guttman-Yassky, E. (2019). The Unique Molecular Signatures of Contact Dermatitis and Implications for Treatment. Clin. Rev. Allergy Immunol. 56, 1-8. doi:10.1007/s12016-018-8685-0
Liang, J., Ji, Q., and Ji, W. (2011). Role of Transient Receptor Potential Ankyrin Subfamily Member 1 in Pruritus Induced by Endothelin-1. Neurosci. Lett. 492, 175-178. doi:10.1016/j.neulet.2011.02.009

Liao, J. J., Huang, M. C., and Goetzl, E. J. (2007). Cutting Edge: Alternative Signaling of Th17 Cell Development by Sphingosine 1-phosphate. J. Immunol. 178, 5425-5428. doi:10.4049/jimmunol.178.9.5425

Lieu, T., Jayaweera, G., Zhao, P., Poole, D. P., Jensen, D., Grace, M., et al. (2014). The Bile Acid Receptor TGR5 Activates the TRPA1 Channel to Induce Itch in Mice. Gastroenterology 147, 1417-1428. doi:10.1053/j.gastro.2014.08.042

Lin, Z., Chen, Q., Lee, M., Cao, X., Zhang, J., Ma, D., et al. (2012). Exome Sequencing Reveals Mutations in TRPV3 as a Cause of Olmsted Syndrome. Am. J. Hum. Genet. 90, 558-564. doi:10.1016/j.ajhg.2012.02.006

Lisby, S., and Baadsgaard, O. (2006). "Mechanisms of Irritant Contact Dermatitis," in Contact Dermatitis. Editors P. J. Frosch, T. Menné, and J.-P. Lepoittevin (Berlin, Heidelberg: Springer), 69-82. doi:10.1007/3-540-31301-X_4

Liu, B., Escalera, J., Balakrishna, S., Fan, L., Caceres, A. I., Robinson, E., et al. (2013). TRPA1 Controls Inflammation and Pruritogen Responses in Allergic Contact Dermatitis. FASEB J. 27, 3549-3563. doi:10.1096/fj.13-229948

Liu, B., Tai, Y., Achanta, S., Kaelberer, M. M., Caceres, A. I., Shao, X., et al. (2016). IL-33/ST2 Signaling Excites Sensory Neurons and Mediates Itch Response in a Mouse Model of Poison Ivy Contact Allergy. Proc. Natl. Acad. Sci. U S A. 113, E7572-E7579. doi:10.1073/pnas.1606608113

Liu, B., Tai, Y., Liu, B., Caceres, A. I., Yin, C., and Jordt, S. E. (2019). Transcriptome Profiling Reveals Th2 Bias and Identifies Endogenous Itch Mediators in Poison Ivy Contact Dermatitis. JCI Insight 5, 124497. doi:10.1172/jci.insight.124497

Liu, Q., and Dong, X. (2015). The Role of the Mrgpr Receptor Family in Itch. Handb Exp. Pharmacol. 226, 71-88. doi:10.1007/978-3-662-44605-8_5

Liu, Q., Sikand, P., Ma, C., Tang, Z., Han, L., Li, Z., et al. (2012a). Mechanisms of Itch Evoked by $\beta$-alanine. J. Neurosci. 32, 14532-14537. doi:10.1523/ JNEUROSCI.3509-12.2012

Liu, Q., Tang, Z., Surdenikova, L., Kim, S., Patel, K. N., Kim, A., et al. (2009). Sensory Neuron-specific GPCR Mrgprs Are Itch Receptors Mediating Chloroquine-Induced Pruritus. Cell 139, 1353-1365. doi:10.1016/j.cell.2009. 11.034

Liu, Q., Weng, H. J., Patel, K. N., Tang, Z., Bai, H., Steinhoff, M., et al. (2011). The Distinct Roles of Two GPCRs, MrgprC11 and PAR2, in Itch and Hyperalgesia. Sci. Signal. 4, ra45. doi:10.1126/scisignal.2001925

Liu, T., Berta, T., Xu, Z. Z., Park, C. K., Zhang, L., Lü, N., et al. (2012b). TLR3 Deficiency Impairs Spinal Cord Synaptic Transmission, central Sensitization, and Pruritus in Mice. J. Clin. Invest. 122, 2195-2207. doi:10.1172/JCI45414

Liu, T., Xu, Z. Z., Park, C. K., Berta, T., and Ji, R. R. (2010). Toll-like Receptor 7 Mediates Pruritus. Nat. Neurosci. 13, 1460-1462. doi:10.1038/nn.2683

Lundeberg, L., El-Nour, H., Mohabbati, S., Morales, M., Azmitia, E., and Nordlind, K. (2002). Expression of Serotonin Receptors in Allergic Contact Eczematous Human Skin. Arch. Dermatol. Res. 294, 393-398. doi:10.1007/s00403-0020350-y

Luo, J., Feng, J., Yu, G., Yang, P., Mack, M. R., Du, J., et al. (2018). Transient Receptor Potential Vanilloid 4-expressing Macrophages and Keratinocytes Contribute Differentially to Allergic and Nonallergic Chronic Itch. J. Allergy Clin. Immunol. 141, 608-e7. e7. doi:10.1016/j.jaci.2017.05.051

Mack, M. R., and Kim, B. S. (2018). The Itch-Scratch Cycle: A Neuroimmune Perspective. Trends Immunol. 39, 980-991. doi:10.1016/j.it.2018.10.001

Malek, M., Gleń, J., Rębała, K., Kowalczyk, A., Sobjanek, M., Nowicki, R., et al. (2015). Il-31 Does Not Correlate to Pruritus Related to Early Stage Cutaneous T-Cell Lymphomas but Is Involved in Pathogenesis of the Disease. Acta Derm Venereol. 95, 283-288. doi:10.2340/00015555-1958

Malik, K., Ungar, B., Garcet, S., Dutt, R., Dickstein, D., Zheng, X., et al. (2017). Dust Mite Induces Multiple Polar T Cell Axes in Human Skin. Clin. Exp. Allergy 47, 1648-1660. doi:10.1111/cea.13040

Mandadi, S., Sokabe, T., Shibasaki, K., Katanosaka, K., Mizuno, A., Moqrich, A., et al. (2009). TRPV3 in Keratinocytes Transmits Temperature Information to Sensory Neurons via ATP. Pflugers Arch. 458, 1093-1102. doi:10.1007/s00424009-0703-x

Masuoka, M., Shiraishi, H., Ohta, S., Suzuki, S., Arima, K., Aoki, S., et al. (2012). Periostin Promotes Chronic Allergic Inflammation in Response to Th2 Cytokines. J. Clin. Invest. 122, 2590-2600. doi:10.1172/JCI58978

Matterne, U., Böhmer, M. M., Weisshaar, E., Jupiter, A., Carter, B., and Apfelbacher, C. J. (2019). Oral H1 Antihistamines as 'add-On' Therapy to 
Topical Treatment for Eczema. Cochrane Database Syst. Rev. 1, CD012167. doi:10.1002/14651858.CD012167.pub2

McQueen, D. S., Noble, M. A., and Bond, S. M. (2007). Endothelin-1 Activates ETA Receptors to Cause Reflex Scratching in BALB/c Mice. Br. J. Pharmacol. 151, 278-284. doi:10.1038/sj.bjp.0707216

Meixiong, J., Anderson, M., Limjunyawong, N., Sabbagh, M. F., Hu, E., Mack, M. R., et al. (2019a). Activation of Mast-Cell-Expressed Mas-Related G-ProteinCoupled Receptors Drives Non-histaminergic Itch. Immunity 50, 1163-e5. e5. doi:10.1016/j.immuni.2019.03.013

Meixiong, J., Vasavda, C., Snyder, S. H., and Dong, X. (2019b). MRGPRX4 Is a G Protein-Coupled Receptor Activated by Bile Acids that May Contribute to Cholestatic Pruritus. Proc. Natl. Acad. Sci. U S A. 116, 10525-10530. doi:10. 1073/pnas.1903316116

Mettang, T., and Kremer, A. E. (2015). Uremic Pruritus. Kidney Int. 87, 685-691. doi:10.1038/ki.2013.454

Mettang, T., Pauli-Magnus, C., and Alscher, D. M. (2002). Uraemic Pruritus-Nnew Perspectives and Insights from Recent Trials. Nephrol. Dial. Transpl. 17, 1558-1563. doi:10.1093/ndt/17.9.1558

Mihara, H., Boudaka, A., Sugiyama, T., Moriyama, Y., and Tominaga, M. (2011). Transient Receptor Potential Vanilloid 4 (TRPV4)-dependent Calcium Influx and ATP Release in Mouse Oesophageal Keratinocytes. J. Physiol. 589, 3471-3482. doi:10.1113/jphysiol.2011.207829

Mishra, S. K., and Hoon, M. A. (2013). The Cells and Circuitry for Itch Responses in Mice. Science 340, 968-971. doi:10.1126/science.1233765

Mishra, S. K., Tisel, S. M., Orestes, P., Bhangoo, S. K., and Hoon, M. A. (2011). TRPV1-lineage Neurons Are Required for thermal Sensation. EMBO J. 30, 582-593. doi:10.1038/emboj.2010.325

Mishra, S. K., Wheeler, J. J., Pitake, S., Ding, H., Jiang, C., Fukuyama, T., et al. (2020). Periostin Activation of Integrin Receptors on Sensory Neurons Induces Allergic Itch. Cell Rep 31, 107472. doi:10.1016/j.celrep.2020.03.036

Möbs, M., Gryzik, S., Haidar, A., Humme, D., Beyer, M., and Vandersee, S. (2015). Analysis of the IL-31 Pathway in Mycosis Fungoides and Sézary Syndrome. Arch. Dermatol. Res. 307, 479-485. doi:10.1007/s00403-014-1527-x

Moore, C., Cevikbas, F., Pasolli, H. A., Chen, Y., Kong, W., Kempkes, C., et al. (2013). UVB Radiation Generates Sunburn Pain and Affects Skin by Activating Epidermal TRPV4 Ion Channels and Triggering Endothelin-1 Signaling. Proc. Natl. Acad. Sci. U S A. 110, E3225-E3234. doi:10.1073/pnas.1312933110

Moore, C., Gupta, R., Jordt, S. E., Chen, Y., and Liedtke, W. B. (2018). Regulation of Pain and Itch by TRP Channels. Neurosci. Bull. 34, 120-142. doi:10.1007/ s12264-017-0200-8

Morita, T., McClain, S. P., Batia, L. M., Pellegrino, M., Wilson, S. R., Kienzler, M. A., et al. (2015). HTR7 Mediates Serotonergic Acute and Chronic Itch. Neuron 87, 124-138. doi:10.1016/j.neuron.2015.05.044

Moussion, C., Ortega, N., and Girard, J. P. (2008). The IL-1-like Cytokine IL-33 Is Constitutively Expressed in the Nucleus of Endothelial Cells and Epithelial Cells In Vivo: a Novel 'alarmin'? PLoS One 3, e3331. doi:10.1371/journal.pone.0003331

Mullins, T. B., Sharma, P., Riley, C. A., and Sonthalia, S. (2021). "Prurigo Nodularis," in StatPearls (Treasure Island (FL): StatPearls Publishing). Available at: http://www.ncbi.nlm.nih.gov/books/NBK459204/(Accessed April 12, 2021).

Myśliwiec, H., Baran, A., Harasim-Symbor, E., Choromańska, B., Myśliwiec, P., Milewska, A. J., et al. (2017). Increase in Circulating Sphingosine-1-Phosphate and Decrease in Ceramide Levels in Psoriatic Patients. Arch. Dermatol. Res. 309, 79-86. doi:10.1007/s00403-016-1709-9

Nakahara, T., Kido-Nakahara, M., Tsuji, G., and Furue, M. (2021). Basics and Recent Advances in the Pathophysiology of Atopic Dermatitis. J. Dermatol. 48, 130-139. doi:10.1111/1346-8138.15664

Nakamura, M., Toyoda, M., and Morohashi, M. (2003). Pruritogenic Mediators in Psoriasis Vulgaris: Comparative Evaluation of Itch-Associated Cutaneous Factors. Br. J. Dermatol. 149, 718-730. doi:10.1046/j.1365-2133.2003.05586.x

Namer, B., Carr, R., Johanek, L. M., Schmelz, M., Handwerker, H. O., and Ringkamp, M. (2008). Separate Peripheral Pathways for Pruritus in Man. J. Neurophysiol. 100, 2062-2069. doi:10.1152/jn.90482.2008

Narbutt, J., Olejniczak, I., Sobolewska-Sztychny, D., Sysa-Jedrzejowska, A., SłowikKwiatkowska, I., Hawro, T., et al. (2013). Narrow Band Ultraviolet B Irradiations Cause Alteration in Interleukin-31 Serum Level in Psoriatic Patients. Arch. Dermatol. Res. 305, 191-195. doi:10.1007/s00403-012-1293-6
Narita, I., Alchi, B., Omori, K., Sato, F., Ajiro, J., Saga, D., et al. (2006). Etiology and Prognostic Significance of Severe Uremic Pruritus in Chronic Hemodialysis Patients. Kidney Int. 69, 1626-1632. doi:10.1038/sj.ki.5000251

Nattkemper, L. A., Martinez-Escala, M. E., Gelman, A. B., Singer, E. M., Rook, A. H., Guitart, J., et al. (2016). Cutaneous T-Cell Lymphoma and Pruritus: The Expression of IL-31 and its Receptors in the Skin. Acta Derm Venereol. 96, 894-898. doi:10.2340/00015555-2417

Nattkemper, L. A., Tey, H. L., Valdes-Rodriguez, R., Lee, H., Mollanazar, N. K., Albornoz, C., et al. (2018). The Genetics of Chronic Itch: Gene Expression in the Skin of Patients with Atopic Dermatitis and Psoriasis with Severe Itch. J. Invest. Dermatol. 138, 1311-1317. doi:10.1016/j.jid.2017.12.029

Nattkemper, L. A., Zhao, Z. Q., Nichols, A. J., Papoiu, A. D. P., Shively, C. A., Chen, Z. F., et al. (2013). Overexpression of the Gastrin-Releasing Peptide in Cutaneous Nerve Fibers and its Receptor in the Spinal Cord in Primates with Chronic Itch. J. Invest. Dermatol. 133, 2489-2492. doi:10.1038/jid. 2013.166

Naukkarinen, A., Harvima, I. T., Aalto, M. L., Harvima, R. J., and Horsmanheimo, M. (1991). Quantitative Analysis of Contact Sites between Mast Cells and Sensory Nerves in Cutaneous Psoriasis and Lichen Planus Based on a Histochemical Double Staining Technique. Arch. Dermatol. Res. 283, 433-437. doi:10.1007/BF00371778

Nguyen, K. D., Sundaram, V., and Ayoub, W. S. (2014). Atypical Causes of Cholestasis. World J. Gastroenterol. 20, 9418-9426. doi:10.3748/wjg.v20.i28. 9418

Nguyen, M. Q., von Buchholtz, L. J., Reker, A. N., Ryba, N. J., and Davidson, S. (2021). Single-nucleus Transcriptomic Analysis of Human Dorsal Root Ganglion Neurons. eLife 10, e71752. doi:10.7554/eLife.71752

Nieto-Posadas, A., Picazo-Juárez, G., Llorente, I., Jara-Oseguera, A., MoralesLázaro, S., Escalante-Alcalde, D., et al. (2011). Lysophosphatidic Acid Directly Activates TRPV1 through a C-Terminal Binding Site. Nat. Chem. Biol. 8, 78-85. doi: $10.1038 /$ nchembio.712

Niyonsaba, F., Ushio, H., Hara, M., Yokoi, H., Tominaga, M., Takamori, K., et al. (2010). Antimicrobial Peptides Human Beta-Defensins and Cathelicidin LL-37 Induce the Secretion of a Pruritogenic Cytokine IL-31 by Human Mast Cells. J. Immunol. 184, 3526-3534. doi:10.4049/jimmunol.0900712

Oetjen, L. K., Mack, M. R., Feng, J., Whelan, T. M., Niu, H., Guo, C. J., et al. (2017). Sensory Neurons Co-opt Classical Immune Signaling Pathways to Mediate Chronic Itch. Cell 171, 217-e13. e13. doi:10.1016/j.cell.2017.08.006

Ohmatsu, H., Sugaya, M., Suga, H., Morimura, S., Miyagaki, T., Kai, H., et al. (2012). Serum IL-31 Levels Are Increased in Patients with Cutaneous T-Cell Lymphoma. Acta Derm Venereol. 92, 282-283. doi:10.2340/00015555-1345

Ohta, T., Ikemi, Y., Murakami, M., Imagawa, T., Otsuguro, K., and Ito, S. (2006). Potentiation of Transient Receptor Potential V1 Functions by the Activation of Metabotropic 5-HT Receptors in Rat Primary Sensory Neurons. J. Physiol. 576, 809-822. doi:10.1113/jphysiol.2006.112250

Onderdijk, A. J., Hekking-Weijma, I. M., Florencia, E. F., and Prens, E. P. (2017). Surgical Denervation in the Imiquimod-Induced Psoriasiform Mouse Model. Methods Mol. Biol. 1559, 75-81. doi:10.1007/978-1-4939-6786-5_6

Panula, P., Chazot, P. L., Cowart, M., Gutzmer, R., Leurs, R., Liu, W. L., et al. (2015). International Union of Basic and Clinical Pharmacology. XCVIII. Histamine Receptors. Pharmacol. Rev. 67, 601-655. doi:10.1124/pr.114.010249

Park, C. W., Kim, H. J., Choi, Y. W., Chung, B. Y., Woo, S. Y., Song, D. K., et al. (2017). TRPV3 Channel in Keratinocytes in Scars with Post-Burn Pruritus. Int. J. Mol. Sci. 18. doi:10.3390/ijms18112425

Pauli-Magnus, C., Klumpp, S., Alscher, D. M., Kuhlmann, U., and Mettang, T. (2000). Short-term Efficacy of Tacrolimus Ointment in Severe Uremic Pruritus. Perit Dial. Int. 20, 802-803.

Paus, R., Schmelz, M., Bíró, T., and Steinhoff, M. (2006). Frontiers in Pruritus Research: Scratching the Brain for More Effective Itch Therapy. J. Clin. Invest. 116, 1174-1186. doi:10.1172/JCI28553

Pavlovic, S., Daniltchenko, M., Tobin, D. J., Hagen, E., Hunt, S. P., Klapp, B. F., et al. (2008). Further Exploring the Brain-Skin Connection: Stress Worsens Dermatitis via Substance P-dependent Neurogenic Inflammation in Mice. J. Invest. Dermatol. 128, 434-446. doi:10.1038/sj.jid.5701079

Peier, A. M., Reeve, A. J., Andersson, D. A., Moqrich, A., Earley, T. J., Hergarden, A. C., et al. (2002). A Heat-Sensitive TRP Channel Expressed in Keratinocytes. Science 296, 2046-2049. doi:10.1126/science. 1073140 
Pereira, M., Zeidler, C., Wallengren, J., Halvorsen, J., Weisshaar, E., Garcovich, S., et al. (2021). Chronic Nodular Prurigo: A European Cross-Sectional Study of Patient Perspectives on Therapeutic Goals and Satisfaction. Acta Derm Venereol. 101, adv00403. doi:10.2340/00015555-3726

Pergolizzi, S., Vaccaro, M., Magaudda, L., Mondello, M. R., Arco, A., Bramanti, P., et al. (1998). Immunohistochemical Study of Epidermal Nerve Fibres in Involved and Uninvolved Psoriatic Skin Using Confocal Laser Scanning Microscopy. Arch. Dermatol. Res. 290, 483-489. doi:10.1007/s004030050340

Perner, C., Flayer, C. H., Zhu, X., Aderhold, P. A., Dewan, Z. N. A., Voisin, T., et al. (2020). Substance P Release by Sensory Neurons Triggers Dendritic Cell Migration and Initiates the Type-2 Immune Response to Allergens. Immunity 53, 1063-e7. e7. doi:10.1016/j.immuni.2020.10.001

Petra, A. I., Tsilioni, I., Taracanova, A., Katsarou-Katsari, A., and Theoharides, T. C. (2018). Interleukin 33 and Interleukin 4 Regulate Interleukin 31 Gene Expression and Secretion from Human Laboratory of Allergic Diseases 2 Mast Cells Stimulated by Substance P And/or Immunoglobulin E. Allergy Asthma Proc. 39, 153-160. doi:10.2500/aap.2018.38.4105

Pincelli, C. (2000). Nerve Growth Factor and Keratinocytes: a Role in Psoriasis. Eur. J. Dermatol. 10, 85-90.

Pisoni, R. L., Wikström, B., Elder, S. J., Akizawa, T., Asano, Y., Keen, M. L., et al. (2006). Pruritus in Haemodialysis Patients: International Results from the Dialysis Outcomes and Practice Patterns Study (DOPPS). Nephrol. Dial. Transpl. 21, 3495-3505. doi:10.1093/ndt/gfl461

Plant, T. D., Zöllner, C., Kepura, F., Mousa, S. S., Eichhorst, J., Schaefer, M., et al. (2007). Endothelin Potentiates TRPV1 via ETA Receptor-Mediated Activation of Protein Kinase C. Mol. Pain 3, 35. doi:10.1186/1744-8069-3-35

Priestley, J. V. (2009). "Neuropeptides: Sensory Systems," in Encyclopedia of Neuroscience. Editor L. R. Squire (Oxford: Academic Press), 935-943. doi:10.1016/B978-008045046-9.01465-0

Proksch, E., Brandner, J. M., and Jensen, J. M. (2008). The Skin: an Indispensable Barrier. Exp. Dermatol. 17, 1063-1072. doi:10.1111/j.1600-0625.2008.00786.x

Provitera, V., Nolano, M., Pappone, N., di Girolamo, C., Stancanelli, A., Lullo, F., et al. (2005). Distal Degeneration of Sensory and Autonomic Cutaneous Nerve Fibres in Systemic Sclerosis. Ann. Rheum. Dis. 64, 1524-1526. doi:10.1136/ard. 2005.038935

Qin, B., Sun, C., Chen, L., Wang, S., Yang, J., Xie, Z., et al. (2021). The Nerve Injuries Attenuate the Persistence of Psoriatic Lesions. J. Dermatol. Sci. 102, 85-93. doi:10.1016/j.jdermsci.2021.02.006

Qu, L., Fu, K., Shimada, S. G., and LaMotte, R. H. (2017). Cl- Channel Is Required for CXCL10-Induced Neuronal Activation and Itch Response in a Murine Model of Allergic Contact Dermatitis. J. Neurophysiol. 118, 619-624. doi:10. $1152 /$ jn.00187.2017

Qu, L., Fu, K., Yang, J., Shimada, S. G., and LaMotte, R. H. (2015). CXCR3 Chemokine Receptor Signaling Mediates Itch in Experimental Allergic Contact Dermatitis. PAIN 156, 1737-1746. doi:10.1097/j.pain.0000000000000208

Raychaudhuri, S. P., and Farber, E. M. (1993). Are Sensory Nerves Essential for the Development of Psoriatic Lesions? J. Am. Acad. Dermatol. 28, 488-489. doi:10. 1016/s0190-9622(08)81760-4

Razykov, I., Levis, B., Hudson, M., Baron, M., and Thombs, B. D.Canadian Scleroderma Research Group (2013). Prevalence and Clinical Correlates of Pruritus in Patients with Systemic Sclerosis: an Updated Analysis of 959 Patients. Rheumatology (Oxford) 52, 2056-2061. doi:10.1093/rheumatology/ket275

Reich, A., Orda, A., Wiśnicka, B., and Szepietowski, J. C. (2007). Plasma Neuropeptides and Perception of Pruritus in Psoriasis. Acta Derm Venereol. 87, 299-304. doi:10.2340/00015555-0265

Rendon, A., and Schäkel, K. (2019). Psoriasis Pathogenesis and Treatment. Int. J. Mol. Sci. 20. doi:10.3390/ijms 20061475

Ringkamp, M., Schepers, R. J., Shimada, S. G., Johanek, L. M., Hartke, T. V., Borzan, J., et al. (2011). A Role for Nociceptive, Myelinated Nerve Fibers in Itch Sensation. J. Neurosci. 31, 14841-14849. doi:10.1523/JNEUROSCI.3005-11. 2011

Rossbach, K., Nassenstein, C., Gschwandtner, M., Schnell, D., Sander, K., Seifert, R., et al. (2011). Histamine H1, H3 and H4 Receptors Are Involved in Pruritus. Neuroscience 190, 89-102. doi:10.1016/j.neuroscience.2011.06.002

Ru, F., Sun, H., Jurcakova, D., Herbstsomer, R. A., Meixong, J., Dong, X., et al. (2017). Mechanisms of Pruritogen-Induced Activation of Itch Nerves in Isolated Mouse Skin. J. Physiol. 595, 3651-3666. doi:10.1113/JP273795
Rustemeyer, T., van Hoogstraten, I. M. W., von Blomberg, B. M. E., and Scheper, R. J. (2006). "Mechanisms in Allergic Contact Dermatitis," in Contact Dermatitis. Editors P. J. Frosch, T. Menné, and J.-P. Lepoittevin (Berlin, Heidelberg: Springer), 11-43. doi:10.1007/3-540-31301-X_2

Ruzicka, T., Hanifin, J. M., Furue, M., Pulka, G., Mlynarczyk, I., Wollenberg, A., et al. (2017). Anti-Interleukin-31 Receptor A Antibody for Atopic Dermatitis. N. Engl. J. Med. 376, 826-835. doi:10.1056/NEJMoa1606490

Sandoval-Talamantes, A. K., Gómez-González, B. A., Uriarte-Mayorga, D. F., Martínez-Guzman, M. A., Wheber-Hidalgo, K. A., and Alvarado-Navarro, A. (2020). Neurotransmitters, Neuropeptides and Their Receptors Interact with Immune Response in Healthy and Psoriatic Skin. Neuropeptides 79, 102004. doi:10.1016/j.npep.2019.102004

Sanjel, B., Maeng, H. J., and Shim, W. S. (2019). BAM8-22 and its Receptor MRGPRX1 May Attribute to Cholestatic Pruritus. Sci. Rep. 9, 10888. doi:10. 1038/s41598-019-47267-5

Saraceno, R., Kleyn, C. E., Terenghi, G., and Griffiths, C. E. (2006). The Role of Neuropeptides in Psoriasis. Br. J. Dermatol. 155, 876-882. doi:10.1111/j.13652133.2006.07518.x

Schaper, K., Rossbach, K., Köther, B., Stark, H., Kietzmann, M., Werfel, T., et al. (2016). Stimulation of the Histamine 4 Receptor Upregulates Thymic Stromal Lymphopoietin (TSLP) in Human and Murine Keratinocytes. Pharmacol. Res. 113, 209-215. doi:10.1016/j.phrs.2016.08.001

Schmelz, M., Michael, K., Weidner, C., Schmidt, R., Torebjörk, H. E., and Handwerker, H. O. (2000). Which Nerve Fibers Mediate the Axon Reflex Flare in Human Skin? Neuroreport 11, 645-648. doi:10.1097/00001756200002280-00041

Schmelz, M. (2015). Neurophysiology and Itch Pathways. Handb Exp. Pharmacol. 226, 39-55. doi:10.1007/978-3-662-44605-8_3

Schmelz, M., Schmidt, R., Bickel, A., Handwerker, H. O., and Torebjörk, H. E. (1997). Specific C-Receptors for Itch in Human Skin. J. Neurosci. 17, 8003-8008. doi:10.1523/jneurosci.17-20-08003.1997

Schmelz, M., and Schmidt, R. (2010). Microneurographic Single-Unit Recordings to Assess Receptive Properties of Afferent Human C-Fibers. Neurosci. Lett. 470, 158-161. doi:10.1016/j.neulet.2009.05.064

Schmelz, M., Schmidt, R., Weidner, C., Hilliges, M., Torebjork, H. E., and Handwerker, H. O. (2003). Chemical Response Pattern of Different Classes of C-Nociceptors to Pruritogens and Algogens. J. Neurophysiol. 89, 2441-2448. doi: $10.1152 /$ jn.01139.2002

Schmidt, R., Schmelz, M., Forster, C., Ringkamp, M., Torebjörk, E., and Handwerker, H. (1995). Novel Classes of Responsive and Unresponsive C Nociceptors in Human Skin. J. Neurosci. 15, 333-341. doi:10.1523/jneurosci.15-01-00333.1995

Schmidt, R., Schmelz, M., Ringkamp, M., Handwerker, H. O., and Torebjörk, H. E. (1997). Innervation Territories of Mechanically Activated C Nociceptor Units in Human Skin. J. Neurophysiol. 78, 2641-2648. doi:10.1152/jn.1997.78.5.2641

Schmidt, R., Schmelz, M., Weidner, C., Handwerker, H. O., and Torebjörk, H. E. (2002). Innervation Territories of Mechano-Insensitive C Nociceptors in Human Skin. J. Neurophysiol. 88, 1859-1866. doi:10.1152/jn.2002.88.4.1859

Seo, S. H., Kim, S., Kim, S. E., Chung, S., and Lee, S. E. (2020). Enhanced Thermal Sensitivity of TRPV3 in Keratinocytes Underlies Heat-Induced Pruritogen Release and Pruritus in Atopic Dermatitis. J. Invest. Dermatol. 140, 2199-e6. e6. doi:10.1016/j.jid.2020.02.028

Serhan, N., Basso, L., Sibilano, R., Petitfils, C., Meixiong, J., Bonnart, C., et al. (2019). House Dust Mites Activate Nociceptor-Mast Cell Clusters to Drive Type 2 Skin Inflammation. Nat. Immunol. 20, 1435-1443. doi:10.1038/s41590-019-0493-z

Shim, W. S., and Oh, U. (2008). Histamine-induced Itch and its Relationship with Pain. Mol. Pain 4, 29. doi:10.1186/1744-8069-4-29

Shimada, S. G., and LaMotte, R. H. (2008). Behavioral Differentiation between Itch and Pain in Mouse. Pain 139, 681-687. doi:10.1016/j.pain.2008.08.002

Shirani, Z., Kucenic, M. J., Carroll, C. L., Fleischer, A. B., Feldman, S. R., Yosipovitch, G., et al. (2004). Pruritus in Adult Dermatomyositis. Clin. Exp. Dermatol. 29, 273-276. doi:10.1111/j.1365-2230.2004.01510.x

Shirazian, S., Kline, M., Sakhiya, V., Schanler, M., Moledina, D., Patel, C., et al. (2013). Longitudinal Predictors of Uremic Pruritus. J. Ren. Nutr. 23, 428-431. doi:10.1053/j.jn.2013.08.002

Shouman, K., and Benarroch, E. E. (2021). Peripheral Neuroimmune Interactions: Selected Review and Some Clinical Implications. Clin. Auton. Res. 31, 477-489. doi:10.1007/s10286-021-00787-5 
Sikand, P., Dong, X., and LaMotte, R. H. (2011). BAM8-22 Peptide Produces Itch and Nociceptive Sensations in Humans Independent of Histamine Release. J. Neurosci. 31, 7563-7567. doi:10.1523/JNEUROSCI.1192-11.2011

Silva, S. R., Viana, P. C., Lugon, N. V., Hoette, M., Ruzany, F., and Lugon, J. R. (1994). Thalidomide for the Treatment of Uremic Pruritus: a Crossover Randomized Double-Blind Trial. Nephron 67, 270-273. doi:10.1159/000187978

Singh, L. K., Pang, X., Alexacos, N., Letourneau, R., and Theoharides, T. C. (1999). Acute Immobilization Stress Triggers Skin Mast Cell Degranulation via Corticotropin Releasing Hormone, Neurotensin, and Substance P: A Link to Neurogenic Skin Disorders. Brain Behav. Immun. 13, 225-239. doi:10.1006/brbi.1998.0541

Slominski, A., Pisarchik, A., Zbytek, B., Tobin, D. J., Kauser, S., and Wortsman, J. (2003). Functional Activity of Serotoninergic and Melatoninergic Systems Expressed in the Skin. J. Cell Physiol 196, 144-153. doi:10.1002/jcp.10287

Slominski, A. T. (2015). On the Role of the Endogenous Opioid System in Regulating Epidermal Homeostasis. J. Invest. Dermatol. 135, 333-334. doi:10.1038/jid.2014.458

Soeberdt, M., Kilic, A., and Abels, C. (2020). Small Molecule Drugs for the Treatment of Pruritus in Patients with Atopic Dermatitis. Eur. J. Pharmacol. 881, 173242. doi:10.1016/j.ejphar.2020.173242

Sokabe, T., Fukumi-Tominaga, T., Yonemura, S., Mizuno, A., and Tominaga, M. (2010). The TRPV4 Channel Contributes to Intercellular junction Formation in Keratinocytes. J. Biol. Chem. 285, 18749-18758. doi:10.1074/jbc.M110.103606

Song, J. S., Tawa, M., Chau, N. G., Kupper, T. S., and LeBoeuf, N. R. (2017). Aprepitant for Refractory Cutaneous T-Cell Lymphoma-Associated Pruritus: 4 Cases and a Review of the Literature. BMC Cancer 17, 200. doi:10.1186/s12885-017-3194-8

Sonkoly, E., Muller, A., Lauerma, A. I., Pivarcsi, A., Soto, H., Kemeny, L., et al. (2006). IL-31: a New Link between T Cells and Pruritus in Atopic Skin Inflammation. J. Allergy Clin. Immunol. 117, 411-417. doi:10.1016/j.jaci.2005.10.033

Ständer, S., Weisshaar, E., Mettang, T., Szepietowski, J. C., Carstens, E., Ikoma, A., et al. (2007). Clinical Classification of Itch: a Position Paper of the International Forum for the Study of Itch. Acta Derm Venereol. 87, 291-294. doi:10.2340/00015555-0305

Ständer, S., Siepmann, D., Herrgott, I., Sunderkötter, C., and Luger, T. A. (2010). Targeting the Neurokinin Receptor 1 with Aprepitant: A Novel Antipruritic Strategy. PLOS ONE 5, e10968. doi:10.1371/journal.pone.0010968

Steck, O., Bertschi, N. L., Luther, F., Berg, J., Winkel, D. J., Holbro, A., et al. (2020). Rapid and Sustained Control of Itch and Reduction in Th2 Bias by Dupilumab in a Patient with Sézary Syndrome. J. Eur. Acad. Dermatol. Venereol. 35, 1331-1337. doi:10.1111/jdv.17001

Steinhoff, M., Bienenstock, J., Schmelz, M., Maurer, M., Wei, E., and Bíró, T. (2006). Neurophysiological, Neuroimmunological, and Neuroendocrine Basis of Pruritus. J. Invest. Dermatol. 126, 1705-1718. doi:10.1038/sj.jid.5700231

Storan, E. R., O'Gorman, S. M., McDonald, I. D., and Steinhoff, M. (2015). Role of Cytokines and Chemokines in Itch. Handb Exp. Pharmacol. 226, 163-176. doi:10.1007/978-3-662-44605-8 9

Strober, B., Sigurgeirsson, B., Popp, G., Sinclair, R., Krell, J., Stonkus, S., et al. (2016). Secukinumab Improves Patient-Reported Psoriasis Symptoms of Itching, Pain, and Scaling: Results of Two Phase 3, Randomized, PlaceboControlled Clinical Trials. Int. J. Dermatol. 55, 401-407. doi:10.1111/ijd.13236

Sun, S., Xu, Q., Guo, C., Guan, Y., Liu, Q., and Dong, X. (2017). Leaky Gate Model: Intensity-dependent Coding of Pain and Itch in the Spinal Cord. Neuron 93, 840-e5. e5. doi:10.1016/j.neuron.2017.01.012

Sun, Y. G., and Chen, Z. F. (2007). A Gastrin-Releasing Peptide Receptor Mediates the Itch Sensation in the Spinal Cord. Nature 448, 700-703. doi:10.1038/ nature 06029

Suwarsa, O., Dharmadji, H. P., Sutedja, E., Herlina, L., Sori, P. R., Hindritiani, R., et al. (2019). Skin Tissue Expression and Serum Level of Thymic Stromal Lymphopoietin in Patients with Psoriasis Vulgaris. Dermatol. Rep. 11, 8006. doi:10.4081/dr.2019.8006

Szántó, M., Oláh, A., Szöllősi, A. G., Tóth, K. F., Páyer, E., Czakó, N., et al. (2019). Activation of TRPV3 Inhibits Lipogenesis and Stimulates Production of Inflammatory Mediators in Human Sebocytes-A Putative Contributor to Dry Skin Dermatoses. J. Invest. Dermatol. 139, 250-253. doi:10.1016/j.jid.2018.07.015

Szepietowski, J. C., and Reich, A. (2016). Pruritus in Psoriasis: An Update. Eur. J. Pain 20, 41-46. doi:10.1002/ejp.768

Szolcsányi, J., Pintér, E., Helyes, Z., Oroszi, G., and Németh, J. (1998). Systemic Anti-inflammatory Effect Induced by Counter-irritation through a Local Release of Somatostatin from Nociceptors. Br. J. Pharmacol. 125, 916-922. doi:10.1038/sj.bjp.0702144
Szöllösi, A. G., McDonald, I., Szabó, I. L., Meng, J., van den Bogaard, E., and Steinhoff, M. (2019). TLR3 in Chronic Human Itch: A Keratinocyte-Associated Mechanism of Peripheral Itch Sensitization. J. Invest. Dermatol. 139, 2393-2396. e6. doi:10.1016/j.jid.2019.04.018

Szöllösi, A. G., Vasas, N., Angyal, Á., Kistamás, K., Nánási, P. P., Mihály, J., et al. (2018). Activation of TRPV3 Regulates Inflammatory Actions of Human Epidermal Keratinocytes. J. Invest. Dermatol. 138, 365-374. doi:10.1016/j.jid. 2017.07.852

Takayama, Y., Derouiche, S., Maruyama, K., and Tominaga, M. (2019). Emerging Perspectives on Pain Management by Modulation of TRP Channels and ANO1. Int. J. Mol. Sci. 20. doi:10.3390/ijms20143411

Takayama, Y., Shibasaki, K., Suzuki, Y., Yamanaka, A., and Tominaga, M. (2014). Modulation of Water Efflux through Functional Interaction between TRPV4 and TMEM16A/anoctamin 1. FASEB J. 28, 2238-2248. doi:10.1096/fj.13243436

Takayama, Y., Uta, D., Furue, H., and Tominaga, M. (2015). Pain-enhancing Mechanism through Interaction between TRPV1 and Anoctamin 1 in Sensory Neurons. Proc. Natl. Acad. Sci. U S A. 112, 5213-5218. doi:10.1073/pnas. 1421507112

Taves, S., and Ji, R. R. (2015). Itch Control by Toll-like Receptors. Handb Exp. Pharmacol. 226, 135-150. doi:10.1007/978-3-662-44605-8_7

Tey, H. L., and Yosipovitch, G. (2011). Targeted Treatment of Pruritus: a Look into the Future. Br. J. Dermatol. 165, 5-17. doi:10.1111/j.1365-2133.2011.10217.x

Théréné, C., Brenaut, E., Sonbol, H., Pasquier, E., Saraux, A., Devauchelle, V., et al. (2017). Itch and Systemic Sclerosis: Frequency, Clinical Characteristics and Consequences. Br. J. Dermatol. 176, 1392-1393. doi:10.1111/bjd.14998

Tominaga, M., Caterina, M. J., Malmberg, A. B., Rosen, T. A., Gilbert, H., Skinner, K., et al. (1998). The Cloned Capsaicin Receptor Integrates Multiple PainProducing Stimuli. Neuron 21, 531-543. doi:10.1016/s0896-6273(00)80564-4

Tominaga, M., Ogawa, H., and Takamori, K. (2007). Possible Roles of Epidermal Opioid Systems in Pruritus of Atopic Dermatitis. J. Invest. Dermatol. 127, 2228-2235. doi:10.1038/sj.jid.5700942

Topal, F. A., Zuberbier, T., Makris, M. P., and Hofmann, M. (2020). The Role of IL17, IL-23 and IL-31, IL-33 in Allergic Skin Diseases. Curr. Opin. Allergy Clin. Immunol. 20, 367-373. doi:10.1097/ACI.0000000000000658

Töröcsik, D., Weise, C., Gericke, J., Szegedi, A., Lucas, R., Mihaly, J., et al. (2019). Transcriptomic and Lipidomic Profiling of Eicosanoid/docosanoid Signalling in Affected and Non-affected Skin of Human Atopic Dermatitis Patients. Exp. Dermatol. 28, 177-189. doi:10.1111/exd.13867

Torres, T., Fernandes, I., Selores, M., Alves, R., and Lima, M. (2012). Aprepitant: Evidence of its Effectiveness in Patients with Refractory Pruritus Continues. J. Am. Acad. Dermatol. 66, e14-5. doi:10.1016/j.jaad.2011.01.016

Tóth, B. I., Oláh, A., Szöllősi, A. G., and Bíró, T. (2014). TRP Channels in the Skin. Br. J. Pharmacol. 171, 2568-2581. doi:10.1111/bph.12569

Tóth, B. I., Szallasi, A., and Bíró, T. (2015). Transient Receptor Potential Channels and Itch: How Deep Should We Scratch? Handb Exp. Pharmacol. 226, 89-133. doi:10.1007/978-3-662-44605-8_6

Tóth, B. I., Szöllősi, A. G., and Bíró, T. (2020). “TRP Channels in Itch and Pain," in Itch and Pain. Similarities, Interactions, and Differences (Washington, D.C.: IASP - Wolters Kluwer). Available at: https://shop.lww.com/Itch-and-Pain/p/ 9781975153038

Tóth, K., Ádám, D., Bíró, T., and Oláh, A. (2019). Cannabinoid Signaling in the Skin: Therapeutic Potential of the "C(ut)annabinoid" System. Molecules 24, 918. doi: $10.3390 /$ molecules 24050918

Tsuboi, R., Sato, C., Oshita, Y., Hama, H., Sakurai, T., Goto, K., et al. (1995). Ultraviolet B Irradiation Increases Endothelin-1 and Endothelin Receptor Expression in Cultured Human Keratinocytes. FEBS Lett. 371, 188-190. doi:10.1016/0014-5793(95)00912-s

Umehara, Y., Kiatsurayanon, C., Trujillo-Paez, J. V., Chieosilapatham, P., Peng, G., Yue, H., et al. (2021). Intractable Itch in Atopic Dermatitis: Causes and Treatments. Biomedicines 9. doi:10.3390/biomedicines9030229

Ungar, B., Correa da Rosa, J., Shemer, A., Czarnowicki, T., Estrada, Y. D., FuentesDuculan, J., et al. (2017). Patch Testing of Food Allergens Promotes Th17 and Th2 Responses with Increased IL-33: a Pilot Study. Exp. Dermatol. 26, 272-275. doi:10.1111/exd.13148

Usoskin, D., Furlan, A., Islam, S., Abdo, H., Lönnerberg, P., Lou, D., et al. (2015). Unbiased Classification of Sensory Neuron Types by Large-Scale Single-Cell RNA Sequencing. Nat. Neurosci. 18, 145-153. doi:10.1038/nn.3881 
Valtcheva, M. V., Davidson, S., Zhao, C., Leitges, M., and Gereau, R. W. (2015). Protein Kinase C $\delta$ Mediates Histamine-Evoked Itch and Responses in Pruriceptors. Mol. Pain 11, 1. doi:10.1186/1744-8069-11-1

Vandewauw, I., De Clercq, K., Mulier, M., Held, K., Pinto, S., Van Ranst, N., et al. (2018). A TRP Channel Trio Mediates Acute Noxious Heat Sensing. Nature 555, 662-666. doi:10.1038/nature26137

Varricchi, G., Pecoraro, A., Marone, G., Criscuolo, G., Spadaro, G., Genovese, A., et al. (2018). Thymic Stromal Lymphopoietin Isoforms, Inflammatory Disorders, and Cancer. Front. Immunol. 9, 1595. doi:10.3389/fimmu.2018.01595

Verduzco, H. A., and Shirazian, S. (2020). CKD-associated Pruritus: New Insights into Diagnosis, Pathogenesis, and Management. Kidney Int. Rep. 5, 1387-1402. doi:10.1016/j.ekir.2020.04.027

Vij, A., and Duvic, M. (2012). Prevalence and Severity of Pruritus in Cutaneous T Cell Lymphoma. Int. J. Dermatol. 51, 930-934. doi:10.1111/j.1365-4632.2011. 05188.x

Voisin, T., Perner, C., Messou, M. A., Shiers, S., Ualiyeva, S., Kanaoka, Y., et al. (2021). The CysLT2R Receptor Mediates Leukotriene C4-Driven Acute and Chronic Itch. Proc. Natl. Acad. Sci. U S A. 118. doi:10.1073/pnas.2022087118

Volpe, E., Pattarini, L., Martinez-Cingolani, C., Meller, S., Donnadieu, M. H., Bogiatzi, S. I., et al. (2014). Thymic Stromal Lymphopoietin Links Keratinocytes and Dendritic Cell-Derived IL-23 in Patients with Psoriasis. J. Allergy Clin. Immunol. 134, 373-381. doi:10.1016/j.jaci.2014.04.022

Vriens, J., Nilius, B., and Voets, T. (2014). Peripheral Thermosensation in Mammals. Nat. Rev. Neurosci. 15, 573-589. doi:10.1038/nrn3784

Wahlgren, C. F., and Ekblom, A. (1996). Two-point Discrimination of Itch in Patients with Atopic Dermatitis and Healthy Subjects. Acta Derm Venereol. 76, 48-51. doi:10.2340/00015555764851

Wallrapp, A., Burkett, P. R., Riesenfeld, S. J., Kim, S. J., Christian, E., Abdulnour, R. E., et al. (2019). Calcitonin Gene-Related Peptide Negatively Regulates Alarmin-Driven Type 2 Innate Lymphoid Cell Responses. Immunity 51, 709-e6. e6. doi:10.1016/j.immuni.2019.09.005

Walsh, C. M., Hill, R. Z., Schwendinger-Schreck, J., Deguine, J., Brock, E. C., Kucirek, N., et al. (2019). Neutrophils Promote CXCR3-dependent Itch in the Development of Atopic Dermatitis. eLife 8, e48448. doi:10.7554/eLife.48448

Wang, C., Gu, L., Ruan, Y., Geng, X., Xu, M., Yang, N., et al. (2019). Facilitation of MrgprD by TRP-Al Promotes Neuropathic Pain. FASEB J. 33, 1360-1373. doi:10.1096/fj.201800615RR

Wedi, B. (2020). Ligelizumab for the Treatment of Chronic Spontaneous Urticaria. Expert Opin. Biol. Ther. 20, 853-861. doi:10.1080/14712598.2020.1767061

Weisshaar, E., and Dalgard, F. (2009). Epidemiology of Itch: Adding to the burden of Skin Morbidity. Acta Derm VenereolVenereol 89, 339-350. doi:10.2340/ 00015555-0662

Weisshaar, E., Szepietowski, J. C., Dalgard, F. J., Garcovich, S., Gieler, U., GiménezArnau, A. M., et al. (2019). European S2k Guideline on Chronic Pruritus. Acta Derm Venereol. 99, 469-506. doi:10.2340/00015555-3164

Weisshaar, E., Ziethen, B., and Gollnick, H. (1997). Can a Serotonin Type 3 (5HT3) Receptor Antagonist Reduce Experimentally-Induced Itch? Inflamm. Res. 46, 412-416. doi:10.1007/s000110050213

Werfel, T., Layton, G., Yeadon, M., Whitlock, L., Osterloh, I., Jimenez, P., et al. (2019). Efficacy and Safety of the Histamine H4 Receptor Antagonist ZPL3893787 in Patients with Atopic Dermatitis. J. Allergy Clin. Immunol. 143, 1830-e4. e4. doi:10.1016/j.jaci.2018.07.047

Wilson, S. R., Gerhold, K. A., Bifolck-Fisher, A., Liu, Q., Patel, K. N., Dong, X., et al. (2011). TRPA1 Is Required for Histamine-independent, Mas-Related G ProteinCoupled Receptor-Mediated Itch. Nat. Neurosci. 14, 595-602. doi:10.1038/nn.2789

Wilson, S. R., Thé, L., Batia, L. M., Beattie, K., Katibah, G. E., McClain, S. P., et al. (2013). The Epithelial Cell-Derived Atopic Dermatitis Cytokine TSLP Activates Neurons to Induce Itch. Cell 155, 285-295. doi:10.1016/j.cell.2013.08.057

Wilson, S. R., and Bautista, D. M. (2014). "Role of Transient Receptor Potential Channels in Acute and Chronic Itch," in Mechanisms And Treatment Frontiers in Neuroscience. Editors E. Carstens and T. Akiyama (Boca Raton (FL): CRC Press/Taylor \& Francis). Available at: http://www.ncbi.nlm.nih.gov/books/ NBK200927/(Accessed July 16, 2021).

Xie, Z., and Hu, H. (2018). TRP Channels as Drug Targets to Relieve Itch. Pharmaceuticals (Basel) 11. doi:10.3390/ph11040100

Yamanoi, Y., Kittaka, H., and Tominaga, M. (2019). Cheek Injection Model for Simultaneous Measurement of Pain and Itch-Related Behaviors. JoVE 151. doi: $10.3791 / 58943$
Yang, T. B., and Kim, B. S. (2019). Pruritus in Allergy and Immunology. J. Allergy Clin. Immunol. 144, 353-360. doi:10.1016/j.jaci.2019.06.016

Yang, Y. D., Cho, H., Koo, J. Y., Tak, M. H., Cho, Y., Shim, W. S., et al. (2008). TMEM16A Confers Receptor-Activated Calcium-dependent Chloride Conductance. Nature 455, 1210-1215. doi:10.1038/nature07313

Yoshioka, T., Imura, K., Asakawa, M., Suzuki, M., Oshima, I., Hirasawa, T., et al. (2009). Impact of the Gly573Ser Substitution in TRPV3 on the Development of Allergic and Pruritic Dermatitis in Mice. J. Invest. Dermatol. 129, 714-722. doi:10.1038/jid.2008.245

Yosipovitch, G., Misery, L., Proksch, E., Metz, M., Ständer, S., and Schmelz, M. (2019). Skin Barrier Damage and Itch: Review of Mechanisms, Topical Management and Future Directions. Acta Derm Venereol. 99, 1201-1209. doi:10.2340/00015555-3296

Yosipovitch, G., Ständer, S., Kerby, M. B., Larrick, J. W., Perlman, A. J., Schnipper, E. F., et al. (2018). Serlopitant for the Treatment of Chronic Pruritus: Results of a Randomized, Multicenter, Placebo-Controlled Phase 2 Clinical Trial. J. Am. Acad. Dermatol. 78, 882-e10. e10. doi:10.1016/j.jaad.2018.02.030

Yu, H., Zhao, T., Liu, S., Wu, Q., Johnson, O., Wu, Z., et al. (2019). MRGPRX4 Is a Bile Acid Receptor for Human Cholestatic Itch. Elife 8. doi:10.7554/ eLife.48431

Zeidler, C., Yosipovitch, G., and Ständer, S. (2018). Prurigo Nodularis and its Management. Dermatol. Clin. 36, 189-197. doi:10.1016/j.det.2018.02.003

Zhang, S., Edwards, T. N., Chaudhri, V. K., Wu, J., Cohen, J. A., Hirai, T., et al. (2021). Nonpeptidergic Neurons Suppress Mast Cells via Glutamate to Maintain Skin Homeostasis. Cell 184, 2151-e16. e16. doi:10.1016/j.cell.2021. 03.002

Zhang, X., and He, Y. (2020). The Role of Nociceptive Neurons in the Pathogenesis of Psoriasis. Front. Immunol. 11, 1984. doi:10.3389/fimmu.2020.01984

Zhang, Z., Malewicz, N. M., Xu, X., Pan, J., Kumowski, N., Zhu, T., et al. (2019). Differences in Itch and Pain Behaviors Accompanying the Irritant and Allergic Contact Dermatitis Produced by a Contact Allergen in Mice. Pain Rep. 4, e781. doi:10.1097/PR9.0000000000000781

Zhao, J., Munanairi, A., Liu, X. Y., Zhang, J., Hu, L., Hu, M., et al. (2020). PAR2 Mediates Itch via TRPV3 Signaling in Keratinocytes. J. Invest. Dermatol. 140, 1524-1532. doi:10.1016/j.jid.2020.01.012

Zhao, Z. Q., Huo, F. Q., Jeffry, J., Hampton, L., Demehri, S., Kim, S., et al. (2013). Chronic Itch Development in Sensory Neurons Requires BRAF Signaling Pathways. J. Clin. Invest. 123, 4769-4780. doi:10.1172/JCI70528

Zheng, Y., Danilenko, D. M., Valdez, P., Kasman, I., Eastham-Anderson, J., Wu, J., et al. (2007). Interleukin-22, a $\mathrm{T}(\mathrm{H}) 17$ Cytokine, Mediates IL-23-induced Dermal Inflammation and Acanthosis. Nature 445, 648-651. doi:10.1038/ nature 05505

Zhu, T. H., Nakamura, M., Farahnik, B., Abrouk, M., Lee, K., Singh, R., et al. (2016). The Role of the Nervous System in the Pathophysiology of Psoriasis: A Review of Cases of Psoriasis Remission or Improvement Following Denervation Injury. Am. J. Clin. Dermatol. 17, 257-263. doi:10.1007/ s40257-016-0183-7

Conflict of Interest: AO provides consultancy services to Monasterium Laboratory Skin \& Hair Research Solutions GmbH.

The remaining authors declare that the research was conducted in the absence of any commercial or financial relationships that could be construed as a potential conflict of interest.

Publisher's Note: All claims expressed in this article are solely those of the authors and do not necessarily represent those of their affiliated organizations, or those of the publisher, the editors and the reviewers. Any product that may be evaluated in this article, or claim that may be made by its manufacturer, is not guaranteed or endorsed by the publisher.

Copyright (๑) 2022 Szöllösi, Oláh, Lisztes, Griger and Tóth. This is an open-access article distributed under the terms of the Creative Commons Attribution License (CC $B Y)$. The use, distribution or reproduction in other forums is permitted, provided the original author(s) and the copyright owner(s) are credited and that the original publication in this journal is cited, in accordance with accepted academic practice. No use, distribution or reproduction is permitted which does not comply with these terms. 